\title{
Waste of Place: Heritage Conservation within the context of the Canadian Environmental Assessment Act
}

\author{
by
}

Christienne Uchiyama

A thesis submitted to the Faculty of Graduate and Postdoctoral Affairs in partial fulfillment of the requirements for the degree of

Master of Arts

in

Canadian Studies, Heritage Conservation

Carleton University

Ottawa, Ontario

(C) 2012, Christienne Uchiyama 
Library and Archives

Canada

Published Heritage

Branch

395 Wellington Street

Ottawa ON K1A ON4

Canada
Bibliothèque et

Archives Canada

Direction du

Patrimoine de l'édition

395 , rue Wellington

Ottawa ON K1A ON4

Canada
Your file Votre référence

ISBN: 978-0-494-91593-6

Our file Notre référence

ISBN: $978-0-494-91593-6$
NOTICE:

The author has granted a nonexclusive license allowing Library and Archives Canada to reproduce, publish, archive, preserve, conserve, communicate to the public by telecommunication or on the Internet, loan, distrbute and sell theses worldwide, for commercial or noncommercial purposes, in microform, paper, electronic and/or any other formats.

The author retains copyright ownership and moral rights in this thesis. Neither the thesis nor substantial extracts from it may be printed or otherwise reproduced without the author's permission.
AVIS:

L'auteur a accordé une licence non exclusive permettant à la Bibliothèque et Archives Canada de reproduire, publier, archiver, sauvegarder, conserver, transmettre au public par télécommunication ou par l'Internet, prêter, distribuer et vendre des thèses partout dans le monde, à des fins commerciales ou autres, sur support microforme, papier, électronique et/ou autres formats.

L'auteur conserve la propriété du droit d'auteur et des droits moraux qui protege cette thèse. $\mathrm{Ni}$ la thèse ni des extraits substantiels de celle-ci ne doivent être imprimés ou autrement reproduits sans son autorisation.
In compliance with the Canadian Privacy Act some supporting forms may have been removed from this thesis.

While these forms may be included in the document page count, their removal does not represent any loss of content from the thesis.
Conformément à la loi canadienne sur la protection de la vie privée, quelques formulaires secondaires ont été enlevés de cette thèse.

Bien que ces formulaires aient inclus dans la pagination, il n'y aura aucun contenu manquant. 


\begin{abstract}
The cultural heritage aspect of Environmental Assessments (EAs), particularly under the Canadian Environmental Assessment Act (CEAA), has yet to be adequately addressed in Canada. Owing to a systemic separation of culture and nature in education, training, and organizational structures in the broader context, cultural heritage is at a disadvantage in the policy, legislation and bureaucratic framework overseeing EA. As a result, there is a lack of fully developed, formalized tools and techniques for the assessment of project impacts on cultural heritage. This paper identifies evaluative asymmetry and examines problems related to the legislative status of cultural heritage within the context of the CEAA. It examines avenues of future investigation and development to arrive at possible solutions to these issues.
\end{abstract}




\section{Acknowledgements}

This thesis would not have been possible without the support and guidance of a long list of people.

I would like to thank my supervisor, Paul Litt, for his encouragement and guidance. I would also like to thank the members of my committee, in particular Victoria Angel, whose encouragement and knowledge of heritage conservation in the federal realm was of immeasurable benefit.

I am grateful to my colleagues in the Heritage Conservation programme who helped shape this thesis over coffee, caipirinhas and greasy brunches.

I am indebted to the numerous interview subjects in the federal and provincial government as well as private industry, who took the time to sit down and share their views and experience with me.

I would also like to thank my family and friends who have supported me throughout this arduous process, especially Jon, without whom I would have likely given up somewhere in Chapter 2.

Finally, I would like to dedicate this paper to Herb Stovel, teacher and mentor to so many. I cannot thank you enough for starting me out on this journey and providing advice along the way. 


\section{Table of Contents}

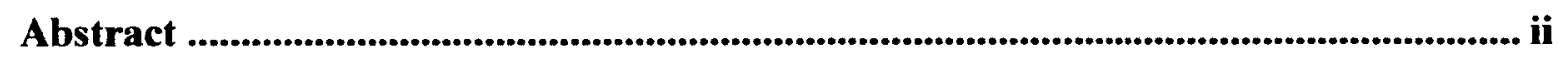

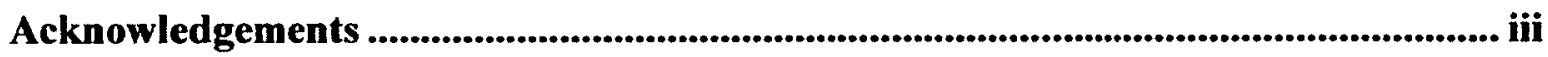

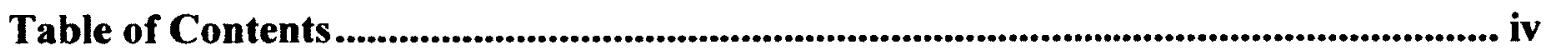

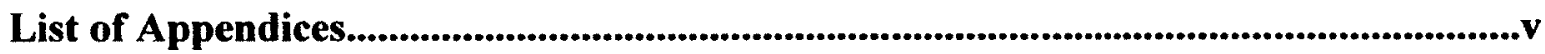

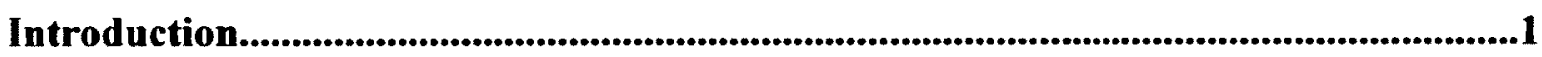

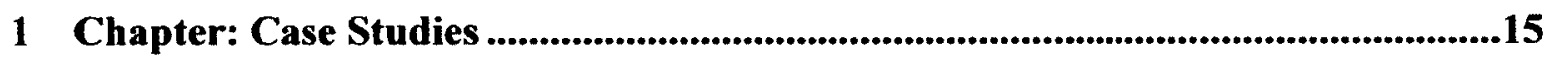

2 Chapter: Federally Legislated Environmental Assessments ..............................44

3 Chapter: Technical Concerns ........................................................................63

4 Chapter: Process Management Concerns ..............................................................94

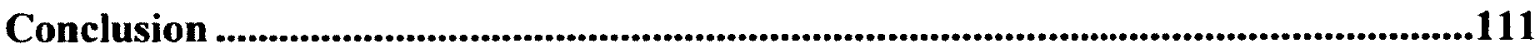

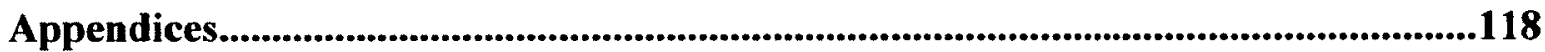

Appendix A Criteria for the assessment of outstanding universal value .............................118

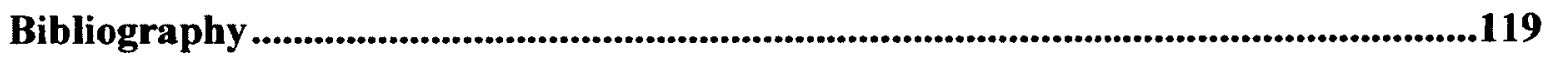




\section{List of Appendices}

Appendix A Criteria for the assessment of outstanding universal value $\ldots \ldots \ldots \ldots \ldots 117$ 


\section{Introduction}

The desire to conserve history and culture is one that transcends time and place. Humankind is compelled to preserve and share the past through various media, both tangible and intangible. At the same time, the human species is driven by a desire to learn, improve and expand. The question of how to effectively conserve heritage while continuing to shape and develop our communities is rarely answered with satisfaction.

These two compulsions are often competing interests in the planning process. In the realm of planning, heritage conservation finds a voice in Environmental Assessment. The practice of Environmental Assessment (EA) has over the past 40 years become a formal part of planning systems throughout the developed world. EA is undertaken at every level of government in Canada and an understanding of the practice is integral to understanding how we conserve, or sometimes fail to conserve, our shared heritage. The goal of this paper is to determine if the interests of heritage conservation in Canada are being satisfied within the Canadian Environmental Assessment Act (CEAA) framework.

The research question posed at the outset of this study was, "How can Environmental Assessment under the $C E A A$ be an effective tool for managing and conserving cultural heritage resources and landscapes?" More specifically:

- How does heritage fit into the context of EA?

- What methods can be applied to the EA process to a) identify cultural heritage resources and landscapes, b) measure the value of those resources, and c) identify and measure potential adverse impacts on those resources?

- What groups or communities should be involved in this process?

- What models or best practices can be applied to improve the current Canadian system? 
This paper identifies deficiencies within the federal planning system and opportunities for making it a more effective system of heritage conservation.

The $C E A A$ requires that potential direct and indirect adverse impacts be identified and measured for any federal project not excluded through the legislation. While heritage has been accepted into the process in principle, in practice the technical methods applied and bureaucratic system in charge do not consistently encompass heritage. This paper analyses why and concludes that two problems, evaluative asymmetry and legislative status, impede the full integration of heritage concerns into the EA process. It goes on to offer solutions for these problems that, if implemented, could lead to more effective conservation of cultural heritage resources within the federal planning process. Evaluative asymmetry, in this case, can be defined as an inequality in the weighing of natural environment concerns compared to cultural heritage concerns within the decisionmaking process. ${ }^{1}$ This asymmetry is manifested in both the technical approach to impact assessment of natural versus cultural factors as well as their relative perceived level of importance within the planning system. Legislative status within the context of this paper refers to the position or rank of cultural heritage within Canadian federal legislation and, more specifically, within the CEAA and its associated definitions.

Evaluative asymmetry stems from inherent differences between cultural heritage resources and natural resources protected through the EA process. Vagaries related to the identification and measurement of impacts on heritage values often highlight the apparent deficiencies of the 'science' of heritage when compared to other disciplines such as

\footnotetext{
'Not to be confused with A.F. MacKay's Asymmetry Thesis concerning the inequalities of the perceived values of causes versus consequences. A.F. Mackay, "Evaluative Asymmetry," American Philosophical Quarterly 11 (1975): 37-46.
} 
biology, geology, and engineering involved in EA. While policies and legislation ensure heritage conservation has a place within the practice of EA, it remains unclear how heritage conservation can produce meaningful results within that EA framework. Without a widely accepted method for demonstrating the value of cultural heritage resources and landscapes, it is not possible for cultural heritage to compete effectively with other interests in the EA process.

Under the $C E A A$, physical and cultural heritage resources are included in the environmental considerations for federal projects but methods for identification and evaluation of the resources as well as identification and measurement of adverse impacts do not necessarily fit the scientific process of EA. One possible solution to this technical issue is to encourage a truly interdisciplinary approach to EA and to view cultural heritage resources as one component in a diverse ecosystem comprised of biotic and abiotic features and apply methods of identification and valuation of those cultural heritage resources that are appropriate for a dynamic system in which the other components are measured in scientific terms.

Legislative status, or rather, the lack of legislative status for heritage at the federal level is another key deficiency of heritage conservation within the context of the CEAA. Although there does exist legislation concerning cultural heritage, such as the Railway Station Protection Act and the Lighthouse Protection Act, there is no pan-Canadian legislation concerning cultural heritage in general. Perhaps the biggest concern for cultural heritage within the CEAA is the definition of environment, which does not include cultural heritage, although impacts on cultural heritage are included in the definition of environmental effects. One possible solution to the problem of legislative 
status might be the creation of federal legislation similar to the National Historic Preservation Act (NHPA) in the United States. Such legislation could have a positive impact on process management issues concerning the lack of permitting for cultural heritage resources and landscapes, issues of provincial/territorial jurisdiction over cultural heritage in the midst of a federal process, and confusion regarding the roles and responsibilities of federal heritage authorities.

The current state of heritage conservation policies and practices within the $C E A A$ is the result of three major processes: 1) the development of EA as an authoritative planning process; 2 ) the evolution of heritage conservation theory and practice; and 3) the creation of the myriad bureaucratic policies and procedures that govern EA and heritage conservation. Literature reviewed for this paper spanned all three processes and included sources written over the past 40 years on the theory and practice of EA, historical and contemporary heritage conservation philosophies, legislation, policy documents and guidance materials prepared by the Canadian Environmental Assessment Agency (the Agency) and other federal departments. In addition to literature reviewed, case studies were used to identify deficiencies in both policy and practice. Of those, two are presented in the body of this paper: the Ardenville Wind Farm near Fort MacLeod, Alberta and the demolition of the south side of Colborne Street in Brantford, Ontario. Interviews were conducted with experts from private industry and the public service in order to inform research.

This paper argues that issues with the $C E A A$ fall into two categories: technical issues and process management issues. Technical issues relate to the methods used to 
assess impacts on cultural heritage, while process management issues pertain to the mechanics of the $C E A A$ process itself. Technical issues identified include:

- lack of universally accepted methods to identify and evaluate non-designated cultural heritage resources that might be affected by a project; and

- lack of tools to effectively identify and measure impacts on those resources.

Central to the process of environmental impact assessment is the ability to both apply a value (either quantitative or subjective) to the resource and to measure potential negative impacts on that resource. This process is somewhat straightforward in most of the areas analyzed in an EA under $C E A A$. A fisheries biologist is able to identify and count various species of fish existing in surrounding streams, rivers, or drainage ditches that might be affected by a proposed project. Vibrations and noise levels from construction activities can be estimated based on similar activities and measured through the use of electronic monitors. This type of empirical significance measurement may not be possible for heritage resources. Quasi-quantitative evaluation systems, such as the FHBRO evaluation system, which allow for the comparison of properties, do exist. These systems differ from the aforementioned scientific measurement systems in that they remain highly subjective and lack the repeatability required to be truly authoritative tools of measurement. ${ }^{2}$

Murray Gray's 2004 Geodiversity, valuing and conserving abiotic nature, offers new perspective to the debate within the heritage conservation community concerning the measurement of the often intangible commodity of cultural heritage resources. In

\footnotetext{
${ }^{2}$ The FHBRO evaluation system awards points to properties in the criteria of historical associations, architecture, and environment. Each of the criteria, and sub-criteria are weighted differently and properties are awarded a predetermined number of points based on whether they are considered to be worthy of a grade of A, B, C or D in each sub-criterion. A building receiving 49 or less is 'not designated', 50 to 74 is 'Recognized', and 75 to 135 of 'Classified'. Although the system applies a numerical value to each property evaluated, a committee is required to come to a consensus regarding the final score of the property as awarding points remains a subjective activity.
} 
Geodiversity, Murray applies geological and geographical theory to the valuation of abiotic resources which, to humans, often have less intrinsic value than biotic resources. ${ }^{3}$ Gray's work offers a holistic approach towards an understanding of diverse ecological systems and has been applied to a multidisciplinary EA setting at the Norwegian Institutes for Nature Research, Cultural Heritage Research, Urban Regional Research and Water Research. ${ }^{4}$

Recent research into assessing the value of heritage resources includes the 2000 and 2002 publications by the Getty Conservation Institute entitled Assessing the Values of Cultural Heritage. In particular the works of Randall Mason, Setha M. Low and Theresa Satterfield provide analysis of the issue of applying value to heritage resources that is applicable to the EA process. Mason discusses the limitations of methodologies for assessment of heritage values in his essay Assessing Values in Conservation Planning: Methodological Issues and Choices. Mason considers the problems with heritage value assessment to stem from the diverse nature of heritage values, the evolving nature of heritage values, and the influence of context on the values of a heritage resource. ${ }^{5} \mathrm{~A}$ "deliberate, systematic, and transparent process of analyzing and assessing all the values of heritage" is promoted over the more prevalent highly subjective approach that is based on a small number of established criteria. ${ }^{6}$ This systematic approach is necessary if heritage conservation is to exist as an equal player in the EA process where other

\footnotetext{
${ }^{3}$ Murray Gray, Geodiversity: valuing and conserving abiotic nature (Mississauga: John Wiley and Sons, 2004), 65-66.

${ }^{4}$ Lars Erikstad et.al., "Environmental value assessment in a multidisciplinary ElA setting," Environmental Impact Assessment Review 28:(2008):131-143.

"Randall Mason, "Assessing Values in Conservation Planning: Methodological Issues and Choices," in Assessing the Values of Cultural Heritage, ed. Marta de la Torre (Los Angeles: The Getty Conservation Institute, 2002), 5.

${ }^{6}$ Mason, "Assessing Values," 5.
} 
disciplines are able to present quantitative and tested evidence of adverse effects. Again, heritage conservation is generally perceived as a worthy factor in decision-making, ${ }^{7}$ but as a result of the inability to produce results that can be easily translated into the planning process, heritage concerns lack the authority of more scientific, quantifiable concerns.

The current federal approach to assessing impacts relies on the presupposition that all significant heritage resources and landscapes have previously been identified and that the values of those resources are carefully outlined in a Commemorative Integrity Statement (CIS) or Statement of Significance (SOS). It is from these materially-biased statements of value that potential negative impacts and their respective mitigative measures are identified. What then happens to those resources that have not been evaluated as a result of Treasury Board Policy that insists that buildings of greater than 40 years of age be evaluated for their heritage significance? What happens to all of the landscapes and resources not owned by the federal government that are influenced by projects in their vicinity?

Beyond the questions of the ownership of and responsibility for a resource, site, or landscape are questions of the ownership of and responsibility for the heritage values of that place or thing. Is it the expert or the community that has the authority to assess value? It can be argued that both can and should play very real roles in the process and it is not realistic to presume or even suggest that this evaluation should be taking place at the EA stage of the decision-making process. This paper looks at the Canadian Register as a solution to this problem. In a role similar to that of the National Register in the United States which informs decisions governed by the National Historic Preservation

\footnotetext{
${ }^{7}$ John Pendlebury, Conservation in the Age of Consensus. (New York: Routledge, 2009), 1.
} 
Act (NHPA), the Canadian Register could serve to provide a dynamic inventory for both experts and communities to inform planning. The Register would also essentially provide a thermometer for trends in values based on changing site typologies and prevalent themes. Ultimately, although the Canadian Register is a useful desktop research tool for EA, it is too dependent on outside input and inconsistencies in level of effort have resulted in vast areas of the country currently being under-represented. Furthermore, it is not designed or managed with this purpose in mind and would require a change in mandate to serve as a useful and dynamic tool for the cultural heritage component of EA.

In addition to deficiencies related to the methods used in the assessment of impacts on cultural resources, a number of problems were identified that relate to the mechanics of the process itself. Process management issues identified include:

- lack of permitting or approval process for heritage resources on a federal level;

- confusion regarding which federal department should be contacted and/or act as an authority for heritage resources;

- lack of or confusion regarding triggers for consultation with heritage authorities; and

- issues with respect to the jurisdiction of cultural heritage. 
For general Environmental Assessment theory and best practices, books such as D. Owen Harrop and J. Ashley Nixon's 1998 Environmental Assessment in Practice were consulted. Environmental Assessment in Practice in particular provides context for the role of the consultant or practitioner in the field of Environmental Assessment and builds upon earlier works such as Environmental Impact Assessment: Theory and Practice, edited by Peter Wathern. Both works are indispensable in terms of laying the groundwork for an understanding of the field, its history, terminology and underlying concepts and philosophies.

The core values of Environmental Assessment as outlined in Harrop and Nixon's work are borrowed from a 1996 publication which was the collective work of the Canadian Environmental Assessment Agency (the Agency) and the International Association for Impact Assessment, Environmental Assessment in a Changing World: Evaluating Practice to Improve Performance. The report, which was compiled by Barry Sadler, was based largely on Canadian case studies and experience ${ }^{8}$ and is considered by this study to be of the utmost relevance for its impact on changes to the CEAA in 2004 . The three core values of Integrity, Utility and Sustainability ${ }^{9}$ should be viewed as not only applicable to, but derived from, the Canadian experience.

The Canadian Environmental Assessment Agency (the Agency) has produced the majority of available material pertaining to the $C E A A$ although numerous federal departments have their own guides to working under the CEAA. The 2003 Canadian

\footnotetext{
${ }^{8}$ D. Owen Harrop and J. Ashley Nixon, Environmental Assessment in Practice, (New York: Routledge, 1998), 3.

${ }^{9}$ Barry Sadler, Environmental Assessments in a Changing World: Evaluating Practice to Improve Performance, (Ottawa: The Canadian Environmental Assessment Agency and the International Association for Impact Assessment, 1996), 20.
} 
Environmental Assessment Act: An Overview, in particular, provides an overview of the steps involved in undertaking an EA under the $C E A A .{ }^{10}$ Very little guidance on assessing impacts on cultural heritage resources has been produced by the Agency. Although impacts on cultural heritage resources are discussed in the $1996 \mathrm{~A}$ Reference Guide for the Canadian Environmental Assessment Act: Assessing Environmental Effects on Physical and Cultural Heritage Resources, the guide is out of touch with current practice and inadequate in terms of identifying actual methods for the valuation of resources and the measurement of impacts. Likewise, Federal Heritage Buildings Review Office (FHBRO) and Parks Canada guidance on the subject of EA provide few specifics with regard to valuation and measurement; being primarily concerned with interventions to previously designated buildings and sites. The documents that provide an overview of where these authorities on heritage conservation become involved in the EA process are A Guide to Working with the Federal Heritage Buildings Review Office and Parks Canada Guide to Compliance with the Canadian Environmental Assessment Act. The Standards and Guidelines for the Conservation of Historic Places in Canada provide further information with regard to evaluation and assessment.

While all of the guidance material and policy further highlight technical problems with the assessment of cultural heritage resources, they also fail to outline a coherent and consistent process for federal departments or other bodies undertaking EAs under the CEAA to follow with regard to potentially significant cultural heritage resources. The 1996 A Reference Guide for the Canadian Environmental Assessment Act: Assessing Environmental Effects on Physical and Cultural Heritage Resources, in particular, has

\footnotetext{
${ }^{10}$ Canadian Environmental Assessment Agency, Canadian Environmental Assessment Act: An Overview, (Ottawa: Canadian Environmental Assessment Agency, 2003), 5-23.
} 
not been kept up to date with contact information for federal authorities concerned with heritage. At the same time, no one federal authority concerned with heritage has been given the mandate of overseeing this process. For any given project, one could presumably contact Parks Canada, Public Works and Government Services Canada or the Department of Canadian Heritage." All four process management deficiencies mentioned above - lack of permitting and approval, confusion regarding which federal department should act as an authority, lack of triggers, and issues with respect to jurisdiction -stem from the need for pan-Canadian legislation that could be applied in the case of EA.

Pan-Canadian legislation could potentially have a significant and positive impact on the conservation of our shared cultural heritage resources, sites, and landscapes. Such legislation would ideally identify one federal authority whose mandate (or part thereof) would be to manage the Register and provide advice, review and permits to projects that affect a resource on the Register, or one that satisfies the heritage values derived from the Register. Legislation could potentially legitimize the role of cultural heritage in the federal planning process and provide a framework for provinces and territories.

In Chapter 1 two case studies are introduced and examined; the Ardenville Wind Project near Fort MacLeod, Alberta and the demolition of the south side of Colborne Street in Brantford, Ontario. Both cases were chosen as examples that highlight the management of heritage resources within the context of the $C E A A$ and also within the planning and EA process more generally. The Ardenville Wind Project was chosen precisely because it was not a particularly extraordinary or controversial project and it

\footnotetext{
1 This is not the case for federally designated buildings, where the responsibility to consult with FHBRO is generally, but not always, understood.
} 
followed all the regulated procedures with respect to cultural heritage. Although the case is not an example of cultural heritage resources lost or destroyed, it outlines, in a straightforward way, where valuable cultural resources could be and have been lost along the EA process. The Colborne Street demolitions, in stark contrast, are an example where a similar process was followed and all of the right decisions were made (with respect to the $C E A A$ ), yet a block of forty pre-confederation commercial buildings meeting the criteria for designation in their province were demolished. Both cases demonstrate issues concerning the evaluative asymmetry and lack of legislative status of cultural heritage.

Chapter 2 of this paper provides an overview of the development of the CEAA and of EA more generally. The inter-connectedness of the built and natural environment is examined in this chapter in order to place cultural heritage within the context of sustainable development, which is ultimately the goal of the EA process. The chapter highlights deficiencies in the current framework and legislation with respect to cultural heritage. In particular, the exclusion of cultural heritage from the definition of 'environment' under the CEAA will be examined.

The development of heritage conservation theory is outlined in Chapter 3, with a view to identifying how cultural heritage values are and can be assessed within the EA process. This chapter discusses the ongoing development of the technical undertaking of Heritage Impact Assessments and begins to offer perspective on approaching the disconnect between natural and heritage conservation strategies and policies.

Chapter 4 examines how heritage conservation and EA are handled by the federal government and highlights the separation of responsibilities that keeps the two concerns 
separate. The chapter also investigates the mechanisms under which heritage and project impacts on heritage are assessed and the people and groups undertaking those assessments. Deficiencies and confusion with respect to the legislative framework and the constitutional jurisdiction of cultural heritage will also be addressed in Chapter 4 . The paper concludes that the goals of heritage conservation are not served by the CEAA for a number of reasons:

1. Heritage Impact Assessment (HIA) remains a novel and underdeveloped practice which lacks, a) the tools and techniques required to formalize the process and develop an authoritative professional designation for experts undertaking HIAs, and b) an accepted pan-Canadian process for undertaking HIAs that can be easily interpreted by decision makers.

2. The separation of heritage conservation from the natural environmental sciences has resulted in a federal system where heritage conservation professionals are unfamiliar with the EA process and EA practitioners are unfamiliar with heritage conservation theory and practice.

3. The lack of federal legislation or permitting with regard to cultural heritage, or inclusion of cultural heritage in the definition of environment, prevents Canada from effectively meeting its international obligations with respect to cultural heritage and sustainable development.

Although this study was ultimately not able to arrive at fully developed solutions to the problems of evaluative asymmetry and legislative status, it is clear that massive change is required. The issue of legislative status would best be addressed through the participation of cultural heritage interest groups participating in CEAA reviews and lobbying for a more inclusive definition of 'environment' under the Act. Evaluative asymmetry concerns are, however, more problematic. On the one hand, cultural heritage is at a disadvantage within the prevailing planning and EA paradigm and would be better served if the entire process were more fluid and inclusive. On the other hand, within the existing paradigm, a more systematic and standardized approach to Heritage Impact Assessment must continue to develop. The $C E A A$ is currently in flux and cultural heritage is in 
danger of being muscled out of this more streamlined process if interest groups do not engage in the process. 


\section{Chapter: Case Studies}

This chapter presents two case studies in order to outline the management of heritage resources within the context of the $C E A A$ process and underscore associated technical and process management problems which have arisen. The two case studies discussed are the Ardenville Wind Farm project near Fort MacLeod, Alberta and the demolition of the south side of Colborne Street in Brantford, Ontario.

The Ardenville Wind Farm project was chosen as a case study for discussion because it is a project that resulted in both an EA screening under the CEAA and a Historical Resources Impact Assessment under Alberta's Historical Resources Act. As culture is jurisdictionally a provincial or territorial concern in Canada, the need for a Heritage Impact Assessment is generally triggered by provincial or territorial requirements rather than federal process.

The choice of a wind energy project was furthermore influenced by growing concerns, in Canada and abroad, over visual impacts of wind energy projects on cultural heritage resources and landscapes. ${ }^{12}$ The interest in the visual impact of wind turbines was addressed early on by Scottish Natural Heritage and the 2002 research report out of the University of Newcastle, Visual Assessment of Windfarms: Best Practice. The Scotrenewables Ltd. Merranblo Windfarm project, in particular, raised a number of questions with regard to measuring visual impacts on the landscape. ${ }^{13}$ Although outside

\footnotetext{
12 Jerpasen, Gro B. and Kari C. Larsen, "Visual impact of wind farms on cultural heritage: A Norwegian case study," Environmental Impact Assessment Review 31 (2011): 206 and Simon Clarke, "Balancing Environmental and Cultural Impact against the Strategic Need for Wind Power," International Journal of Heritage Studies 15 no. 2-3 (2009): 175-176.

${ }^{13}$ Scotrenewables Ltd., Merranblo Windfarm Environmental Statement (Merranblo, Scotland: Scotrenewables, 2002) and Susan Denyer, Precognition for Susan Denyer, ICOMOS-UK, Public Local
} 
the boundaries of the Orkney Islands World Heritage Site proper, the proximity of the project to a World Heritage Site led to the need for visual assessment guidelines in Scotland. The project also highlighted a paucity of Heritage Impact Assessment best practice guidelines as well as a dearth of understanding as to how to address, measure, and protect against negative visual impacts. Heritage Impact Assessment is a new practice, having been undertaken in only the past five to ten years, and there remains a distinct lack of Canadian material to address the value of certain viewsheds and visual impacts.

The following section describes the Ardenville Wind Farm project and outlines the regulations and legislation that led to a screening type EA of the project under the $C E A A$. Discussions of the screening report prepared by Natural Resources Canada and the Environmental Impact Statement prepared by the proponent, TransAlta, are also included in this section. A review of the Historical Resources Impact Assessment will also highlight a tendency toward focusing on archaeological resources as the most important, or, oftentimes, only consideration when cultural heritage is included in an EA as an environmental component. This focus on archaeology has likely come about for such reasons as: a history of accidental archaeological finds delaying construction projects; ${ }^{14}$ standardization of archaeological practice; and established legislation and policies at various level of government dealing specifically with archaeological resources. It is important to note that the Ardenville Wind Farm project was not chosen as an example of a particularly positive or negative outcome. It was not an exceptional or

Inquiry into an application for the Proposed Erection of Three Wind Turbines at Merranblo, Orkney, (Merranblo, Scotland: ICOMOS-UK, 2008).

${ }_{14}$ The stigma attached to uncovering human remains emphasizes the need for archaeological assessment in many cases. 
controversial project. Rather Ardenville Wind Farm represents a typical project that followed typical processes and involved typical reporting.

The Ardenville Wind Farm project in Alberta was completed in December, $2010,{ }^{15}$ although the development phase began several years earlier and involved numerous applications to provincial and federal authorities. The Ardenville Wind Farm is situated in southwestern Alberta, approximately $13 \mathrm{~km}$ south of Fort MacLeod. The project site is approximately $3.2 \mathrm{~km}$ wide and $8 \mathrm{~km}$ long, although a larger area was studied in order to take into account a wider array of indirect natural and socio-economic impacts. The general project area is a mix of cultivated agricultural land and native pasture. ${ }^{16}$ The main project components include 23 wind turbines (each $80 \mathrm{~m}$ tall), access roads for construction and maintenance, and transmission lines - both above and below ground. Two meteorological towers for data collection and a substation were also constructed. $^{17}$

The main approval authority in the case of the Ardenville Wind Farm was the Alberta Utilities Commission (AUC). TransAlta Wind filed an application with the AUC in April, 2009 to construct and operate the wind farm and associated substation. The AUC approved the project on January 15,2010 after reviewing the application and allowing for a 30-day appeal period. The application was required to demonstrate due diligence with respect to fully assessing the feasibility of the project and any potential adverse environmental or socio-economic effects that might result from the construction

\footnotetext{
${ }^{15}$ TransAlta, "Ardenville Wind Farm", accessed December, 2011 at http://www.transalta.com/facilities/facilities-development/ardenville.

${ }^{16}$ Natural Resources Canada (NRCan), Environmental Screening Report, (Ottawa, 2010), 6. TransAlta Wind Development Permit Application to the Municipal District of Willow Creek for the Ardenville Wind Farm (Calgary, 2008), 3.

${ }_{17}$ TransAlta, Development Permit, 3 and NRCan, Environmental Screening Report, 8.
} 
or operation of the wind farm. The level of consultation with relevant agencies and communities was also considered in the application. ${ }^{18}$ As part of this approvals process, the proponent submitted reports to relevant regulatory authorities. The Ardenville Wind Farm Natural Environment Study, essentially a report on the EA process undertaken by TransAlta Wind, was accepted by Alberta Sustainable Resource Development (ASRD) in March, 2009. The main considerations of the ASRD review appear to have been the potential impact of the project on bat and bird species, Species at Risk, and the site plan's adherence to established setbacks outlined in the ASRD's Wildlife Guidelines for Alberta Wind Projects Energy. ${ }^{19}$ The application to the AUC also demonstrated that the Historical Resources Impact Assessment undertaken for TransAlta Wind had been submitted to Alberta Culture and Community Spirit and had received Historical Resources Act clearance in April, 2009. ${ }^{20}$

There is no evidence to suggest that the ASRD considered potential adverse effects on cultural resources in their review of the EA process undertaken by TransAlta Wind $^{21}$ or that Alberta Culture and Community Spirit considered the natural environment in their review. This separation of interest, authority and knowledge does not necessarily support sustainable development, although it does ensure that natural and cultural environmental components of projects are reviewed by experts in their respective fields.

\footnotetext{
${ }^{18}$ Alberta Utilities Commission (AUC), 2010, Decision Report: TransAlta Wind Ardenville Wind Plant and Substation, (Edmonton: 2010), 2.

${ }^{19}$ Ibid., 2.

${ }^{20}$ Ibid., 3.

${ }^{21}$ The mission of ASRD is, in fact, focused solely on the natural environment and is stated as follows, "Alberta Sustainable Resource Development (SRD) encourages balanced and responsible use of Alberta's natural resources through the application of leading practices in management, science, and stewardship". Alberta Sustainable Resources Development, Alberta Sustainable Resources Development: About Us, accessed January, 2012 http://www.srd.alberta.ca/AboutSRD/AlbertaSustainableResourceDevelopment/Default.aspx.
} 
The separation of nature and culture is a pervasive characteristic of the field of EA in

Canada and will be revisited throughout this paper.

In addition to the required approval processes, the proponent, TransAlta

Corporation, applied to Natural Resources Canada (NRCan) for financial support under

its ecoEnergy for Renewable Power (ecoRP) program. The CEAA was triggered by the decision to provide or refuse federal monies for the project under section 5 (1)(b) of the $C E A A$, which states:

5 (1) An Environmental assessment of a project is required before a federal authority exercises one of the following powers or performs one of the following duties or functions in respect of a project, namely, where a federal authority

(b) makes or authorizes payments or provides a guarantee for a loan or any other form of financial assistance to the proponent for the purpose of enabling the project to be carried out in whole or in part, except where the financial assistance is in the form of any reduction, avoidance, deferral, removal, refund, remission or other form of relief drom the payment of any tax, duty or impost imposed under any Act of parliament, unless that financial assistance is provided for the purpose of enabline an individual project specifically named in the Act, regulation or order that provides the relief to be carried out ${ }^{22}$.

NRCan was determined to be the Resonsible Authority ${ }^{23}$ and undertook a screening type EA in order to meet the requirements of the $C E A A .^{24}$ Although the project was subject to approval from the AUC, in-land wind projects do not require provincial EAs in the Province of Alberta and a separate Environmental Assessment Screening Report was prepared by NRCan. ${ }^{25}$ The scope of the screening accounted for the construction,

\footnotetext{
${ }^{22}$ Canadian Environmental Assessment Act S.C., 1992, c.37 s.5 (1)(b). Emphasis added.

${ }^{23}$ Responsible Authority (RA) is defined by the CEAA as the federal authority required to ensure that an EA is conducted for a project where a federal decision is required. The RA can range from a federal department undertaking a project to the Treasury Board - in some cases where financial assistance may be granted to a non-federal project.

${ }_{24}$ NRCan, Environmental Screening Report, 2010.

${ }^{25} \mathrm{Had}$ the project triggered a provincial EA, a harmonized provincial-federal approach would likely have been undertaken in order to avoid duplication of effort.
} 
operation, maintenance and decommissioning phases of the project. The screening report was completed in November, 2010 and resulted in a decision to provide funding under the ecoRP program. ${ }^{26}$ The screening report outlined mitigation and monitoring conditions under which the decision had been made. All of the recommendations were based on those already outlined in the proponent's Environmental Impact Statement from December, 2009 and subsequent reponses to federal comments. ${ }^{27}$

The purpose of the NRCan EA screening report was not to simply rehash information already contained within the proponent's Environmental Impact Statement, but to examine the thoroughness of TransAlta's EA process and to "identify and determine the significance of residual effects" ${ }^{28}$ of the project on its environment. In other words, NRCan was assessing the impact of the project as augmented by the mitigation measures to be instated throughout the construction, operation and decommissioning of the wind farm. As such, the authors of the EA screening report did not discuss at length all of the factors assessed by TransAlta, rather the report focusses on what were deemed to be the most important environmental and socio-economic concerns. $^{29}$

NRCan's screening report betrays a bias towards the natural environment. The 2010 report summarises the "impacts of primary interest" proponent's Environmental Impact Statement. This review of potential project impacts

\footnotetext{
${ }^{26}$ NRCan, Environmental Assessment Screening Report, 19.

27 Ibid., 9.

28 Ibid., 9.

${ }^{29}$ These issues were deemed "impacts of primary concern" in the screening report. NRCan, Emironmental Screening Report, 9.

${ }^{30}$ NRCan, Environmental Impact Statement Guidelines for Screenings of Inland Wind Farms Under the Canadian Environmental Assessment Act, (Ottawa: Wind Power Production Incentive, Natural Resources Canada, 2003), 9.
} 
focusses first on impacts on birds and bats. This is not unusual for wind energy projects given the high profile concerns of wind turbines in terms of collision, increased mortality rates and migratory patterns of birds and bats. The screening also presents a relatively indepth overview of impacts and mitigation measures related to noise and setbacks which are often emphasized in wind energy projects. In addition, the screening report provided an overview of adverse effects on Species at Risk. ${ }^{31}$

The choice to include these factors in the body of the report and to provide an overview of all other environmental components, impacts and mitigation measures in a table at the end of the report is one that deserves examination. It is indeed unnecessary to address all environmental components at length in the body of each EA screening report, given the low potential for impacts on some components and the level of effort required to address each component at length when an EA has already been undertaken for the project $;^{32}$ however, one must be able to justify which components are highlighted. In the case of the 2010 NRCan screening report birds, bats, noise and setbacks are all concerns of the ASRD and guidelines for each of the four factors are outlined in the ASRD's Wildlife Guidelines for Alberta Wind Energy Projects, as are Species at Risk. ${ }^{33}$ The need to satisfy provincial requirements to obtain permits may have led the proponent to study some environmental components more in depth than others. On the other hand, the project also required clearance under the Historical Resources Act which led to the

\footnotetext{
${ }^{31}$ NRCan, Environmental Assessment Screening Report, 10.

${ }^{32}$ One must balance the level of effort for an EA with the size of the project and the potential for significant adverse effects on various environmental components.

${ }^{33}$ Government of Alberta, Wildlife Guidelines for Alberta Wind Energy Projects, (Edmonton: Fish and Wildlife Division, Sustainable Resource Development, 2011 ), 3.
} 
preparation of an Historical Resources Impact Assessment (HRIA), but not inclusion of heritage resources in the screening report's discussion of potential impacts.

It is far more likely that the inclusion of the five environmental components birds, bats, noise, setbacks and Species at Risk - is more related to the natural bias ${ }^{34}$ of the authors and reviewers. After all, if one wishes to study EA or become an EA practitioner, the common courses of education are the natural sciences, geography or geology.

Another common thread in the environmental components reviewed is the interest of Environment Canada, acting as a Federal Authority. Protection of Species at Risk, in particular, is federally legislated by the 2002 Species at Risk Act and enforced by Environment Canada and its provincial counterparts. As a Federal Authority, Environment Canada made recommendations to TransAlta with respect to setbacks from habitat, scheduling of construction to avoid breeding seasons, and a post-construction monitoring program to track collisions with turbines and changes to breeding bird populations. $^{35}$

The assessment of heritage resources is not, however, excluded from NRCan's screening report entirely. Heritage resources are discussed in relation to First Nations consultation and in the mitigation table presented as an appendix. Both references to cultural heritage deserve to be addressed here.

Section 7.2 of the NRCan EA screening report outlines all of the activities related to First Nations consultation undertaken as part of the EA and project planning for Ardenville Wind Farm. The activities can be summarised as follows:

\footnotetext{
${ }^{34}$ As opposed to a cultural bias.

${ }^{35}$ NRCan, Environmental Assessment Screening Report, 9-11.
} 
- TransAlta sent letters to the Piikani First Nation and Kainai Nation ${ }^{36}$ Chiefs and Councils to inform them of the project and to schedule a public open house;

- A representative from the Piikani First Nation contacted TransAlta to request a copy of the HRIA for use in their Traditional Use Study and to share the information with elders in the community;

- Both a draft and final copy of the HRIA were sent to the Piikani First Nation;

- A Traditional Use Study was completed by the Piikani First Nation which did not identify any conflicts or project impacts; and

- Representatives from TransAlta were invited to a Blackfoot/Piikani ceremony to receive validation approval for the projet.

The process, although inclusive of First Nation considerations, is indicative of an assessment process that separates land use activities from existing resources rather than an assessment that attempts to account for a range of cultural activities, resources and landscapes.

Traditional land use is not included in the summary of mitigation presented in the appendices of the EA screening report, perhaps because no impacts were identified. The summary table does, however, include 'Archaeological and Cultural Resources'. The table identifies the potential for the disturbance of archaeological/cultural resources and recommends the following mitigation measures:

A Heritage Resource Impact Assessment (HRIA) will be completed by a licensed archaeologist. The HRIA will involve additional research and consultation with ASU, Historic Places and local historical societies, as well as fieldwork (e.g. walkover and judgemental testing). Should resources be found that may be disturbed or destroyed by Project activities, areas will be fenced and excluded from construction activities, or resources will be recovered. Known historical sites will be fenced and flagged before ROW construction starts and be avoided during interconnection construction activities. ${ }^{37}$

\footnotetext{
${ }^{36}$ The Kainai Nation did not respond.

${ }^{37}$ NRCan, Environmental Assessment Screening Report, Appendix B.
} 
The presented mitigation is derived from the Environmental Impact Statement but when read in context of the project, it is clear that the presented mitigation undertaken at the recommended development stage would be ineffective. The point of the HRIA should be to identify archaeological potential, cultural heritage resources and cultural landscapes as part of the EA process, not after the EA. This mitigation, proposed after the EA process and just prior to the construction phase, leaves inadequate time to allow for flexibility in project design. The wording used in the summary illustrates a lack of understanding of how cultural heritage is meant to be treated within the process and, moreover, a lack of concern for cultural heritage resources within an assessment of the environment.

What the 2010 NRCan EA screening report illustrates is the natural bias of EA authors and reviewers and the lack of participation of a Federal Authority concerned with cultural heritage. ${ }^{38}$ It remains unclear if the lack of a cultural heritage Federal Authority is more often the result of a deficiency in triggers to consult or shortcomings in the universal understanding of what components are and should be included in the assessment of a project's environment. In this case no obvious or outstanding cultural heritage resources or landscapes were lost, but it is clear that the possibility of their existence was not fully assessed or understood.

The 2010 screening report makes reference to a 2003 document prepared by NRCan in order to provide guidance for proponents preparing an Environmental Impact Statement when applying for financial support under the Wind Power Production

\footnotetext{
${ }^{38}$ This lack of participation and its causes will be further discussed in Chapter 4. Often lack of participation is the result of proponents or RAs not identifying a need to consult with a Federal Authority or not knowing who to contact if there are cultural heritage concerns. Many EA practitioners use existing heritage designation as a trigger to involve heritage consultants or Federal Authorities and consider the lack of legal protection the equivalent of a lack of heritage value. Other problems lie in confusion between the federal departments concerned with cultural heritage. They are often unclear as to their role or need to participate in the EA process.
} 
Incentive program. The 2003 document, Environmental Impact Statement Guidelines for Screenings of Inland Wind Farms Under the Candian Environmental Assessment Act, provides some insight with regard to NRCan's priorities as a Responsible Authority when scoping EA screening reports and reviewing EISs submitted by proponents.

The 2003 guideline document lists a number of environmental components to be described, at minimum, in the proponent's EIS. These components are organized in standard groupings of: Geophysical Environment; Aquatic Environment; Terrestrial Environment; Atmospheric Environment; and Socio-Economic Conditions. ${ }^{39}$ Under each of these headings, the document lists a number of sub-headings representing components to be addressed in the Environmental Impact Statement. The heading of Socio-Economic Conditions is - by far - the longest list of components, and includes:

- Population

- Land Use

- Cultural Resources

- Existing Noise Level

- Heritage Sites, Archaeological Sites and Other Cultural Resources

- Recreation Areas (including tourism areas)

- Land and Resources Used for Traditional Purposes by Aboriginal Persons

- Safety Issues

- Visual Landscapes ${ }^{40}$

The document does not provide definitions or expand on any of the listed components, thus it is not possible to determine the difference between "Cultural Resources" and "Heritage Sites, Archaeological Sites and Other Cultural Resources". The list and its heading, "Socio-Economic Conditions", display a lack of consideration of the

\footnotetext{
${ }^{39}$ NRCan, Emvironmental Impact Statement Guidelines for Screenings of Inland Wind Farms Under the Canadian Environmental Assessment Act, Ottawa: Natural Resources Canada, 2003$), 13$.

40 Ibid, 13.
} 
components listed as being part of the environment. Rather, it appears to be more of a 'miscellaneous' or 'troublesome to define' category.

TransAlta Wind's 2009 EIS follows the outline presented in the 2003 guidance document very closely. ${ }^{41}$ Overall, heritage is not treated as a valued environmental component throughout the report. It is barely mentioned outside of the brief section specifically addressing heritage and archaeology or First Nations consultation. Cultural heritage is not included in the discussion of issues raised by regulatory agencies ${ }^{42}$ nor the overall literature review. ${ }^{43}$ With the exception of the HRIA no references related to cultural heritage or assessment of impacts on those resources are cited in the report. Pertaining to the assessment of potential negative impacts on cultural resources, the report states, "To determine if archaeological resources will be affected by Project-related activities, a Historical Resources Impact Assessment (HRIA) was completed in late Fall 2008. ${ }^{, 44}$ The report discusses the results of the HRIA in terms of archaeological sites identified and mitigative measures for those sites, but does not discuss any nonarchaeological cultural heritage resources. Ironically, TransAlta emphasised the heritage of the project site in their public consultation materials, stating:

We are proud of the projects that we build, own and operate. We are also happy to be a part of the local community, and take pride in learning about the community's history, incorporating aspects into our project names. For this project, we feel that naming it after the settlement of Ardenville would be most appropriate.

Ardenville is named after one of the early homesteaders of the region, Arden Simpson.

\footnotetext{
${ }^{41}$ TransAlta Corporation, Environmental Assessment Report, Ardenville Wind Farm. Report prepared Natural Resources Canada, (Calgary, 2009)1-4.

${ }^{42}$ Ibid., 3-4.

${ }^{43}$ Ibid., 3-6.

${ }^{44}$ Ibid., 4-13.
} 
The Ardenville Post Office, located near the southwest part of our project site, was open from 1910 to 1948 .

Do you have knowledge of the community's past? If so, we'd love to hear about it. Please share your stories! $!^{45}$

No mention of the community's past is made in any of the EA reports or applications.

This suggests that while TransAlta understood the importance of the community's heritage they lacked the capacity to integrate this heritage into the EA process.

In addition to requirements legislated under the $C E A A$ and those of the $\mathrm{AUC}$, the project also fell under the jurisdiction of the Province of Alberta's Historical Resources Act and an HRIA was prepared by Dr. Brian Reeves during the development phase of the project in 2008-2009. The project and HRIA were reviewed by Alberta Culture and Community Spirit, Historic Resources Branch in April, 2009 at which point the project was granted conditional Historical Resources Act clearance which required that outlined mitigative measures were followed. ${ }^{46}$

The HRIA prepared for the Ardenville Wind Project provides a historical background of the general area, discussing more than 2000 years of pre-contact land use as well as late $19^{\text {th }}$ century Euro-Canadian transportation routes through the McBride Lake Uplands along the Riplinger Trail and early homesteads. The report provides a description of the desktop survey undertaken prior to the field visit. Desktop research included consultation with both the Archaeological Survey of Alberta and Historic Sites Service of Alberta databases. Field reconnaissance was also undertaken during which a number of archaeological sites were identified. The report indicates that "No intact

\footnotetext{
${ }^{45}$ Trans Alta, Public Open House Posters, (Calgary, 2009).

${ }^{46}$ Letter of clearance from David Link, Executive Director, Alberta Culture and Community Spirit to TransAlta representatives, April 20, 2009.
} 
historic structures or structural remains were noted within the lands proposed for development." Although there were farmsteads in the project area which were active and occupied, the report does not provide a methodology for the assessment of those farmsteads as having no heritage value. Furthermore, no mention is made of potential cultural landscapes, despite the potential for extant landscape components associated with pre-contact land use or late $19^{\text {th }}$ century wagon trails.

With the exception of a desktop search of the Historic Sites Service of Alberta database and the statement that no intact historic structures or remains were noted during the field activities, the report is essentially an archaeological assessment. This is not surprising given the undeveloped nature of this particular project area; however, the same emphasis on archaeological assessment can be seen in HRIA reports compiled in most jurisdictions across the country. There are a number of possible reasons why the tendancy is to focus more heavily on archaeological impacts and to often rely on archaeologists as the technical experts in this field. This is of course not generally the case when the project is focussed on a specific building considered to be of heritage value. In such cases, conservation architects or architectural historians are sought for technical advice. In greenfield projects, or those projects not centred around designated heritage buildings, however, archaeological concerns tend to be the main focus when cultural heritage is considered. The author suggests:

- archaeological assessment is an established and expected stage of most provincial and municipal planning and permitting processes;

- archaeologists are well-established as professionals, with recognized academic degrees, professional licences and designations across Canada and internationally;

\footnotetext{
${ }^{47}$ Lifeways of Canada, Historical Resource Impact Assessment: Ardenville Wind Farm Project, Final Report. (Report prepared for TransAlta Corporation, 2009).
} 
- the stigma of accidental discovery of archaeological sites (in particular burial sites) and the associated delays and costs are ingrained in the planning and development community; and

- legislation, policies and review processes are more instituted for archaeological undertakings in most Canadian jurisdictions than those concerned with a broader spectrum of cultural heritage issues.

It is also possible, perhaps, that the use of the term 'resource' is better suited to moveable objects than sites, buildings or landscapes and is therefore more applicable to archaeological features and artifacts. On the other hand, under Alberta's Historical Resources Act 'historic resource' is defined as, "any work of nature or of humans that is primarily of value for its palaeontological, archaeological, prehistoric, historic, cultural, natural, scientific or esthetic interest including, but not limited to, a palaeontological, archaeological, prehistoric, historic or natural site, structure or object..."48 and Alberta's definition is certainly not unique.

Alberta is not alone in this approach to HRIA which attempts to address broader heritage concerns through existing mechanisms in the planning process which have traditionally been the responsibility of professional archaeologists. This approach ignores the specialised education and training that most professional archaeologists in Canada have received. It furthermore expects that, with limited guidance from the relevant authorities, these archaeologists can and should assess resources that are outside of the scope of their professional interest. Moreover, one of the greatest dangers in applying archaeological methodologies to the assessment of project impacts is the limited range of impacts that have traditionally been associated with archaeological sites and resources - namely, loss or destruction of the archaeological record without proper

\footnotetext{
${ }^{48}$ Historical Resources Act, R.S.A. 2000, Chapter H-9, Section l(e).
} 
documentation. The same cannot be said of heritage resources in general, to which a wider spectrum of impacts may be possible, including but not limited to: damage, destruction, isolation, and a wide range of visual impacts.

What the Ardenville case highlights is: the importance of triggers to undertake Heritage Impact Assessment; the separation of interest of those concerned with the natural environment versus the cultural environment (and vice versa); and the emphasis on archaeological assessment as a means to assess impacts on heritage resources in general. The provincial requirement to obtain clearance under the Historical Resources $A c t$ was, in this case, the trigger to evaluate the potential impact of the project on cultural heritage. Without that requirement, the project would not necessarily have triggered a response to heritage concerns during the NRCan review of the EIS, nor would it have necessarily triggered consultation with a federal agency or department concerned with cultural heritage. Because the project area does not coincide with any National Historic Sites or National Parks, there was no requirement to send a Federal Coordination Letter to Parks Canada as a Federal Authority. Likewise, there was no trigger for a Federal Coordination Letter to the Heritage Conservation Directorate of Public Works and Government Services Canada as there are no designated historic buildings within the project area. Finally, the Ardenville case highlights an emphasis on archaeological assessment as a means to assess impacts on heritage resources more generally.

One of the most controversial plans for demolition in the recent history of Southern Ontario caught the attention of the province's heritage conservation community early in the fall of 2009. The City of Brantford had voted earlier in the year to expropriate and demolish a stretch of 41 buildings along the south side of Colborne Street 
in the city's downtown core. The city had a vision for redevelpment, and this line of deteriorating buildings - many predating Confederation - was standing in the way. In order to help fund the demolition, the City of Brantford applied to the Southern Ontario Federal Development Agency (FedDev) for financial assistance. The decision for FedDev to provide or refuse funding triggered the $C E A A$ under Section $5(1)(b)$. In the end, FedDev decided to refuse funding and the City of Brantford chose to proceed without federal support.

The demolition of the south side of Colborne Street in Brantford, Ontario was chosen as a case study because it illustrates a number of technical and process management problems with the cultural heritage aspect of EAs under the CEAA. Firstly, the Brantford case highlights inconsistencies related to preparation of the cultural heritage aspect of EAs as a result of a) a lack of clear and up to date guidance on the assessment of cultural heritage within the CEAA framework, b) the undeveloped nature of techniques, tools and methods to undertake formal assessments of impacts on cultural heritage, and c) a common misconception that only legally designated resources need to be accounted for in the EA process. Secondly, the Brantford case underscores several issues related to process management and the legislative status of cultural heritage. The case highlights deficiencies in the process as a result of a) the separation of culture and nature in the organizational structure of the federal government and its relevant departments and agencies, and b) difficulties associated with cooperation between various levels of governments in cases where roles, responsibilities, and authority have yet to be developed. 
This section of the paper provides an overview of the project and a brief discussion of the recent history of the buildings in question and the downtown core of Brantford more generally. It will also examine how the $C E A A$ was triggered and explore the EA that was prepared, the review of the EA document, and reaction to review comments. Finally, this section will highlight the technical and process management problems the Brantford case illustrates which will be discussed in greater detail in Chapters 2,3 and 4. Although Brantford is likely to serve as an example in the coming years for the importance of sustainable community planning, the dangers of hasty planning decisions made to satisfy difficult timeframes for federal funding, and the power of community involvement and activism, the focus of this section will be limited to decisions made with respect to the EA prepared under the CEAA.

Towards the end of the $20^{\text {th }}$ century, the City of Brantford experienced an economic downturn as a result of the loss of traditional industries. During the $1980 \mathrm{~s}$ Brantford's manufacturing sector was decimated and thousands of jobs were lost. ${ }^{49}$ Shortly after his 1994 election Brantford's mayor, Chris Friel, was quoted in the Toronto Star, describing Brantford's downtown as "the worst downtown in Canada". ${ }^{50}$ The construction of Highway 403 in the 1990s improved the city's economy bringing suburbs, big box stores and new industries. Unfortunately, these new benefits were focused in the north end of the city, drawing many of the remaining businesses and

\footnotetext{
${ }^{49}$ Leo Groarke, Reinventing Brantford: A university comes downtown (Toronto: Natural Heritage Books, 2009), 29.

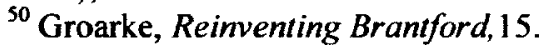


residents away from the downtown core. ${ }^{51}$ Downtown Brantford continued to deteriorate.

The first major breakthrough in the revitalisation of the downtown core came with the September, 1999 opening of the Brantford campus of Wilfrid Laurier University. The opening came after nearly a decade of lobbying within the city for a post-secondary institution as a way of stimulating economic development in the downtown core. Laurier Brantford made use of a number of existing buildings, including landmarks such as the Carnegie Library. The arrival of the Laurier Brantford campus and subsequent Mohawk College institutions stimulated the downtown economy and paved the way for the opening of a new downtown public square in June, $2008 .{ }^{52}$

With the revitalisation of the downtown core, the city looked towards the future and commissioned a Master Plan study for downtown Brantford in 2007 and 2008. The Master Plan, Towards a Stronger Future, outlined improvements which had occurred over the preceding decade and identified areas of the downtown that still required attention. The document drew attention to the wealth of historic built resources in the downtown core which both defined the character of the downtown streets and held the potential for adaptive re-use. The Master Plan highlighted the ailing south side of Colborne, in particular, stating:

The special historic character of Brantford's two main streets should be noted. Although not formally designated, several structures along Colborne Street and Dalhousie Street are of note for their historic significance. The City's Heritage Inventory included the buildings along the south side of Colborne Street, from $\# 35$ to \#171. The majority of the buildings are pre-Confederation and 100 years or older. Fifteen of the properties (35\%) are identified as being of Architectural Significance

\footnotetext{
${ }^{51}$ Ibid., 30.

52 Ibid., 15.
} 
while eight of the properties (20\%) are Historically Significant. In total, more than half the buildings are highly rated as being either architecturally or historically significant.

Although these structures are identified as heritage assets, their present condition limits opportunities for adaptive re-uses. The disrepair that many of the buildings appear to have fallen into creates poor market conditions and risks creating a downward spiral of disinvestment if intervention is not undertaken. ${ }^{53}$

The 2008 document considered the revitalisation of Colborne Street to be a key element to the Master Plan and a priority for City Council. ${ }^{54}$ The study offered three potential options to explore for the south side of Colborne Street, 1) full scale preservation and refurbishment of all buildings, 2) selective preservation, or 3) demolition of all or substantive portions of the block. The document also recommended that studies be undertaken immediately to determine most favourable option in order to avoid further vacancies and deterioration of the structures. ${ }^{55}$

The problems of the south side of Colborne Street had been considered for quite some time and had resulted in the creation of a South Side of Colborne Task Force. It was not until the 2009 announcement of federal stimulus funding for infrastructure that a decision was imperative. A decision to expropriate the properties along the south side of Colborne Street with the goal of demolition was made by City Council on August 4, 2009..$^{56}$ Applications to the Federal Economic Development Agency for Southern Ontario (FedDev) were required to demonstrate that they would be "shovel-ready" by

\footnotetext{
${ }^{53}$ Urban Strategies, A Master Plan for Downtown Brantford: Towards a Stronger Future, (Report prepared for the City of Brantford, 2008): 19.

${ }^{54}$ Ibid., 100.

s5 Ibid., 102.

${ }^{56}$ Michael-Allan Marion, "Council Oks purchase of Colborne properties," Brantford Expositor, August 5, $2009, \mathrm{~A} 2$.
} 
March, 2010. There was also pressure related to an August 18, 2009 deadline for application for federal support of a possible joint YM-YWCA and Laurier Brantford proposal fo a sports complex to be constructed on the site. Because of the time sensitive nature of federal stimulus monies, there were projects across the country that were rushed through the planning phase in order to be 'shovel-ready' by March $31^{\text {st }}, 2010$ and others that were arguably rushed through the EA screening process by federal reviewers in order to meet their demanding timelines for distribution of the funds. It is not surprising, therefore, that the city was unaware of the requirements for an EA under the $C E A A$ to be completed under the terms of the agreement for funding until early in 2010 .

Federal funding for the demolition project in the amount of $\$ 1.38$ million was announced in late January, $2010 .^{57}$ However, according to Section 5 (1)(b) of the $C E A A$ the decision for FedDev to provide or refuse federal monies for the project triggered the need for an EA screening report to be undertaken. A draft EA screening report was prepared by UEM Consulting in February, $2010^{58}$ and submitted to FedDev and Public Works and Government Services Canada (PWGSC) for review on March 1, 2010. ${ }^{59}$ UEM Consulting was directed to conduct the EA screening in accordance with the PWGSC template and to ensure that cultural heritage and archaeological considerations were addressed.

Although many federal departments and agencies undertake their own EA screenings under the $C E A A$, there are those that lack the expertise and capabilities as it falls outside of their mandate. In these cases, PWGSC can be contracted to undertake or

\footnotetext{
${ }^{57}$ Tom Kennedy, "\$1.38M from feds for south side demolition," Brant News, January $21,2010$.

${ }^{58}$ Michael-Allan Marion, "City getting ready to demolish," Brantford Expositor, February 12, 2010.

${ }^{59}$ UEM Consulting Project Team, Issues and Implications of FedDev Review, Letter report dated June 2 , 2010.
} 
review EAs. In the case of the Branford project, PWGSC was under a Standing Offer with FedDev to provide advice and services with respect to EAs. One of the main roles of PWGSC in this capacity was to review applications for funding to determine if they were excluded from EA requirements under the CEAA. As a demolition project, the Brantford application triggered the requirement for an EA screening and was notified of this requirement in February, $2010 .^{60}$ Submission of the draft EA screening report uncovered a number of gaps in PWGSC capabilities. Although Regional Environmental Specialists are highly trained in EA, for the most part, their educational background is in the natural sciences, geography or geology. Conversely, PWGSC employs some of the most highly tranined heritage conservation experts in the country, almost none of whom are trained in or familiar with the practice of EA. ${ }^{61}$ In addition to their own in-house services, PWGSC also maintains Standing Offers with consulting firms across the country who are able to prepare and review EAs. In this case, PWGSC contracted two firms, AMEC Earth and Environmental and Taylor Hazell Architects to review the archaeological and cultural heritage aspects of the EA screening report, respectively. Officials at the Ontario Ministry of Tourism and Culture were also consulted as subject matter experts.

In addition to the technical assessments of various environmental components in the EA, PWGSC also reviewed consultation processes followed by the city, newspaper articles, and letters that had been received by FedDev directly and through the Canadian Environmental Assessment Registry (CEAR) from agencies and organisations regarding

\footnotetext{
${ }^{60}$ Anonymous interview subject 1.

${ }^{61}$ Anonymous interview subjects 1 and 2 .
} 
the project which included the Ontario Ministry of Tourism and Culture and the Heritage Canada Foundation.

The review of EA screening report which was completed in May, 2010 found a number of deficiencies, particularly with respect to cultural heritage. First, the EA screening report compiled by UEM Consulting was based on demolition as the project, and only alternative. ${ }^{62}$ In order to fully assess impacts on various environmental components and provide comprehensive and effective mitigative measures, an EA screening report should include consideration of project alternatives, as outlined under Section $16(1)(\mathrm{e})$ of the CEAA. By predicating an EA on one alternative alone, it becomes a checklist for mitigation rather than a tool for decision-making.

Second, FedDev indicated that in order to meet the regulatory requirements under the CEAA a detailed HIA would need to be undertaken. ${ }^{63}$ Such an HIA would necessitate further evaluation of the heritage values of the properties as well as structural and economic analyses of project alternatives.

The third recommendation of the review was that consultation with federal, provincial and local authorities on heritage should be undertaken. Furthermore, the City of Brantford was advised that it should consider the involvement of advocacy organizations such as the Architectural Conservancy of Ontario and the Heritage Canada Foundation. $^{64}$

Finally, recommendations were made with respect to the timing of Stage 2 archaeological assessment of the project area. The Stage 1 Archaeological Assessment

\footnotetext{
${ }^{62}$ UEM, Issues and Implications, 2.

${ }^{63}$ Ibid., 3.

${ }^{64}$ Ibid., 3.
} 
report completed for the EA screening report recommended Stage 2 assessment be undertaken prior to new construction, while the review suggested that it would more appropriate prior to demolition. ${ }^{65}$

Based on the estimated cost and scheduling delays that the city's consultant estimated to address FedDev's concerns, the City of Brantford determined that it would undertake the demolitions without federal funding.

The Brantford case provides insight into the inconsistencies between various Canadian provinces and territories with respect to legislation and authority. In the case of the Ardenville Wind Farm Project, the project triggered a need for Historical Resources Act clearance and an Historical Resources Impact Assessment was submitted to Alberta Culture and Community Spirit for approval. In contrast, the demolition of 41 century-old buildings did not trigger any participation or review by the Ontario Ministry of Tourism and Culture under the Ontario Heritage Act. Under the 2005, Ontario Heritage Act, section 29 (1) municipalities are responsible for the designation of properties of cultural heritage value through municipal by-laws. Municipal governments also have authority to approve or deny applications to alter or demolish an individual property ${ }^{66}$ or erect or demolish a property within a designated Heritage Conservation District. ${ }^{67}$ No restrictions under the Ontario Heritage Act apply if a property is not designated.

Involvement of provincial heritage authorities in Ontario in planning processes is becoming more frequent. It is becoming more common for municipalities to submit heritage assessments prepared for Municipal Class EAs to the Ministry of Culture for

\footnotetext{
${ }^{65}$ Ibid., 3.

${ }^{66}$ Ontario Heritage Act, R.S.O. 1990, c.O.18, Part IV, s.33 and 34.

${ }^{67}$ Ontario Herilage Act, R.S.O. 1990, c.O.18, Part V, s.42.
} 
review. Furthermore, certain sections of Ontario Regulation 359/09, Renewable Energy Approvals Under Part V.0.1 of the Environmental Protection Act require HIAs and archaeological assessments be undertaken and accepted by the Ministry Culture as part of the Renewable Energy Application process. Much of the authority over cultural heritage in Ontario, however, lies at the municipal level. This downloading of authority leaves bigger municipalities with impossibly large portfolios and smaller municipalities with limited training and expertise and all municipalities with conflicts of interest on projects. $^{68}$

The Ontario Minister of Culture does have authority under the Ontario Heritage $A c t$ to exercise certain powers which include the authority to "designate any property within a municipality or in unorganized territory as property of cultural heritage value or interest of provincial significance" under section 34.5 (1) and the authority to "issue a stop order" under section 35.2 (1) "with respect to any property in the Province to prevent the alteration of the property, any damage to the property or the demolition or removal of any building or structure on the property" if the property is considered to potential have cultural heritage value or interest of provincial significance. Although the stop-work order has been exercised in the extreme 1990 case of the Maclean house in Toronto, the power to designate under section 34.5 (1) has never been exercised.

The Brantford case underscores a number of technical concerns and deficiencies with respect to the legislative status of cultural heritage that will be discussed in later chapters. There is a lack of clear and up-to-date guidance on the assessment of cultural

\footnotetext{
${ }^{68}$ This was the case in Brantford where City Council had the authority to designate to protect the buildings or the authority to demolish those same buildings. It is also the case in Ottawa where council has voted to de-designate the Agricultural Pavillion and Lansdowne so that it can be relocated for a development project in which the City is partnering with private firms.
} 
heritage within the $C E A A$ framework. The EA screening report prepared by UEM adhered to the PWGSC template for EA, but available guidance on the cultural heritage aspect of EAs under the CEAA dates to 1996. Chapter 3 will outline the development of heritage conservation theory and practice. The past ten years have seen dramatic changes in the attitudes of many practitioners and a wealth of knowledge and new ideas currently being practiced and investigated. This includes an increasingly more formalised approach to Heritage Impact Assessment (HIA). Despite recent advancement, the practice of HIA remains underdeveloped, particularly with respect to tools, techniques and methods for assessment of impacts on cultural heritage. It is no surprise that the EA screening report prepared for the City of Brantford assessed cultural heritage at a vastly different level than was expected by PWGSC, given the inconsistencies in the degree of assessment of cultural heritage across the country.

Perhaps the most noteworthy concern raised by examination of this case is the misconception that only legally designated properties and archaeological resources need to be accounted for in the EA process. The prevalence of archaeological resources has been discussed in relation to the Ardenville Wind Farm Project and will not be restated here. The perception that designation is a measure for cultural heritage value is both a problem with the technical undertaking of cultural heritage impact assessments as well as the historical legislative status of cultural heritage. The Reference Guide on Physical and Cultural Heritage Resources clearly states, "not all valued cultural heritage resource have official designation status and therefore may not always be identified in governement 
heritage registries. They may not even be formally recognized or documented."69 More often than not, in practice, it seems that assessments are limited to designated resources. Although the majority of demolished buildings were included in the City's Heritage Inventory, ${ }^{70}$ they were not deemed by the EA screening report prepared for the City as being of sufficient heritage value for the impact of demolition to have a significant and irreversible adverse effect on the environment. ${ }^{71}$ The fixation on legal designation as the primary tool of identifying value is a function of the historic goals of natural and cultural heritage conservation legislation which will be discussed in greater detail in Chapter 4.

Other legislative status concerns raised by the Brantford case include: the separation of nature and culture in training, education and the organizational structure of the federal government; and the conflicts associated with the jurisdiction of cultural heritage between various levels of government. In this case, the separation of nature and culture manifested in a situation where PWGSC experts in EA were unfamiliar with theories and practice related to cultural heritage as well as the local and provincial policies and legislation governing their identification and protection. It also identified the lack of familiarity of cultural heritage experts in the federal and provincial governments with the EA process, particularly under the CEAA. Furthermore, the roles, responsibilities

\footnotetext{
${ }^{69}$ Canadian Environmental Assessment Agency, The Canadian Environmental Assessment Act: Reference Guide on Physical and Cultural Heritage Resources, (Ottawa: Canadian Environmental Assessment Agency, 1996), 2.

${ }^{70}$ Urban Strategies, Towards a Stronger Future, 19.

${ }^{71}$ This also raises the issue of the efficacy of EAs when consultants are hired by the proponent to assess impacts and recommend mitigation. Although it is not the purpose of an EA to justify a project, there have been concerns raised in previous reviews of the CEAA that EAs are increasingly becoming mitigation checklists rather than decision-making tools. One of the major concerns PWGSC had with the City's EA was the lack of alternatives. The EA was written on the premise that the demolition was the only alternative and the purpose of the EA was to make the project permissible under existing federal and provincial legislation rather than support project-planning that might result in a project that reflects the principles of sustainable development.
} 
and authority of provincial heritage authorities in the $C E A A$ process were unclear and have yet to be fully understood. The fact that letters from the Ontario Ministry of Culture were originally received through the CEAR suggests a need to develop a better relationship between the Ministry of Culture, regional PWGSC offices, and other federal authorities undertaking development projects in the province.

The case studies presented in this chapter, the Ardenville Wind Farm Project near Fort MacLeod, Alberta and the Demolition of the South Side of Colborne Street in Brantford, Ontario, presented the preparation of the cultural heritage aspect of an EA under the $C E A A$ in two very different ways with two very different results. Examination of both cases revealed a number of problems related to evaluative asymmetry and legislative status.

Evaluative asymmetry concerns raised by both cases include the importance of triggers to undertake Heritage Impact Assessment (HIA). There was a requirement for Historical Resources Act clearance in the Ardenville case, whereas the cultural heritage aspect of the EA screening report in the Brantford case, where there were no formal triggers for an HIA, proved inadequate to assess the project's impact on the environment. This is also a result of the lack of clear and up-to-date guidance on the assessment of cultural heritage within the $C E A A$ framework. Both cases highlight inconsistencies with regard to the tools, techniques and methods employed to undertake HIA and the narrow scope of assessment which often includes only designated properties and archaeological concerns. This fixation on legal designation and archaeology is most likely a result of conservation legislation and policy which has historically been focussed on identification and legal protection of built resources and archaeological sites. 
Other legislative status concerns highlighted by these two cases include the separation of nature and culture in training, education and the organizational structure of the federal government and the conflicts associated with roles, responsibility and authority between federal departments and agencies and between the various levels of government. This last problem in particular hampers the ability for cultural heritage to be seen as a valued environmental component given the level of development of the interdepartmental and inter-governmental relationships, roles and responsibilities of those concerned with the natural environment. 


\section{Chapter: Federally Legislated Environmental Assessments}

The state of heritage conservation within the Canadian Environmental Assessment Act $(C E A A)$ is founded in three major processes and their associated viewpoints. First is the development of EA as an authoritative planning process, spurred on by the environmental movement. Second is the evolution of heritage conservation theory and practice, and third is the complex of bureaucratic policies, procedures and legislation which have come to govern both EA and heritage conservation.

This chapter focuses on EA as a planning tool. It outlines the development of EA from the passing of the National Environmental Policy Act of 1969 (NEPA) in the United States to present-day $C E A A$ legislation, procedures and guidelines. Included in this retrospective examination are the implications of Canada's international obligations with respect to sustainable development and the environment. In particular, the chapter deals with the impact of the 1987 Brundtland Commission, the 1992 Rio Declaration on Environment and Development, and the understanding that cultural heritage is integral to the concept of sustainable development. Although Canada has responded to these obligations and has adopted policies and legislation with respect to sustainable development, the policies are ineffective because they ignore the inter-relatedness of the built and natural environment. The overseeing federal bureaucracy, furthermore, continues to separate the roles and responsibilities of those concerned with cultural heritage from those concerned with natural heritage. The latter are often tasked with overseeing and reviewing EAs and EA policies; effectively excluding federal cultural heritage specialists from the EA process. 
The definition of environment under the CEAA is problematic for cultural heritage as a result of the ambiguities related to the inclusion of cultural heritage in the definition of environmental effect and its exclusion from the definition of environment. This exclusion of cultural heritage from the definition of environment will be discussed in this chapter, as it is detrimental not only to cultural heritage but also to sustainable development policies in Canada.

EA first became part of a federal project planning process in 1970 when the United States government passed the National Environmental Policy Act of 1969 (NEPA). Prior to the NEPA, federal infrastructure projects in the United States were judged primarily on economic and engineering constraints and factors, but following the $N E P A$, socio-economic and environmental factors became included in project planning at a federal level. ${ }^{72}$ The NEPA was the first national legislation enacted that weighed the quality of the environment as an important public value. ${ }^{73}$ It required an Environmental Impact Statement (EIS) for all federal projects where there was no Finding of No Significant Impact (FONSI). Since that time, countless governments and international bodies have followed suit and EA has become common practice in the public realm. In 1987, the World Commission on Environment and Development, better known as the Brundtland Commission, released their Report of the World Commission on Environment and Development: Our Common Future which challenged the international community to adopt sustainable development strategies. The report encouraged a new approach to planning that invited communities and governments to consider the causes of

\footnotetext{
${ }^{72}$ Owen D. Harrop and Nixon, Environmental Assessment in Practice (New York: Routledge, 1998), 9.

${ }^{73}$ Lynton Keith Caldwell, The National Environmental Policy Act (Bloomington: Indiana University Press, 1998), 23.
} 
negative development patterns rather than simply fighting against the results of development. ${ }^{74}$ Sustainable development is defined in the report as "development that meets the needs of the present without compromising the ability of future generations to meet their own needs". ${ }^{75}$ This definition is widely accepted and often quoted, but the two key concepts associated with the Brundtland Commission's definition are rarely communicated, at least in North America. The two key concepts are:

- the concept of 'needs', in particular the essential needs of the world's poor, to which overriding priority should be given; and

- the idea of limitations imposed by the state of technology and social organization on the environment's ability to meet present and future needs. $^{76}$

Neither of these keys concepts is focused exclusively on the natural environment. Yet somehow the North American audience has over time turned sustainability into a compartmentalized exercise that focusses almost entirely on natural environmental components and ignores the inter-relatedness of social, built, and natural environmental factors. The Brundtland Commission's second key concept, in particular, can be applied as much to projects in urban environments as it can to resource extraction or pipeline projects in Canada's north.

Our Common Future supported burgeoning EA practices and policies by reemphasizing the need to weigh environmental factors along with economics and politics in decision-making processes. The Brundtland Commission went even further by

\footnotetext{
${ }^{74}$ Denhez, The Heritage Strategy Planning Handbook, (Toronto: Dundurn Press, 1997), 39.

${ }^{75}$ Gro Harlem Brundtland and the World Commission on Environment and Development, The Report of the Commission on Environment and Development: Our Common Future (New York: United Nations, 1987), accessed online November, 2011 at http://www.un-documents.net/wced-ocf.htm.

76 Ibid.
} 
identifying the need to consider a wider spectrum of factors in development decisions and policies, including social factors.

The climax of the growing international concern for biological and social concerns in relation to development came in June of 1992 when more than 100 heads of State and approximately $2400 \mathrm{NGO}$ representatives met in Rio de Janeiro, Brazil for the one week Earth Summit, chaired by Canadian Maurice Strong. ${ }^{77}$ The resulting Rio Declaration on Environment and Development resolved in Principle 17 that "environmental impact assessment, as a national instrument, shall be undertaken for proposed activities that are likely to have a significant adverse impact on the environment and are subject to a decision of a competent national authority". ${ }^{78}$ That same month the Canadian Environmental Assessment Act (CEAA) was passed.

In Canada, federal involvement in EA can be traced to the 1973 creation of the Environmental Assessment and Review Process (EARP). ${ }^{79}$ The EARP was a policy document. It outlined the federal government's policy with respect to EA and established a two-phase process to be followed: an assessment phase and a public panel review phase. The EARP resulted in the creation of the Federal Environmental Assessment Review Office (FEARO) in order to oversee the process. The Minister of Environment was given the authority to issue the guidelines for administering the EARP in 1979 and the EARP Guidelines Order was issued in 1984. The 1984 guidelines order outlined the

${ }^{77}$ United Nations, 2011. "Earth Summit", accessed online at http://www.un.org/geninfo/bp/enviro.html. ${ }^{78}$ United Nations, 1992, "Report of the United Nations Conference on Environment and Development, Annex 1: Rio Declaration on Environment and Development", A/CONF.151/26 (Vol. 1), accessed online at http://www.un.org/documents/ga/confl51/aconf15126-lannex1.htm.

${ }^{79}$ Alan Gilpin, Environmental Impact Assessment: Cutting Edge for the Twenty-First Century, (New York: Cambridge University Press, 1995), 114. 
roles and responsibilities of those participating in order to implement the $E A R P .{ }^{80}$

Responsibility for EAs was also given to the Minister of the Environment under the 1985

Department of the Environment Act, which required that, the Minister:

...ensure that new federal projects, programs and activities are assessed early in the planning process for potential adverse effects on the quality of the natural environment and that a further review is carried out of those projects, programs and activities that are found to have probable significant adverse effects, and the results thereof are taken into account. ${ }^{81}$

Taken together, the EARP Guidelines Order and the Department of the Environment Act gave the impression that Canada had enacted measures to provide for environmentally responsible and sustainable development strategies at the federal level. This was, however, not the case. The application of the EARP Guidelines Order was problematic and its fundamental flaws were highlighted in two court cases, the Rafferty-Alameda case in Saskatchewan and the Friends of the Oldman River Society v. Canada Supreme Court case, which resulted in an overhaul of federal EA policies. ${ }^{82}$

The Rafferty-Alameda (1989) and Oldman River (1992) cases both involved dam projects that required federal licences, under the International River Improvements Act and the Navigable Waters Protection Act, respectively. Both projects were proposed during a period of increasing public concern for the natural environment and a growing awareness among Canadians that a number of development projects in the previous 20 years had resulted in considerable environmental damage. During the late 1980s, public

\footnotetext{
${ }^{80}$ M. Husain Sadar and William J. Stolte "An Overview of the Canadian Experience in Environmental Impact Assessment (EIA)," Impact Assessment, 14 No.2 (1996): 215-216.

${ }^{81}$ Department of the Environment Act R.S.C., 1985, c. E-10, s. 5(a)(ii).

${ }^{82}$ Kristen Douglas, Bill C-13: Canadian Environmental Assessment Act, Legislative Summary (Ottawa: Library of Parliament, 1992) 1.
} 
expectations changed dramatically. ${ }^{83}$ Provincial governments, including those in Saskatchewan and Alberta, had developed their own policies and legislation to govern EA by this time, but jurisdictional authority over the process remained unclear in cases such as Rafferty-Alameda and Oldman River and there was a lack of procedural guidance to support federal-provincial cooperation in the process.

In the case of Rafferty-Alameda, the Souris Basin Development Authority (SBDA) had been given the responsibility of designing and constructing the Rafferty Dam on the Souris River and the Alameda Dam on Moose Mountain Creek along with a small number of other related project components. Existing provincial legislation for that type of project was followed, which included:

- submission of the proposal by the proponent (the SBDA, in this case);

- a decision by Saskatchewan Environment and Public Safety as to whether an EA is required;

- preparation of project specific EA guidelines by Saskatchewan Environment and Public Safety, public notice, and a request for the proponent to complete an Environmental Impact Statement (EIS);

- public input and Board of Inquiry, if necessary;

- a decision to approve or not approve the project subject to conditions. ${ }^{84}$

As the Souris River is an international river, the project was subject to the International River Improvements Act, under which Environment Canada was required to issue or refuse a permit. Considering the EA prepared under provincial legislation to be sufficient, Environment Canada chose not to require an EA under the EARP and issued the permit in 1988. The project was brought to the Federal Court in 1989 by the Canadian Wildlife Foundation and two affected land-owners on the grounds that the EARP had not been properly applied. Although Environment Canada had acted on the

\footnotetext{
${ }^{83}$ W. J. Stolte and M. H. Sadar, "The Rafferty-Alameda Project and its Environmental Review: Structures, Objectives and History," Canadian Water Resources Journal, 18 no.l (1993): 7-8.

${ }^{84}$ Ibid., 8.
} 
assumption that the EARP was a Cabinet Policy Statement and not law, the court found that the provincial requirements had not, in this case, adequately addressed areas of federal responsibility and required that Environment Canada conduct a review of the project under the $E A R P{ }^{85}$ The case highlighted the lack of mechanisms in place to manage provincial-federal $\mathrm{EAs}^{86}$ and the judgment effectively increased the responsibility of federal authorities to make decisions for projects that had previously been treated as peripheral to federal jurisdiction.

The Friends of the Oldman River Society v. Canada Supreme Court case is associated with a far more complex and controversial project than the Rafferty-Alameda project and the details of the project will not be discussed here in great detail, except where they apply to the discussion of the EARP.

The Oldman River project involved the construction of a dam by the Alberta Government in an effort to resist drought and support irrigation. The project had been in the works since the 1970 s and the Alberta government had undertaken a number of environmental studies which appeared to ultimately favour the construction of a dam on the Oldman River. The Government of Alberta applied for a federal permit under the Navigable Waters Protection Act in March, 1986. Approval for the project was issued by the Minister of Transport in September, 1987 after project activities were already underway. ${ }^{87}$

Exchanges between environmental and social interest groups and the federal government in the late 1980s highlight provincial-federal tension associated with

\footnotetext{
${ }^{85}$ Ibid., 9.

${ }^{86}$ This problem still exists in the case of provincial-federal cooperation and communication when assessing impacts on cultural heritage resources.

${ }^{87}$ James Glen, Once Upon an Oldman (Vancouver: UBC Press, 1999), 61.
} 
delegated and constitutional authority. The first exchange involved the Southern Alberta Environmental Group (SAEG) and a letter written to the Minister of Fisheries and Oceans in August, 1987. SAEG detailed the impact a dam on the Oldman River would have on fisheries and fish habitat for which the minister was responsible and implored the minister to initiate an environmental assessment. The minister's response was that "in view of...the fact that the potential problems associated with the dam are being addressed, 1 do not propose to intervene in this matter. ${ }^{88}$ In December of that same year the Friends of Oldman River (FOR) appealed to the federal Minster of the Environment, as the minister responsible for federal environmental assessment. The response to FOR's request that the project be subject to review under the EARP was that "because of 'administrative arrangements' with Alberta on fisheries management and environmental impact assessments, it 'would not be appropriate' for the federal government to intervene in the Oldman." ${ }^{299} \mathrm{~A}$ third request for action from the federal government, this time from the Peigan Nation to the Minister of Indian Affairs, was met with a response in March, 1989 that the minister would 'consult with' provincial authorities and that their request would be forwarded to the Minister of Environment. ${ }^{90}$ These three exchanges reinforce the notion that the federal government has a history of being, at the very least, reluctant to exercise any authority over matters outside of their mandate if a provincial or territorial government can be given the responsibility, even if the result is the neglect of certain federal responsibilities.

\footnotetext{
${ }^{88}$ Letter from Hon. Tom Siddon, Minister of Fisheries and Oceans to Mary Bailey, president SAEG, August 25, 1987 as quoted in Glen, Once Upon an Oldman, 62.

${ }^{89}$ Letter from Holly Martell, special assistant, Office of the Minister of Environment to Cliff Wallis, Friends of Oldman River, January 15, 1987 as quoted in Glen, Once Upon an Oldman, 62.

${ }^{90}$ Letter from Hon. Pierre Cadieux, minister of Indian affairs to Chief Peter Yellowhorn, Peigan Nation, March 9, 1989 as quoted in Glen, Once Upon an Oldman, 62.
} 
In 1989, when the Federal Court ruled that a review of the Rafferty-Alameda under the EARP was required before a federal permit was issued for the project, interest groups opposed to the Oldman River Dam saw a means of bolstering their arguments given that the project fell under federal jurisdiction as a result of its implications for the Peigan Indians and fish habitat in the river. ${ }^{91}$ Although the federal Minister of Transport had issued a permit for the project under the Navigable Waters Protection Act, the EARP had not been applied prior to the permit issuance.

A Federal Court judge ruled against FOR in August, 1989 on the grounds that there was no EA requirement under the Navigable Waters Protection Act or the Fisheries Act and, as a result, the EARP did not need to be applied, whereas there was a EA requirement for approval under the International Waters Improvement Act. ${ }^{92}$ FOR appealed and in March, 1990 the Federal Court of Appeal overturned the majority of the August, 1989 ruling and ordered the Ministry of Transport and the Minister of Fisheries and Oceans to adhere to the EARP Guideline Orders. ${ }^{93}$ On January 23,1992 , the Supreme Court of Canada ruled that the EARP Guideline Orders were not mere Cabinet Policy Statements and "had the force of law, and consequently, had to be complied with in all cases to which they applied." 94 Another finding of the Oldman River case, which will be revisited in Chapter 4, was the notion that the environment transcends jurisdiction and its protection is the shared responsibility of all levels of government. More specifically, the Constitution Act, 1867 does not assign the "matter of 'environment' ... to

\footnotetext{
${ }^{91}$ Ibid., 61 .

92 Ibid., 65.

${ }^{93}$ No stop work order was ever issued, citing safety concerns as dam construction was well underway.

${ }^{94}$ Monique Hébert, "The Oldman River Decision of the Supreme Court of Canada," Library of Parliament, Research Branch. Background Paper BP-287E (Ottawa: Library of Parliament, 1992), 1.
} 
either the provinces or Parliament," as the environment "does not comfortably fit within the existing division of powers without considerable overlap and uncertainty.",95

Cultural heritage was one area of environmental impact in the Oldman River Dam Project as a result of both the archaeological importance of the Three Rivers region and the traditional and continuing use of the Oldman River and surrounding landscape by the Peigan Nation. Both the FEARO panel report and the Supreme Court ruling highlighted the removal of approximately 175,000 individual artifacts $^{96}$ and the regrettable and irreversible loss of the associated archaeological evidence. ${ }^{97}$ The Supreme Court ruling in particular re-emphasized the importance of considering cultural and social factors in development planning decisions, citing the Brundtland Commission holistic view of sustainable development. In his report, Supreme Court Justice Gérard La Forest stated, "I cannot accept that the concept of environmental quality is confined to the biophysical environment alone." 98

Judges in both the Rafferty-Alameda and Oldman River cases ordered the relevant federal ministers to comply with the EARP Guidelines Order and found that the federal EA process needed to be followed for all projects where a federal decision was required. $^{99}$

The EARP Guideline Orders had previously been criticized for their narrow scope and ineffectiveness and the Rafferty-Alameda and Oldman River rulings highlighted the

\footnotetext{
${ }^{95}$ Friends of the Oldman River Society v. Canada (Minister of Transport), Supreme Court Ruling (January 23, 1992), 9-10.

${ }^{96}$ Glen, Once Upon an Oldman, 156.

${ }^{97}$ Although modern archaeological best practices involve meticulous recording of archaeological features, excavation is a destructive and irreversible undertaking regardless of whether the goal is mitigation or academic research.

${ }^{98}$ Friends of Oldman River Society v. Canada Supreme Court Ruling (Ottawa: Supreme Court, 1992 ), 43.

99 Douglas, Bill C-13, 2.
} 
inadequacies of the EARP Guidelines Orders as the basis for legislation. ${ }^{100} E A R P$ was superseded in 1992 by the $C E A A$ which replaced the FEARO with the Canadian Environmental Assessment Agency (the Agency). The Agency was formed in 1994 in preparation for the coming into force of the CEAA in January of $1995 .^{101}$ The $C E A A$ preamble outlines the four over-arching objectives or principles of the Act:

WHEREAS the Government of Canada seeks to achieve sustainable development by conserving and enhancing environmental quality and by encouraging and promoting economic development that conserves and enhances environmental quality;

WHEREAS environmental assessment provides an effective means of integrating environmental factors into planning and decision-making processes in a manner that promotes sustainable development;

WHEREAS the Government of Canada is committed to exercising leadership within Canada and internationally in anticipating and preventing the degradation of environmental quality and at the same time ensuring that economic development is compatible with the high value Canadians place on environmental quality;

AND WHEREAS the Government of Canada is committed to facilitating public participation in the environmental assessment of projects to be carried out by or with the approval or assistance of the Government of Canada and providing access to the information on which those environmental assessments are based. ${ }^{102}$

The preamble speaks to Canada's responsibility as a signatory State Party to the Rio Declaration. It responds to Principle 17, which resolves that EA should be undertaken at a national level when activities subject to national authority might be the cause of significant negative environmental impacts. The $C E A A$ also responds to Principle 4 of the Rio Declaration which resolves that "in order to achieve sustainable development,

\footnotetext{
100 Ibid., 2.

${ }^{101}$ Canadian Environmental Assessment Agency, Canadian Environmental Assessment Agency, accessed November, 2011, http://www.ceaa.gc.ca/default.asp?lang=En\&n=C10DF5DB-1 \&offset=14\&toc=show.

${ }^{102}$ Canadian Environmental Assessment Act, R.S., 1992, c. 37. (emphasis added)
} 
environmental protection shall constitute an integral part of the development process and cannot be considered in isolation from it." 103 Following the coming into force of the $C E A A$, all federal projects became subject to the $C E A A$, which bears with it the responsibility for Responsible Authorities (RAs) to consider potential project-related adverse effects on cultural heritage resources.

At this point, it seems appropriate to focus on the significance of cultural heritage as a part of sustainable development prior to discussing how cultural heritage has been handled within the context of the CEAA up to the present day. It is also pertinent to discuss the relationship between the natural environment and the built environment.

The primary misconception regarding the heritage conservation movement is that it is rooted in the firm belief that all old buildings should be preserved, in a museum-like state, in perpetuity. This is simply not the case, as demonstrated by increasing examples of adaptive re-use and re-purposing of existing building stock. It is also no longer the case that the only resources meriting conservation are military sites and the homes or institutions of the elite. The change in interest is reflected in the increased international focus on vernacular architecture, cultural landscapes, and intangible heritage. This development of heritage conservation practice and theory, particularly with respect to values, will be discussed in further detail in Chapter 3. It seems pertinent to the present discussion, however, to dispel these misconceptions up front. Heritage conservation in Canada is in the burgeoning stages of an environmentally-conscious paradigm which promotes the retention and integration of the existing building stock into future development plans with a view to promoting healthy and vital communities, saving

\footnotetext{
${ }^{103}$ UNESCO, Report on the United Nations Conference on Environment and Development, Annex I: Rio Declaration on Environment and Development, A/CONF.151/26 Vol.1, (Paris: UNESCO, 1992).
} 
energy, reducing the exploitation of new resources, and reducing the amount of waste from demolition. ${ }^{104}$ The past few decades have also seen a developing understanding of cultural landscapes, which are, by definition, the result of the interactions of human societies with their natural or urban environments. Internationally, expert-led community involvement has been a key component in the identification, evaluation, and management of these cultural landscapes.

Parks Canada, the federal authority mandated with Canada's cultural and natural heritage, places emphasis on the relationship between people and their built and natural environments, stating in its guiding principles that, "people and the environment are inseparable." ${ }^{105}$ Unfortunately, in practice, and particularly with respect to protection, there continues to be a separation of nature and culture. ${ }^{106}$ There also exists a physical and intellectual separation of those persons responsible for natural heritage and cultural heritage. This division of responsibilities has led to a general lack of knowledge and guidance among cultural heritage professionals in the federal government about EA practices and theory. Conversely EA practitioners, who generally have a background in the natural environment, lack knowledge and guidance of heritage conservation practice and theory. This has been less the case in the United States and Europe where land-use and management policies are approached in a manner that integrates natural and cultural resources and concerns.

\footnotetext{
${ }^{104}$ Heritage Canada Foundation, Exploring the Connection Between Built and Natural Heritage (Ottawa: Heritage Canada Foundation, 2001), 1, accessed November, 2011 http://www.heritagecanada.org/eng/GreenReport2Eng-Read.pdf.

${ }^{105}$ Parks Canada, Parks Canada Guiding Principles and Operational Policies, (Ottawa: Parks Canada, 2009). Accessed November, 2011 at http:/www.pc.gc.ca/docs/pc/poli/princip/sec 1/partl d.aspx.

${ }^{106}$ Heritage Canada Foundation, Exploring the Connection, 4.
} 
In the United Kingdom, in particular, English Heritage has promoted the concept of the historic environment over the past decade. This historic environment approach challenges those in the field of heritage conservation to broaden their notion of heritage to be more inclusive of the concerns of the environment as a whole. The process encourages a sustainable approach to interventions on heritage resources ${ }^{107}$ that considers a wide range of cultural, historical, and environmental factors in decision-making. This change in attitudes ensures that English Heritage undertakes restoration, renovation, and adaptation of historic buildings with a sustainable development approach that will encourage retention of existing buildings and ultimately result in viable building use, healthier communities and economic sustainability. ${ }^{108}$

In Canada, construction and demolition accounts for 11 million tonnes of waste annually. ${ }^{109}$ This, coupled with the exploitation of natural resources for new construction materials to replace entire buildings, hardly paints demolition and new construction as a sustainable development policy, particularly when one considers the amount of energy required to deconstruct or demolish a building and construct a completely new building. Yet the federal government - especially in the National Capital Region - perpetuates a cycle of purposefully rendering older buildings redundant, demolishing those structures, and replacing them with new structures (often locating them outside urban centres in areas of urban sprawl). Given the federal government's interest in constructing 'green'

\footnotetext{
${ }^{107}$ Primarily historic buildings, but the approach can certainly be applied to cultural landscapes.

${ }^{108}$ Heritage Canada Foundation, Exploring the Connection, 4 and Patrice Frey "Preservation as a Driver of General Economic Growth," in Making the Case: Historic Preservation as Sustainable Development, Draft White Paper, (2007), 15-17.

${ }^{109}$ Mark Gorgolewski, "Session 1: Ecological Building," in Heritage and Sustainability: Canadian Communities and Kyoto, Heritage Canada Foundation Annual Conference Proceedings, 2005. (Ottawa: Heritage Canada Foundation, 2005), 9-10.
} 
buildings that meet energy efficiency standards, it is discouraging that there is no recognition that conserving buildings also conserves energy and natural resources.

Concerns with respect to cultural heritage and sustainability are not limited to the demolition of heritage buildings. It can be argued that complete demolition of older buildings in favour of new construction entails loss of embodied energy, ${ }^{110}$ an increase of construction materials in landfill, the continued exploitation of natural resources for new construction, and often the loss of wildlife habitat. ${ }^{111}$ Beyond the built environment, there are links between cultural heritage and the natural environment that can be manifested as tangible or intangible resources, or, in some cases, as a combination of the two. Despite the inherent inter-relatedness of culture and nature with respect to cultural landscapes, it remains difficult to articulate those linkages. The $C E A A$ was laid out at a time when there was a limited understanding of the inter-relationships between various components of the environment, particularly the relationship between communities and their environments. ${ }^{112}$ It was only in 1992 that the UNESCO World Heritage Committee recognized the associative cultural values of landscapes and landscape features, particularly for indigenous peoples. ${ }^{113}$ The relationship between communities, heritage values, and the natural environment is still not fully understood, but there can be no doubt that a relationship exists.

\footnotetext{
${ }^{110}$ Embodied energy is a concept that dates back to the 1970 s energy crisis. It can be defined as "the amount of energy associated with extracting, processing, manufacturing, transporting and assembling building materials." A study published by the US National Trust for Historic Preservation 1981 outlines energy savings, in terms of embodied energy, under various scenarios. The study identifies significant savings when existing buildings are retained.

111 Julie Gelfand, "Built Heritage Conservation and Wildlife: a Meeting of the Minds?" ICOMOS Canada Momentum (1991): 8.

${ }^{112}$ Sadar and Stolte, Overview of a Canadian Experience, 226.

${ }^{113}$ Mechtild Rössler, "Linking Nature and Culture: World Heritage Cultural Landscapes, " pp.10-15 in Cultural Landscapes: the Challenges of Conservation. World Heritage Papers 7 (2002), 10.
} 
Given the inherent synergies between the built and the natural environment and the international importance placed on sustainable development of the natural and urban environment, Canada's resistance to the key concepts of sustainability is perplexing and alarming. The causes of this disconnect between environmental policy and cultural heritage may, in fact, lie within the very legislation originally intended to promote sustainable development. The $C E A A$ definitions are problematic for cultural heritage, specifically the ambiguity that results from the inclusion of cultural heritage in the definition of environmental effect and its exclusion from the definition environment. The parliamentary report on the $C E A A$ noted the purposeful adoption of a narrow definition for the environment. ${ }^{114}$ The CEAA defines environment as follows:

"environment" <<environnement $>>$ means the components of the Earth, and includes:

(a) land, water and air, including all layers of the atmosphere,

(b) all organic and inorganic matter and living organisms, and

(c) the interacting natural systems that include components referred to in paragraphs (a) and (b). ${ }^{115}$

Contrary to other widely accepted definitions of environment ${ }^{116}$, the $C E A A$ definition is purposefully limiting.

In contrast, the $C E A A$ definition of environmental effect is much more inclusive and considers human interaction with the natural environment. The $C E A A$ definition for

\footnotetext{
114 Douglas, Bill C-13, 3.

115 Canadian Environmental Assessment Act. R.S., 1992, c.37, Section 2(1).

116 UNESCO defines environment as "the aggregate of surrounding things (biotic and abiotic) and conditions that influence the life of an individual organism or population, including humans. The UNESCO concept of the environment includes a complex of natural, built and social components in the life of humanity." UNESCO, Glossary of Environmental Education Terms, (Hungary: National Centre for Educational Technology, 1983), 11-12.
} 
environmental effect is explicit in the need to consider human elements of the environment, including:

i. health and socio-economic conditions,

ii. physical and cultural heritage,

iii. the current use of lands and resources for traditional purposes by aboriginal persons, or

iv. any structure, site or thing that is of historical, archaeological, paleontological or architectural significance. ${ }^{117}$

${ }^{117}$ Canadian Environmental Assessment Act, R.S., 1992, c.37, Section 2(1). 
In this definition, cultural heritage is implicated in the process. Yet the overall effect of the exclusion of human interactions from the definition of environment works to rank natural environment considerations above socio-economic or cultural considerations in the decision-making process. The narrow definition of environment also has implications with respect to jurisdiction over cultural heritage.

In Canada, constitutional authority over cultural heritage lies with the provinces and territories. However, the Supreme Court ruling in Friends of the Oldman River Society v. Canada that found that the environment transcends jurisdiction and is the shared responsibility of all levels of government also found that the environment should not be narrowly defined and should take into account natural, social and cultural factors. ${ }^{118}$ A definition of environment that included cultural resources would provide a forum for the re-examination of the legislation that governs cultural heritage in Canada. It would also provide a stronger basis for the re-inclusion of cultural heritage into the sustainable development dialogue.

Another key disadvantage for cultural heritage with respect to the $C E A A$ process and the constitutional jurisdiction of cultural heritage is that within the EA process the 'teeth' of various authorities lie within their permitting powers. The CEAA requires that no permits can be given by any power under federal legislation until the EA is complete and a decision is taken. This is advantageous for departments and interests that can give permits; however, as a result of the paucity of federal heritage legislation, there are no federal permits exclusively for cultural heritage.

\footnotetext{
${ }^{118}$ Friends of Oldman River Society v. Canada, 9-10.
} 
Since the inception of the 1969 NEPA in the United States, EA has become an authoritative planning tool in the public realm. The $C E A A$ requires that potential adverse impacts on cultural heritage be considered, but stops short of meaningful inclusion of cultural heritage in the process. The narrow definition of environment under the CEAA excludes cultural heritage, which has left cultural heritage at a disadvantage with regards to:

- exclusion of cultural heritage from popular understanding of sustainable development;

- a lesser perceived importance of cultural heritage within the EA process;

- the effective separation of federal experts in heritage conservation from federal experts in EA;

- trepidation on the part of the federal government to infringe upon the constitutional jurisdiction of the provinces and territories over cultural heritage; and

- a lack of federal permitting authority or powers related to cultural heritage.

In addition, the separation of heritage conservation and EA expertise has led to a dearth of useful information available to EA practitioners in the federal government on the subject of identifying cultural heritage resources and potential impacts on those resources. 


\section{Chapter: Technical Concerns}

This chapter explores the technical undertaking of Heritage Impact Assessment in an attempt to identify facets of the theory, practice or application that might conflict with the EA process and prevailing planning systems more generally. At the outset of this paper, the idea of evaluative asymmetry was introduced as one of the key problems facing heritage conservation within the context of the $C E A A$. This term refers to the perceived level of importance of cultural heritage or the cultural environment within the decisionmaking process as compared to natural components of the environment. The premise of this chapter is to outline the development of heritage conservation theory from Alois Riegl to the present-day in order to emphasize its shift from a material and elite bias to a practice inherently supportive of sustainable development. This evolution of heritage conservation theory has implications for the way cultural heritage value is assessed, interpreted and communicated. In Canada, there has been a dearth of heritage conservation theory over the past century as it has been replaced by public policy and, arguably, a reliance on the private sector to advance conservation practices. The very recent practice of Heritage Impact Assessment (HIA) is an attempt to situate heritage conservation in the EA framework on equal footing with its natural environmental components.

Among the root causes of the evaluative asymmetry facing heritage conservation in the realm of planning and legislation are the undeveloped practice of HIA and difficulties associated with: 1) identifying and evaluating cultural heritage; and 2) measuring and expressing project impacts on those values. This chapter focuses on how 
the identification and evaluation of heritage values has evolved over the past century and which of those paradigms have shaped federal practice and policy with regard to heritage conservation. Finally, this chapter will focus on ways of reconciling the natural and cultural environment within the EA process. The status of cultural heritage in the popular understanding of the term 'environment' was promoted unsuccessfully by those in the heritage field in Canada in the 1990s. However, recent values theory offers more promising ways to integrate heritage conservation practice into the EA regime. Chief among these is Gray's concept of geodiversity, which highlights the importance of abiotic (i.e., non-living chemical and physical components of the environment) resources in our environment.

At the very core of conservation lies 'value'. Communities only save those things to which they ascribe some sort of value. The importance of understanding value is perhaps best articulated in the 1994 Nara Document on Authenticity, which states "Conservation of cultural heritage in all its forms and historical periods is rooted in the values attributed to the heritage." 119 Whether quantifiable or intrinsic, economic or social, the fact remains that society conserves that which it values. The challenge in a planning system with finite resources lies in understanding which values (or valued resources) have the most meaning or importance to a community and determining how to best conserve those values, or at least the material manifestations of those values, for future generations. The goal of EA as a decision-making tool is to identify valued environmental components that might be affected by a proposed project and, in turn, to measure potential adverse impacts on those components. The information collected

${ }^{119}$ ICOMOS, Nara Document on Authenticity, (1994), Article 9. 
during the process of an EA is meant to inform the decision-making process; ultimately resulting in environmentally responsible project planning.

When compared to hard sciences such as biology, geology, and engineering, heritage conservation has difficulty getting its values taken seriously in an EA process which places importance on providing quantitative evidence of significant adverse effects on valued environmental components. ${ }^{120}$ For cultural heritage, deficiencies lie in the technical undertaking of both identification and evaluation of resources and the identification and measurement of project impacts on those resources. Heritage has been legitimately included in the process, but practitioners, lacking accepted methodologies for evaluation and measurement, are often incapable of fully illustrating the value of a cultural heritage resource or landscape. When placed alongside quantitative, re-creatable evidence that can be compared to calculated acceptable thresholds, ${ }^{121}$ a statement of cultural heritage value may seem a bit too 'touchy-feely' for some decision-makers.

The study of heritage conservation is a relatively recent development. While humankind has always been influenced by a desire to transmit its past to future generations, a concerted and self-aware effort to conserve the material manifestations of the past and consider the implications of those actions has only really been made since the early nineteenth century. ${ }^{122}$ It was not until the 1903 publication of Alois Riegl's

\footnotetext{
${ }^{120}$ This statement is based on the attitudes of project managers and decision makers in both the private and public realm, as expressed by interview subjects as well as the author's own ten years of experience undertaking archaeological and cultural heritage impact assessments for environmental assessments at the municipal, provincial and federal level. .

${ }^{121}$ An applicable example might be that of particulate matter (i.e., air pollution) that could potentially be released during the construction phase of a new building. There is a system of measurement for particulate matter and there are maximum acceptable levels that can be released in order to protect nearby biological resources, including humans.

${ }^{122}$ Although histories of the development of heritage conservation theory, such as Jokilehto (2008) and Hunter (1981), are able to cite examples of self-aware preservation of commemorative or historic objects
} 
Moderne Denkmalkultus (The Modern Cult of Monuments) that a typology of values entered into the discussion of preservation.

The work of Alois Riegl has recently regained popularity in conversations on value. Appointed editor of the Austrian Journal for the Research and Preservation of Artistic and Historical Monuments in 1902, Riegl published Moderne Denkmalkultus as a typological study on the artistic and historical values of art and architecture. Riegl's typology took the first steps beyond the "scrape vs anti-scrape" schools of thought that focused entirely on the physical manifestations of heritage, i.e., the buildings and monuments. ${ }^{123}$ More importantly, Riegl demonstrated that the adoption or acceptance of different sets of values led inevitably to vastly different results in the conservation of art, architecture and monuments. ${ }^{124}$ Riegl's value typology included: art value (Kunstwollen), historical value, age value, commemorative value, and present-day value. Although laid out more than 100 years ago, all five of these typologies are pertinent to present-day discussion of value which is moving beyond the material bias of $19^{\text {th }}$ and $20^{\text {th }}$ century practitioners to a more holistic view of cultural heritage.

Riegl presented his typology of values as they applied to Art monuments and Historical monuments (Kunst- und historiche Denkmale), the terms used in Austrian conservation policy dating back to the $16^{\text {th }}$ century. In this sense, monument spoke to

dating much earlier than the $19^{\text {th }}$ century and Denhez (1997) cites legal protection of sites of historical or architectural importance enacted by Roman Emperor Marjoram, as early as AD 457 and systematic inventorying efforts in 1666 Sweden, others such as Lowenthal and Binney (1981) trace the roots of modern systematic preservation to the early $19^{\text {th }}$ century work of figures like John Ruskin, Violet le Duc, and William Morris. The $19^{\text {th }}$ century has been chosen as a starting point for the current discussion of heritage conservation theory.

${ }^{123} \mathrm{It}$ is not therefore surprising that the field is once again turning to the philosophies of Riegl as we attempt to move away from the material bias of $20^{\text {th }}$ century heritage conservation.

${ }^{124}$ Gustavo Araoz, "Preserving heritage places under a new paradigm," Journal of Cultural Heritage Management and Sustainable Development, 1 no. 1 (2011): 56. 
intentional monuments, those which had been constructed explicitly for the purpose of commemoration, as well as to those unintentional monuments, those resulting from the continued existence of a built structure as a representation of the accomplishments, attitudes, and beliefs of an early generation. His typology was not meant to be exclusive to the built form, as demonstrated by the examples he employs, including his famous 'scrap of paper'.

Riegl's value typology was faintly echoed in 1949 by Sir. John Summerson when he published a list of the five types of buildings which deserved preservation, "in certain circumstances."125 Summerson's typology favours high architecture over vernacular, and reflects a post-war shift toward modern architecture and the removal of all but the very best examples of early styles. Whereas Riegl wrote from a position of attempting to preserve art, architecture and monuments from the ravages of time (and at times the reuse of raw materials), Summerson wrote from the midst of an architectural tabula rasa. Summerson's typology of buildings warranting preservation, which follows, was purely aimed at protecting the best of the best and leaving the remainder to succumb to development.

1. The building which is a work of art: the product of a distinct and outstanding creative mind.

2. The building which is not a distinct creation in this sense but possesses in a pronounced form the characteristic virtues of the school of design which produced it.

3. The building which, of no great artistic merit, is either of significant antiquity or composition of fragmentary beauties welded together in the course of time.

\footnotetext{
125 Summerson, 1959 as quoted in Bruce Dawson, "Why are you protecting this crap?": Perceptions of Value for an Invented heritage - a Saskatchewan Perspective," Value Based Decision Making for Conservation, Canadian Studies Heritage Conservation Programme Symposium, Carleton University November 18, $2005,2$.
} 
4. The building which has been the scene of great events or the labour of great men.

5. The building whose only virtue is that in a bleak tract of modernity it alone gives depth in time. ${ }^{126}$

Arguably a step in the wrong direction, Summerson's typology alludes to the material bias and elitism that would underlie the international practice of heritage conservation for much of the $20^{\text {th }}$ century. This particular school of thought came about following the Second World War while Europe was rebuilding and the prevailing architectural style, which had emerged prior to the war, emphasized clean lines and stridently promoted the removal of highly ornate architectural predecessors.

Modernist architects emerging from early $20^{\text {th }}$ century Europe were motivated by progress. The Modern buildings that dominated the first half of the $20^{\text {th }}$ century were touted as superior constructions and economic circumstances provided a convenient argument for more streamlined Modern designs that did away with frivolous ornamentation of the past. Canada followed suit. During the Second World War, Cyril James, Principal of McGill University, lamented to his audience of architects the "comparative misfortune, in that none of the Canadian cities have yet been levelled by the war," offering as solace the prediction that once the war had ended the existing building stock would certainly be demolished, "in order that you may rebuild effectively the cities and communities of which you have long been dreaming."127 In the age of the Garden City and financial incentives from the federal government to generate an industry of mass-produced, cookie-cutter housing, the uniqueness of earlier built form was being systematically annihilated by prevailing architectural trends and public policy. Denhez

\footnotetext{
${ }^{126}$ Summerson, 1949 as quoted in Dawson, Why are you protecting this crap?, 2.

127 James, 1941 as quoted in Denhez, "The Luftwaffe and Other Development Services, 1939-1946" in The Canadian Home (Toronto: Dundurn Press, 1994), 82.
} 
demonstrated in his study of the impact of early $20^{\text {th }}$ century public policy on the evolution of domestic architecture in Canada that demolition and new construction was the preferred policy for economic stimulus. ${ }^{128}$ What resulted from this architectural tabula rasa was a call to arms to protect the most worthy of saving, the best of the best; consequently, the most readily identifiable.

The 1964 Venice Charter and its predecessor, the 1931 Athens Charter, reveal the material bias and best of the best mentality which stemmed from the era of Modernism and pro-demolition and construction public policies. The Venice Charter, written by the International Committee of Monuments and Sites (ICOMOS), focuses entirely on the built form. Although Article 15 does provide guidance on archaeological excavations, it focuses on the care of ruins, artifacts and reconstruction. The Venice Charter recognized only two types of values, historic and aesthetic, and stated that "the intention in conserving and restoring monuments is to safeguard them no less as works of art than as historical evidence." 129 The preoccupation with the built form persisted in Canada and abroad.

The National Historic Preservation Act (NHPA) was passed in the United States in 1966 in the midst of the material preoccupation of heritage conservation. The $N H P A$, which was introduced briefly in Chapter 1, will be discussed in greater detail in Chapter 4 as part the examination of legislative frameworks for the conservation of cultural heritage. As a matter of necessity, a series of criteria for evaluation of the quality of significance of sites were developed in order to create and administer a National Register

\footnotetext{
${ }^{128}$ Denhez, The Luftwaffe and Other Development Services, 79-92.

129 ICOMOS, Venice Charter: International Charter for the Conservation and Restoration of Monuments and Sites, (1964), Article 3.
} 
of Historic Places. Satisfying the criteria for eligibility does not necessarily result in the inclusion of the site or property on the register; it simply requires that the federal project in question be assessed for its impact on that cultural heritage resource. Similar criteria have been adopted across North America. ${ }^{130}$

It was around this same time that Canadian interest in historic sites, places, and buildings was growing. As early as 1951, the Massey Commission noted an 'urgent need for more government investment in preservation. ${ }^{131}$ The National Historic Sites and Monuments Act was passed in 1953, but it was not until the 1960s and early 1970s that government investment in heritage conservation began in earnest. ${ }^{132}$ As a sign of the government's support of (or at the very least recognition of) the growing interest in preserving historic buildings, the Heritage Canada Foundation was formed in 1973, originally intended to act as a Canadian version of the British National Trust. In 1976, Canada became a signatory State to the World Heritage Convention and its first World Heritage Site, l'Anse aux Meadows in Newfoundland was inscribed on the World Heritage List in 1978.

The 1972 UNESCO Convention concerning the Protection of the World Cultural and Natural Property (World Heritage Convention) is aimed at the identification, protection and preservation of humankind's shared cultural and natural heritage. This system of international cooperation set the stage for renewed discussion of values. The

\footnotetext{
${ }^{130}$ Examples include Ontario Regulation 9/06 Criteria for Determining Cultural Heritage Value or Interest under the Ontario Heritage Act, which is derived from the earlier National Parks criteria.

${ }^{131}$ Christina Cameron, "The Spirit of Place: The physical memory of Canada, "Journal of Canadian Studies/revues d'etudes canadiennes 35 no. 1 (2000): 78.

${ }^{132}$ The National Historic Sites and Monuments Board created in 1919 was given the mandate of identifying and commemorating historic places, people, and events (primarily related to the theme of war), but cannot be said to have been concerned with heritage conservation more generally.
} 
World Heritage process required a system of evaluation for those properties to be considered for inclusion on the World Heritage List (the List) and from that operational necessity sprung a set of criteria for determining outstanding universal value (Appendix A). The criteria themselves have remained unchanged since their adoption, but have evolved from two separate lists, six criteria for cultural heritage and four for natural heritage, to one list of ten criteria. A site meeting one or more of the ten criteria and the conditions of integrity and/or authenticity is considered to be of outstanding unlversal value. $^{133}$

The ten criteria for inscription offer a high level overview of the values that the List is meant to reflect. The intention of the criteria is to offer opportunities for a wide range of site typologies to be included on the List; it is the onus of the State Party to demonstrate to the Advisory Bodies and the World Heritage Committee that its site meets the criteria of outstanding universal value. Although the language used in the criteria reinforces the best of the best attitudes of the time of its writing, flexibility in the operations of the World Heritage Committee has resulted in a change (or at least an attempt to change) the values that the List represents. The Global Strategy for a Representative, Balanced and Credible List which has emerged since 1994 has also greatly changed the values expressed on the World Heritage List as a result of efforts to include a more diverse array of vernacular sites and landscapes.

Perhaps the greatest implication of the 1972 World Heritage Convention, as it relates to the present research question, can be found in Article 8 of the Recommendations Concerning the Protection, at a National Level, of the Cultural and

\footnotetext{
${ }^{133}$ UNESCO, Operational Guidelines for the Implementation of the World Heritage Convention, (Paris: UNESCO, 2008), paragraph 77.
} 
Natural Heritage, adopted at the same time, which states, "The protection, conservation and effective presentation of the cultural and natural heritage should be considered as one of the essential aspects of regional development plans, and planning in general, at the national, regional or local level."134 As a signatory state, Canada became obligated to integrate cultural and natural heritage conservation into its planning processes. At the time, the burgeoning EA process offered a valid and feasible system for doing so. Other Canadian obligations to the 1972 World Heritage Convention included:

- ensuring the identification, delineation, conservation, protection, and transmission to future generations of natural and cultural heritage properties (Articles 3 and 4);

- the adoption of policies and creation of services to protect natural and cultural heritage (Article 5); and

- the development of scientific and technical studies and research to facilitate the counteraction of dangers that threaten its natural or cultural heritage (Article 5).

Canadian heritage conservation organizations and authorities began to look at the issue of values as it applied to our built heritage resources in the early $1970 \mathrm{~s} .{ }^{135}$ Whereas previous attempts to inventory and organize the country's historic building stock had broken buildings down to their component parts and architectural features, ${ }^{136}$ new attempts were made to research, list and evaluate a deeper set of values represented by

\footnotetext{
${ }^{134}$ UNESCO, Recommendations Concerning the Protection, at a National Level, of the Cultural and Natural Heritage (Paris: UNESCO, 1972), Article 8. Accessed October, 2011 at http://www.icomos.org/unesco/national72.html.

${ }^{135}$ Dawson, Why are you protecting this crap?, 3.

${ }^{136}$ The Canadian Inventory of Historic Buildings (CIHB) was a national undertaking that resulted in the recording of over 200,000 older buildings across Canada between 1970 and 1975. Over the course of several years, students were given record forms and sent out to survey the existing building stock. Information recorded during these surveys was inputted into a computerized database to be analysed by staff and used to undertake comparative studies. Cameron, Spirit of Place, 79.
} 
those buildings. The ultimate goal, influenced by a positivist methodology, ${ }^{137}$ seemed to be the creation of a scientific system to make value judgments "rationally, objectively and confidently," ${ }^{\prime 38}$ free of the subjectivity of individual experts.

In 1979, Parks Canada published Harold Kalman's attempt at a scientific evaluation process, The Evaluation of Historic Buildings. The basis of Kalman's system is the application of empirical values to the five weighted criteria of: architecture, history, environment, usability, and integrity. At the time, the approach presented a quasiscientific method that lent credibility to the process of evaluating historic buildings. The Kalman approach offered a threshold for cultural heritage value that could be applied to the management of building stock and decision-making processes related to those buildings. Although the system draws criticism, a modified version of it continues in use as a credible and feasible method of valuing and ranking resources in a planning system with finite human and financial resources.

The modified Kalman evaluation, which uses the criteria of historical associations, architecture and environment, is an integral part of the Federal Heritage Buildings Review Office's (FHBRO) administrative duties. FHBRO was established in 1982 from the Treasury Board Heritage Buildings Policy which was replaced in 2006 by the Treasury Board Policy on Management of Real Property. ${ }^{139}$ The role of FHBRO is to evaluate federally owned buildings of 40 years of age or older and to consult with

\footnotetext{
${ }^{137}$ Alastair Kerr, "Re-thinking the Evaluation of Historic Buildings" as discussed in Francois LeBlanc Field Trip Report, Carleton University, Ottawa, Values-Based Decision-Making for Conservation November 18-19, 2005. (Los Angeles: Getty Conservation Institute, 2005). Accessed October, 2011 at http://www.icomos.org/ fleblanc/projects/2001-2007_GCl/field_trip_reports/2005-1 1-canada-ottawacarleton.pdf.

${ }^{138}$ Harold Kalman, The Evaluation of Historic Buildings. (Ottawa: Parks Canada, 1979), 6.

${ }^{139}$ Federal Heritage Buildings Review Office, $A$ Guide to Working with the Federal Heritage Buildings Review Office, (Ottawa: Parks Canada, 2009), 2.
} 
custodian departments to ensure the preservation of the heritage character of those buildings designated as "Classified" or "Recognized." the Kalman evaluation system is its material bias; the maximum score for architecture accounts for just over $40 \%$ of the total possible score for all three criteria in the version used by FHBRO. Similar versions of scoring systems have been adopted across the country.

One of the major concerns instigated by the integration of a scoring approach into the planning system is the concept of legal designation. Legislation for the protection of heritage properties was introduced in provinces and territories across Canada during the 1970 s and with the advent of scoring systems and empirical thresholds for the valuation of cultural heritage resources came the identification and designation of sites and buildings. The 1974 Ontario Heritage Act, for example, made it possible to apply legal protection to buildings of significant value in Ontario. Although of monumental importance to the heritage conservation movement in Ontario, it has been a double-edged sword because it has contributed to the belief among many decision-makers that only legally-designated buildings need be considered in the project planning process. In the context of the $C E A A$, it is easy to dismiss cultural heritage as a valued environmental component early in the screening process if the project does not involve a building designated by FHBRO, a classified or recognized federal heritage building, or a building legally designated by a local jurisdiction. The Section 106 process in the United States, in contrast, does not allow for the dismissal of previously unidentified cultural heritage resources that might be impacted by a federal project. Under Section 106 of the NHPA, a

\footnotetext{
${ }^{140}$ lbid., 5.
} 
federal project must assess potential impacts to any site, place or building that meets the criteria of eligibility on the National Register of Historic Places, regardless of its status on or off the register. ${ }^{141}$

As previously mentioned, one of the other major problems with Kalman's evaluation system was its material bias and weighing of certain values above others. The Australian Burra Charter provided a means for solving these dilemmas. When ICOMOS Australia revised their Charter for the Conservation of Places of Cultural Significance (Burra Charter) in 1981, the document was prefaced with a statement that the purpose of heritage conservation was "to retain the cultural significance of a place." 142 The system of evaluation presented in the Burra Charter was superior to the Kalman system in that it could be applied to all places, not exclusively buildings, and that it weighed all values equally, except where certain values are more important to a site based on site typology or context. What resulted was an approach to the evaluation of heritage places that entails the creation of two separate documents: a written statement that summarizes the values of site, or statement of cultural significance and a written analysis of the site's values, or assessment of cultural significance. This cultural significance approach was adopted by Parks Canada in the 1990s when the practice of writing Commemorative Integrity Statements for National Historic Sites became part of the Cultural Resource Management Policy. ${ }^{143}$ The cultural significance approach was also made a part of the FHBRO evaluation process. Although the empirical Kalman evaluation has not been

\footnotetext{
${ }^{141}$ William J. Murtagh, Keeping Time, $3^{\text {rd }}$ ed., (John Wiley \& Sons Inc., 2006), 51-54.

142 Australia ICOMOS, The Burra Charter, the A ustralia ICOMOS Charter for Places of Cultural Significance, (Burra: Australia ICOMOS, 1999), Article 2.2. The 1981 text stated that the aim was "to retain or to recover the cultural significance of a place" (emphasis added).

${ }^{143}$ Dawson, Why are you protecting this crap?, 4.
} 
replaced, it is now preceded by a written research report to support the evaluation. A Heritage Character Statement was also prepared for designated buildings based on the findings of the written report and evaluation in order to help explain the values of the property and to guide decision-makers on how to best preserve the property's heritage character. ${ }^{144}$

What the cultural significance approach introduced by the Burra Charter highlighted was the systemic material bias in heritage conservation theory, practice and legislation. Up until this point, heritage conservation tools were heavily focused on preserving the material manifestations of the values being protected. The flexibility of the cultural significance approach allowed non-built resources to be identified, evaluated, and ultimately protected. The Florence Charter on Historic Gardens, adopted by ICOMOS in 1982, was the first international charter to deal with landscapes that included both natural and built components as well as associated systems and processes. ${ }^{145}$ The charter lays foundations and articulates issues specific to the study of cultural heritage landscapes such as the nature of historic gardens as living monuments and the interconnectedness of the sum of inorganic and living components within the garden landscape system. ${ }^{146}$

In 1992 cultural landscapes were included in revisions to the Operational Guidelines for the World Heritage Committee. ${ }^{147}$ Cultural landscapes were not a new

\footnotetext{
${ }^{144}$ FHBRO, $A$ Guide, 12.

${ }^{145}$ Gustavo Araoz, "Preserving heritage places under a new paradigm," Journal of Cultural Heritage Management and Sustainable Development 1, no. 1 (2011): 59.

${ }^{146}$ ICOMOS, Charter on the Preservation of Historic Gardens (Florence Charter), (Florence: ICOMOS, 1982), Articles 3, 7 and 14. Accessed September, 2011 at http://www.international.icomos.org/charters/gardens_e.pdf.

${ }^{147}$ The timing of these revisions is of particular importance to this topic given that the expert meeting that recommended these revisions met in France only four months following the Earth Summit in Brazil. The
} 
concept; the term was introduced in the United States in the 1920 s by Carl Sauer. ${ }^{148}$ It was not until the 1990s, however, that the term took hold among heritage conservation professionals. Based on the recommendations of an international expert meeting, the revisions to the Operational Guidelines made a number of key changes to the World Heritage system that represented changing attitudes towards how cultural heritage values are identified, categorized and protected. Firstly, the revisions recognized the associative cultural values of landscapes and landscape features, particularly for indigenous peoples. ${ }^{149}$ They also acknowledged the importance of protecting the biological and cultural diversity of cultural landscapes and set precedents for the legal protection of cultural heritage values that could not necessarily be managed in the same way as buildings. In addition to challenging conventional tools, practices and legal protections of participating States Parties, the revisions also introduced the term 'sustainability' into the World Heritage lexicon. ${ }^{150}$ These changes brought heritage conservation further in line with the EA approach that was taking hold of the public planning process in Canada and abroad during the 1990s.

The cultural landscape approach to heritage conservation required new tools to identify, evaluate and protect cultural heritage, that reached beyond the material bias and elitism of earlier approaches. The cultural significance approach developed in the $1980 \mathrm{~s}$ provided a method to present the values embodied by specific cultural landscapes through

resulting Rio Declaration on Environment and Development declared in Principle 17 that "environmental impact assessment, as a national instrument, shall be undertaken for proposed activities that are likely to have a significant adverse impact on the environment and are subject to a decision of a competent national authority".

${ }^{148}$ Peter Fowler, "World Heritage Cultural Landscapes, 1992-2002: a Review and Prospect," in Cultural Landscapes: the Challenges of Conservation, World Heritage Papers 7 (2002), 17.

${ }^{149}$ Rössler, Linking Nature and Culture, 10.

${ }^{150}$ Ibid., 10. 
written statements of cultural significance, and the identification of character-defining values in these statements could be applied to management plans. Yet the very nature of cultural landscapes raised new questions of authority, ownership, and participation of various communities in the identification, evaluation and management of this new type of cultural heritage. Cultural landscapes are, by very definition, the direct result of past or ongoing land-use by a people that may or may not still be inter-related with that landscape.

The recognition of the significance of cultural landscapes, and the subsequent recommendation from the 1999 experts meeting in Bialystok, Poland, that States Parties extend existing designations and management systems to include cultural landscapes, ${ }^{151}$ required that tools be developed to work with communities to conserve their cultural heritage. Throughout the 1990s the importance of community involvement in heritage conservation was recognized and mechanisms for participation were developed. The International Centre for the Study of the Preservation and Restoration of the Cultural Property (ICCROM) undertook pilot programmes focusing on the management of heritage values in landscapes beginning with the 1995 creation of ICCROM's Integrated Territorial and Urban Conservation (ITUC) Programme and, shortly thereafter, the Living Heritage Programme in order to "integrate community members in the identification and care of landscapes of heritage value." the 1990s and early 2000s reinforced the importance of implementing a sustainable management strategy through community stewardship.

\footnotetext{
${ }^{151}$ Rössler, Linking Nature and Culture, 13.

${ }^{152}$ Katri Lisitzin and HerbStovel, "Training Challenges in the Management of Heritage Territories and Landscapes," in Cultural Landscapes: the Challenges of Conservation. World Heritage Papers 7 (2002), 33.
} 
The prominence of sustainable management strategies and processes in the cultural landscape approach was, no doubt, influenced by international attitudes regarding sustainable development. The World Commission on Environment and Development released Our Common Future in 1987. The report encouraged a new approach to planning that invited communities and governments to consider the causes of negative development patterns rather than simply fighting against the results of development. ${ }^{153}$ Sustainable development suits the cultural landscape approach, which is a more holistic view of cultural heritage than earlier approaches that focused almost entirely on the material.

The 1990s also saw the adoption of the Nara Document on Authenticity which had a profound impact on heritage conservation practice and paved the way for the evolution of theory and practice in the new millennium. Written in 1994, the Nara Document was the culmination of an international experts meeting responding to concerns regarding the test of authenticity in the Operational Guidelines for the World Heritage Committee, but it also speaks to questions of authority. With regard to values, Article 11 of the document states:

All judgments about values attributed to heritage as well as the credibility of related information sources may differ from culture to culture, and even within the same culture. It is thus not possible to base judgments of value and authenticity on fixed criteria. On the contrary, the respect due to all cultures requires that cultural heritage must be considered and judged within the cultural contexts to which it belongs. ${ }^{154}$

The Nara document was a step away from the Euro-centric nature of the World Heritage system, and while it did little to align the practice of heritage conservation with natural

\footnotetext{
${ }^{153}$ Denhez, The Heritage Strategy Planning Handbook, 39.

${ }^{154}$ ICOMOS, The Nara Document, Article 11.
} 
conservation, it did broaden the dialogue surrounding diversity in heritage conservation practice and highlight the importance of communities in valuing and conserving their heritage. This attitude was certainly consistent with aspects of the burgeoning cultural landscape approach, including ICCROM's community-based Living Heritage Programme, which focused on sustainable management through community involvement. Heading into the 2000s, heritage conservation had evolved from a field that focused entirely on high architecture and monuments to one that was exploring concepts and methods that considered stakeholder communities and the natural environment in their approach. Although the theory and practice of heritage conservation had developed greatly over the $20^{\text {th }}$ century, and throughout that time values had remained at the heart of the dialogue, very little concerted examination of value had been undertaken since Alois Riegl published Moderne Denkmalkultus in 1902. The NHPA and Kalman's evaluation did not so much discuss values as try to apply existing value typologies to a planning process, and while international charters recognized the importance of value and outlined typologies and tests for value, none were focused on understanding or explaining the construction of cultural heritage values. Recognizing the paucity of comprehensive research on the subject of values and the lack of understanding of the economic value of cultural heritage, the Getty Conservation Institute undertook an examination of the values and economics of cultural heritage beginning in 1995. Although much of the research relating to economic values addressed tourism, the focus on economic values of heritage, in general, was especially relevant because prevailing attitudes associated with sustainable development called upon communities and governments to identify underlying causal factors of development patterns. 
Among these underlying causes in Canada and the United States are investment and tax policies. The economic realities of cultural heritage cannot be underestimated, yet at the same time they remain very difficult to quantify and address. Denhez (1997) outlined the development of public policy as it relates to sustainable development and the built environment, specifically the historic built environment. Although much of his argument is focused on the very real and very negative impact that early $20^{\text {th }}$ century post Second World War economic policy and its pro-demolition tax system has had on the built environment, he also points to pro-designation policy that has established a system of pedigree for older building stock that ignores the majority of the built environment ${ }^{155}$ and all but avoids the relationship between people, the natural environment, and the built environment. The $20^{\text {th }}$ century compulsion to identify and designate exceptional examples is unnecessary in a sustainable planning system. Based on the concepts presented in Our Common Future, a sustainable development system would promote the management and extension of the lifespan of a wide variety of cultural resources as 'investments.' 156

At the start of the $21^{\text {st }}$ century, cultural heritage was increasingly associated with the processes of sustainable development, and vice versa. In 2005, UNESCO adopted the Convention on the Protection and Promotion of the Diversity of Cultural Expressions. The convention was the first international normative instrument to explicitly discuss the protection of cultural heritage and sustainable development as being inter-related. ${ }^{157}$ Paragraph 6 of the Guiding Principles (Article 2) states in no uncertain terms that, "the

\footnotetext{
${ }^{155}$ Denhez, The Heritage Strategy Planning Handbook, 42.

156 Ibid., 42.

${ }^{157}$ Pereira Roders and Van Oers, "Editorial: bridging cultural heritage and sustainable development." Journal of Heritage Management and Sustainable Development 1, no. 1 (2011): 7.
} 
protection, promotion and maintenance of cultural diversity are an essential requirement for sustainable development for the benefit of present and future generations." 158 The 2005 Convention further emphasizes the necessity of cultural heritage as a "strategic element in national and international development policies." 159 Decision-makers are increasingly becoming aware of and understanding the benefits of cultural heritage within a dynamic planning system. The European Union has made a concerted effort to integrate heritage into the legislation and policies that govern sustainable development. This remains an inconsistent process in Canada, yet more and more municipal governments are adopting planning policies that emphasize - or at the very least recognize - the necessity of a vibrant cultural fabric, composed of both tangible and intangible cultural elements in sustainable communities. There is certainly a willingness to adopt this view on the federal level, particularly among those whose primary concern is cultural heritage, but there is little evidence to indicate a will to adopt a heritageinclusive approach to sustainable development in a meaningful way in the broader professional community involved EAs. ${ }^{160}$

A decade into the new millennium, the heritage conservation paradigm in Canada has clearly changed, and we have yet to find a system for the evaluation of both values and potential project impacts that truly addresses this new understanding of how heritage should fit into a sustainable planning system. Cultural heritage does not exist within a vacuum, and the danger of having focused on the material vessel for so long is a lack of

\footnotetext{
${ }^{158}$ UNESCO, Convention on the Protection and Promotion of the Diversity of Cultural Expressions. (Paris: UNESCO, 2005), Article 2, Paragraph 6. Accessed October, 2011 at http://unesdoc.unesco.org/images/0014/001495/149502e.pdf

${ }^{159}$ UNESCO, Convention on the Protection and Promotion of the Diversity of Cultural Expressions. Preamble.

${ }^{160}$ Given time, one could test this supposition by searching each federal departments' yearly sustainability report for key words such as culture, heritage, history and community.
} 
understanding of how to effectively maneuver within the planning and policy process to serve the interests of cultural heritage. Addressing this very problem at an international level, Gustavo Araoz recently wrote that heritage professionals have never really protected or preserved values, they have protected and preserved the physical embodiment of those values, the materials." ${ }^{\text {161 }}$ The philosophy of conservation, its resulting doctrinal foundation, and the protective legislation and professional protocols for intervention "are all fixated on the protection of the material vessels that carry the value." ${ }^{162}$ Araoz points to this material bias as the primary cause of façadism as a function of a building's value on the real estate market ${ }^{163}$ without perhaps attempting to understand the socio-economic, historic or functional values of the subject building. The emerging paradigm that Araoz discusses is related to less tangible aspects of cultural resources, including building morphology and patterns of use. Community involvement is needed to identify these less tangible values, identify potential project impacts, and properly conserve both tangible and intangible aspects of cultural resources, particularly if the end goal is sustainability. Mr. Araoz posits that "the range of values attributed to heritage places has expanded to reflect its new social role as well as the many ways in which it is appreciated by stakeholding communities whose voices had not been given major consideration in the past." 164

This type of holistic and sustainable approach to a planning process that encompasses cultural heritage has been examined in Canada over the past decade. It is not unlike the approach supported by many indigenous groups in Canada and abroad.

\footnotetext{
${ }^{161}$ Araoz, A new paradigm, 59.

${ }^{162}$ Ibid., 59.

${ }^{163}$ Ibid., 58.

${ }^{164}$ Ibid., 57.
} 
Paci et.al., argue that the formal nature and politicization of the EA process under the $C E A A$ are barriers to truly integrating traditional environmental knowledge into the assessment of project impacts, adding, "Aboriginal lands are influenced and conditioned by historical, cultural, political and environmental variables that reflect very unique conditions." ${ }^{.165}$ Although attempts have been made over the past decade, the current process seems unable to effectively incorporate traditional environmental knowledge into the process in much the same way cultural heritage, more generally, remains on the fringe of the study of EA. The fluid and consultative approach to EA lobbied for by a number of indigenous groups is not possible in the rigid legislative and bureaucratic framework driving the $C E A A$ process. The result is discord that continues to grow as resource extraction projects in Canada's north increase in size and number. The current TransCanada Keystone XL (Northern Gateway) project, for example, will likely have implications regarding consultation and assessment practices, particularly with respect to cultural heritage.

At present, EA requires technical assessments be undertaken to evaluate potential impacts on vastly different types of environmental components and that these very technical assessments be distilled into decision matrices and evaluated against other financial, political and social constraints. Members of the Norwegian Institutes for Nature Research, Cultural Heritage Research, Urban Regional Research and Water Research have studied the interdisciplinary nature of the EA process, focusing particularly on the overarching values driving the various disciplines. The study team used four broad categories of values for their research: direct utilitarian values, indirect

\footnotetext{
${ }^{165}$ Chris Paci, et.al., "Reconsidering the Canadian Environmental Impact Assessment Act: A place for traditional knowledge," Environmental Impact Assessment Review, 22 (2002): 114.
} 
values, potential values, and immaterial values. Cultural heritage falls into the last of the four value types, characterized as "values based on ethical or moral grounds, for example likened to the wish to know the existence of species, to the potential for future generations and the wish to conserve landscape and nature as a part of our cultural and natural heritage." 166

Gray takes the multidisciplinary nature of the EA concept one step further by presenting cultural heritage as being part of a system in which diversity itself is a valued component. Gray lists four types of non-economic values: intrinsic or existence values, cultural values, functional values, and research and educational values. ${ }^{167}$ The geodiversity values typology presented by Gray is applicable to a cultural landscape approach.

Both Gray and the Norwegian research team maintain that value classification systems clearly distinguish between living and non-living resources and that respect for life is a fundamental concept within the context of values assessment. ${ }^{168}$ Gray, however, places a high importance on abiotic resources and geodiversity in his values assessment theory. Ecosystem diversity was recognized by the Rio Convention as an important element in sustainable development, and this includes abiotic resources, including cultural and geological monuments and landscapes. ${ }^{169}$ The importance of biological and cultural diversity and sustainable land-use was further highlighted by the 1992 revisions to the World Heritage Committee's Operational Guidelines.

\footnotetext{
${ }^{166}$ Lars Erikstad et.al., "Environmental value assessment in a multidisciplinary ElA setting," Environmental Impact Assessment Review, 28 (2008): 131.

${ }^{167}$ Gray, Geodiversity, valuing and conserving abiotic nature, (Etobicoke: John Wiley \& Sons, 2004), 6585.

168 Ibid., 133.

${ }^{269}$ Ibid., 133.
} 
The geodiversity approach to values assessment frames the issues faced by the heritage conservation community when trying to offer a system of measure for the valuation of heritage resources that is somehow comparable to the seemingly empirical systems of measure in the biological sciences. Although it is possible to count the number of a fish in a stream which are classified as a Species at Risk or measure the amount of particulate matter in the air as a result of soil remediation, quantifying the historical importance of an office building or the importance of traditional land use remains an inexact science to say the least.

In a sense, geodiversity is an extension of the highly extolled concept of biological diversity. Geodiversity accounts for all of the abiotic components of the environment that have been excluded over time from the popular understanding and definition of biodiversity. In 1991, Bernd von Droste, discussing the increased attention being paid to biological diversity, implored his readers to look beyond protection of biological diversity "to other kinds of diversity, notably the amazing richness of our different lifestyles that is based in the dwindling stock of traditional knowledge and indigenous cultures." $" 170$

It is important to note the shortcomings of geodiversity in applying it to the values of heritage resources. While Gray's work on geodiversity gives context to heritage resources as abiotic resources within the ecosystems being assessed through EAs and identifies how all of the resources should be seen as interrelated, values of heritage resources -both tangible and intangible- are bound to an organic community that gives meaning to them. They cannot, therefore, be viewed as entirely abiotic resources.

\footnotetext{
${ }^{170}$ Bernd von Droste, "Investing in the future of Planet Earth," ICOMOS Canada Momentum (1991), 2.
} 
Furthermore, even if they are weighed as an equal factor within a diverse and dynamic system, there remains a need to measure impacts on cultural heritage resources in a fashion compatible with the current planning system.

Like the CEAA, the 1997 Environmental Assessment Directive of the Council of the European Union requires EAs to address "human beings; fauna and flora; soil; water; air; climate; the landscape; material assets; cultural heritage." Bond, Langstaff, Baxter, Kofoed, Lisitzin and Lundström in the early 2000s examined the cultural heritage aspect of EAs in European Union countries. Given similarities in heritage conservation theory and practice in Canada and Europe, as well as their similar basic requirements governing EA, the study is considered applicable to the Canadian experience, in the absence of a comparable Canadian study. The study included a review of the legal framework, available guidance documents and a survey of heritage conservation and EA professionals in eight member states.

The study found that impacts on cultural heritage were addressed inconsistently despite conditions outlined under the EA Directive and related guidance. ${ }^{172}$ Like the $C E A A$ reference guide for cultural heritage, guidance material published by the European Commission referring to cultural heritage in EA does not limit the definition of cultural heritage to designated or protected sites.

The European study identified three common themes in the course of its surveys and case study reviews: ${ }^{173}$

\footnotetext{
${ }^{171}$ Bond et.al., "Dealing with the cultural heritage aspect of environmental impact assessment in Europe," Impact Assessment and Project Appraisal, 22 no.1 (2004): 37. 172 Ibid., 38.

${ }^{173}$ Ibid., 41 .
} 
1. Assessment of cultural heritage was very narrow, often taking into account only one aspect of cultural heritage, such as built heritage.

2. There was a general lack of assessment techniques or guidelines designed to develop consistency of assessments or formalize the assessment process.

3. Aspects of cultural heritage were considered too late in the planning and design process to be sufficiently addressed or mitigated.

These concerns are not unlike those heard during interviews undertaken for this paper or encountered in the author's experience. The first two issues are technical problems related to how cultural heritage is assessed for the purposes of decision-making. The focus on the practice of Heritage Impact Assessment (HIA) in recent years has attempted to formalize the assessment process and develop tools and techniques to help identify and measure potential project impacts on cultural heritage. The third concern is associated with process management and will be discussed in Chapter 4 as it relates to triggers to consult Federal Authorities as well as the absence of cultural heritage from education and training of planners and EA practitioners.

At the $34^{\text {th }}$ Session of the World Heritage Committee Meeting in Brasilia, Brazil (2010) the subject of HIA was raised more than ever before. This trend continued the following year (Paris, 2011) where HIA was a standard inclusion in Committee recommendations. HIA is a relatively new practice, but it is already required in most provincial and territorial jurisdictions in Canada. The practice of HIA has received a great deal of attention internationally in the very recent past, but the practice is far from established. In 2010, the Centre for Heritage Development in Africa produced on overview of the current state of the practice of HIA across the continent based on a 2009 workshop. The report found a number of startling similarities to common complaints in Canada, including: 
- Insufficient inter-agency cooperation and synergy between environmental and heritage management and legislation;

- Lack of sufficient capacity in state agencies, institutions and consultancy firms to conduct good Heritage Impact Assessments; and

- Lack of sufficient monitoring and quality assurance mechanisms for Heritage Impact Assessment processes. ${ }^{174}$

It was only in January, 2011 that ICOMOS released Guidance on Heritage Impact Assessments for Cultural World Heritage Properties. The publication is meant to provide guidance for commissioning HIAs for World Heritage Sites and relies on preexisting management plans and statements of outstanding universal value that are required prior to the inscription of any site onto the List. As the practice of HIA grows in popularity, methodologies and tools continue to be developed. More attention needs to be paid to this burgeoning practice in Canada as the undertaking and review process remains largely misunderstood and highly inconsistent.

In Ontario, for example, HIA is often undertaken as part of the Municipal Class EA process and is becoming a common requirement of the heritage permit application process. The Ontario Ministry of Tourism, Culture and Sport (MTCS), however, has yet to develop a comprehensive toolset for the preparation of HIAs or a consistent method for the review of HIAs submitted for their comment or approval. Recent requirements under Section 22 of Ontario Regulation 359/09, Renewable Energy Approvals Under Part V.0.1 of the Environmental Protection Act require HIAs be undertaken and accepted by the MTCS as part of the Renewable Energy Application process. MTCS guidance is sparse with regard to HIA; being limited to four pages in the MTCS's InfoSheet series

\footnotetext{
${ }^{174}$ Harriet Deacon, "Cultural Heritage Impact Assessment in Africa. A Review," accessed September, 2011 at http://www.heritageinafrica.org/news/119.html.
} 
interpreting the 2005 Provincial Policy Statement. The InfoSheet outlines seven components to be included in HIAs for the Province: ${ }^{175}$

1. Historical Research, Site Analysis and Evaluation

2. Identification of the Significance and Heritage Attributes of the Cultural Heritage Resources

3. Description of the Proposed Development or Site Alteration

4. Measurement of Development or Site Alteration Impact

5. Consideration of Alternatives, Mitigation and Conservation Methods

6. Implementation and Monitoring

7. Summary Statement and Conservation Recommendations

The document also identifies seven potential negative impacts to be assessed as part of the HIA: destruction; alteration; shadows; isolation; obstruction of views; change in land use; and land disturbances. ${ }^{176}$ This brief outline, which is similar to advice given in other jurisdictions, represents a starting point for the undertaking of HIA. What remains to be done is to explore and standardize methods for the measurement of impacts and the recommendation of mitigation measures that can be applied within the EA process and planning process more generally. It is also clear that, in order to effectively assess impacts on cultural heritage and implement adequate project design and mitigative measures, HIA must be undertaken early in the planning process rather than at the preconstruction phase, as is often the case. Recommendations in the Ardenville Wind Farm project scheduled HIA activities at the pre-construction phase and HIA was absent entirely from the project planning phase of the Brantford demolition project. Although undertaking HIA early in the process limits the accuracy of assessing the full scale of

\footnotetext{
${ }^{175}$ Ministry of Culture (MTCS), "Heritage Impact Assessments and Conservation Plans. Sheet No. 5 , Information Sheet Series from Heritage Resources in the Land Use Planning Process: Cultural Heritage and Archaeology Policies of the Ontario Provincial Statement, 2005," (Toronto: Queen's Printer, 2006), 2-3. ${ }^{176}$ Ibid., 3.
} 
project impacts, it does allow for the identification of cultural resources that should be accounted for in the scoping and design phase.

There is no federal requirement for an HIA to be undertaken for any project, including one involving a designated site, since legislation, policies and guidance documents have not yet incorporated the practice of EA. At present, assessment of impacts on designated federal sites is limited to an assessment of how a proposed project conforms to existing management plans or might impact attributes outlined in preexisting Statements of Significance or Commemorative Integrity Statements. This method of assessment assumes that all significant cultural heritage resources have been identified, properly documented, and that the values and character-defining attributes of that resource or landscape are static.

In Canada, there is also a lack of reliable and comprehensive baseline data that could be used to understand how the cultural heritage aspects of EAs are prepared. Questions that need to be asked of a wider data set than was possible for the current paper include:

- How often does a review of cultural heritage aspects of a project appear in EA reports?

- Who is preparing the cultural heritage portion of an EA?

- Is the review of cultural heritage aspects limited to a narrow scope (e.g., only built heritage, only archaeological resources, or only socioeconomic concerns related to First Nations consultation)?

- How often are HIAs undertaken to support an EA? and

- Who is preparing the HIA?

The end goal is for those preparing and reviewing EAs to accept cultural heritage as a component of the environment and to understand how cultural heritage can be better integrated into the planning process. This may not be possible without consistent and 
well-developed techniques for the assessment of cultural heritage within the EA framework. Before cultural heritage is fully incorporated into the EA process there is a need to develop HIA techniques, tools and methods and to share them with a wider audience through training and education.

In recent years the focus of heritage conservation has moved away from material bias and a preoccupation with freezing buildings in time and place towards a more holistic approach that considers cultural heritage within a broader perspective. The definition of cultural heritage now includes a greater variety of tangible and intangible resources as well as an understanding that not only do these resources exist in a larger environmental system, but often the system itself holds a great deal of cultural heritage value. The conversation now concerns community involvement and change management. The promise of the $C E A A$ is a participatory decision-making process resulting in more sustainable projects. The goals of heritage conservation and the goals of the CEAA are the same, but somehow the process that has evolved over the twenty year history of the $C E A A$ does not properly address cultural heritage. It is necessary to understand and work with the systems and processes in which heritage conservation operates in contemporary society, specifically the field of planning. The focus should be the improvement of heritage conservation practice, in areas such as HIA, so that the field can grow and legitimize itself in order to function effectively within the prevailing public planning system. This is not to say that the current public process is without fault. There are, without a doubt, policy improvements to be made, but it is up to those concerned with heritage conservation to become involved in the debate rather than retreating to a moral 
high ground. The $C E A A$ is periodically reviewed and amended ${ }^{177}$ and a glaring absence from the reports, review panels and interest groups involved in the ongoing amendment process is a strong voice for heritage conservation.

Evaluative asymmetry, or the perceived level of importance of cultural heritage or the cultural environment within the decision-making process as compared to natural components of the environment, is one of the key problems facing heritage conservation within the context of EA and public planning more generally. The preceding chapter traced the evolution of the field of heritage conservation over the past century from Alois Riegl's values theory to present-day practices which are inherently supportive of sustainable development. The technical undertaking of HIA is just one tool that emerged to address the concerns of cultural heritage within the planning framework. The problems of evaluative asymmetry continue to exist, however, as the practice of HIA and methods for its undertaking develop. Difficulties associated with: 1) identifying and evaluating cultural heritage; and 2) measuring and expressing project impacts on those values, persist and must be addressed. The continued separation of the natural and cultural environment in process, practice and policy has a direct impact on how the relative importance of cultural heritage is perceived within the $C E A A$. Chapter 4 will examine issues related to legislative status and process management in the Canadian federal realm which perpetuate this separation and form barriers to the advancement of HIA and related heritage conservation methods.

\footnotetext{
${ }^{177}$ As of writing a review is presently underway.
} 


\section{Chapter: Process Management Concerns}

Administration of the EA process under the $C E A A$ relies on the expert knowledge and technical capabilities of various federal government bodies. There is an expectation that the capacity exists to identify and evaluate impacts on various components being addressed through EA. Bureaucratic practices related to cultural heritage developed in the $20^{\text {th }}$ century with very specific priorities and goals which do not always support the objectives of EA or those of sustainable development. At the same time, other bureaucratic practices have developed to support the undertaking of EA and, as Chapter 4 will illustrate, the policies and practices governing decision-making are generally isolated from those overseeing cultural heritage.

The following chapter explores process management issues related to cultural heritage in the context of the CEAA and the practice of EA more generally. As a whole, these process management concerns are rooted in the legislative status of cultural heritage or rather, its lack of legislative status. The issue of legislative status is defined here as the position or rank of cultural heritage within Canadian federal legislation. The absence of a single, legislated responsible government authority has led to a vacuum in the policy and bureaucratic framework governing heritage conservation. Process management issues are outlined with examples from the case studies discussed in Chapter 1. In addition, this chapter examines the legislative and bureaucratic frameworks which hamper successful integration of cultural heritage into effective EA policy and sustainable development strategies at the federal level. It further offers possibilities for resolving this lack of legislative status. In order to resolve the dissonance between heritage conservation 
theory and best practices and the current EA framework, one or more of the following must occur:

1. Existing legislation at a federal level should be strengthened to address cultural heritage more broadly, or revised at the provincial and territorial level to provide consistent treatment of cultural heritage across the country;

2. The tension arising from cultural heritage being the constitutional jurisdiction of the provinces and territories must be resolved either by:

a) broadening the scope of 'environment' to include cultural heritage,

b) providing more opportunities and avenues for meaningful provincialfederal cooperation with respect to cultural heritage, and/or

c) better defining the roles, responsibilities and authority of various levels of government within the process and related to cultural heritage in general; and/or

3. The separation of culture and nature within the EA organizational framework must be resolved and replaced with a more multidisciplinary approach to EA and sustainable development strategies.

Perhaps the most important consideration when examining the framework governing EA is the question "who". Exactly who is responsible for cultural heritage within the $C E A A$ framework and how are roles, responsibilities and authority determined and shared? Throughout interviews with experts from the public and private realm, process management concerns were repeatedly expressed with respect to triggers, specifically, the lack of triggers for consultation with heritage authorities and confusion with respect to which department, agency or group should be consulted. The following section outlines some of the federal bodies concerned with cultural heritage and identifies several gaps and deficiencies in their mandates and organizational capabilities.

In the first half of the $20^{\text {th }}$ century, Canadian heritage conservation public policy focused on establishing house museums and commemorating historic military sites through bodies such as the National Historic Sites and Monuments Board. Based on the success and popularity of historic reconstructions undertaken by private groups in the 
United States and the National Parks Service, Canada public policy shifted its priorities to reconstructions around the 1960 s. $^{178}$ The Canadian Government undertook the largest reconstruction project in North America, the Fortress of Louisbourg, Nova Scotia starting in 1961. ${ }^{179}$ Similar projects, such as Ontario's Upper Canada Village, were undertaken across the country around this time. As Fulton (1998) describes it, the mid-20 ${ }^{\text {th }}$ century marked an era of "government-sponsored infrastructure of professional historians, archaeologists, architects, engineers, and craftspeople who sought to recreate vignettes of Canadian history as conjecture-free as their scholarship and technical skills could produce." 180

As outlined in Chapter 3, the focus of heritage conservation theory and practice began to shift towards a more values-based approach following the 1972 World Heritage Convention which required, as a matter of practicality in administering the World Heritage List, States Parties to develop statements identifying which values or criteria were embodied by nominated sites. The 1981 Burra Charter furthered this approach, providing a means to administer a values-based system. In the Canadian federal government, this was translated into the preparation of Commemorative Integrity Statements. Despite changes in attitudes regarding the evaluation of heritage values and the preservation treatments (e.g., reconstruction versus rehabilitation), the focus of public policy with respect to cultural heritage remains property-based. In fact, cultural heritage is the jurisdiction of the provinces and territories precisely because it is considered to be a 'real property matter'.

\footnotetext{
${ }^{178}$ Gordon Fulton, "Policy Issues and Their Impact on Practice: Heritage Conservation in Canada," $A P T$ Bulletin, 29, no.3/4 (1998): 13.

179 lbid., 13.

180 Ibid., 13.
} 
Within the context of the $C E A A$, it is vital to understand which groups can act as a Federal Authority for an EA. In other words, which groups, agencies and departments within the federal government can provide advice and review the cultural heritage aspect of EAs? The CEAA guidance document for cultural heritage identifies Regional Offices in the Department of Canadian Heritage and Parks Canada in its list of regional contacts for EAs. These contacts are clearly out of date ${ }^{181}$ and, furthermore, the guidance is not consistently referenced by practitioners. The questions remain, a) Who should be contacted to act as a federal authority? ${ }^{182}$ b) Which department, group or agency is mandated with the role? and c) Which departments, groups or agencies have the expertise to deal with the cultural heritage aspect of an EA?

The Canadian government's senior authority for heritage conservation is Parks Canada, which recently celebrated its $100^{\text {th }}$ anniversary. In 2002 , the agency outlined its mandate which follows below.

On behalf of the people of Canada, we protect and present nationally significant examples of Canada's natural and cultural heritage, and foster public understanding, appreciation and enjoyment in ways that ensure the ecological and commemorative integrity of these places for present and future generations. ${ }^{183}$

The mandate and responsibilities of Parks Canada are clearly focused on nationally significant sites. Although there are instances where Regional Offices provide advice for "non-Parks" projects and properties, the primary concern of Parks Canada are Canada's

\footnotetext{
181 The contact numbers and positions are no longer valid since the reorganization of the Department of Canadian Heritage which saw Parks Canada, as its own agency, move into the department of Environment Canada.

${ }^{182}$ It is also possible that this role should formally be mandated to the provinces and territories since cultural heritage falls under their constitutional jurisdiction.

${ }^{183}$ Parks Canada, The Parks Canada Charter, (Ottawa: Parks Canada, 2002).
} 
National Parks and National Historic Sites and they do not typically act as a Federal Authority on projects which do not directly impact one of their sites.

The role of the Federal Heritage Buildings Review Office (FHBRO), established in $1982,{ }^{184}$ is to evaluate federally-owned buildings of 40 years of age or older and to consult with custodian departments to ensure the preservation of the heritage character of those buildings designated as "Classified" or "Recognized." 185 The FHBRO, at present, is a branch of Parks Canada which deals exclusively with federal real property. Although the FHBRO works closely with building managers and acts as a Federal Authority on projects which may directly or indirectly have an impact on a designated federal property, it does not act as a Federal Authority on cultural heritage aspects of EA more generally.

The Heritage Conservation Directorate (HCD) of Public Works and Government Services Canada (PWGSC) provides technical expertise and advice on heritage assets to other federal departments as well as other groups within PWGSC. ${ }^{186}$ Although the HCD is able to provide advice with respect to built heritage and cultural landscapes, the group lacks training and expertise with respect to EA, as highlighted in the case of the demolitions in Brantford. As a service branch of the federal government, particularly one that deals so often with the $C E A A$, it might be reasonable to expect the $\mathrm{HCD}$ to act as a Federal Authority for the cultural heritage aspect of EAs; however, it has no formal mandate to act in that capacity and would generally do so as a contract service to another federal body.

\footnotetext{
${ }^{184}$ FHBRO, $A$ Guide, 2.

185 Ibid., 5.

186 "Public Works and Government Services Canada, Technical Guides: Heritage Conservation," last modified December 1, 2011. http://www.tpsgc-pwgsc.gc.ca/biens-property/sngp-npms/bi$\mathrm{rp} /$ tech/patrimoine-heritage-eng.html.
} 
Consequently, although several federal bodies possess the capabilities to act as a Federal Authority for cultural heritage in the context of the $C E A A$, there is no federal department, agency or group clearly mandated with the responsibility. It could also be argued that provincial or territorial authorities concerned with cultural heritage should formally act as the Federal Authority for the cultural heritage aspect of EAs in their jurisdiction, given that they have constitutional jurisdiction over cultural heritage. This approach would have avoided tension and confusion when the Ontario Ministry of Culture sent a letter to the City of Brantford in the spring of 2010 asking for further assessment of the cultural heritage values of the 41 buildings along the south side of Colborne Street that were slated for demolition. At the time, City representatives felt that there were no grounds for compliance with the request since there were no legal designations or easements on any of the buildings. ${ }^{187}$ Formally outlining the role of provincial authorities with respect to the cultural heritage aspect of EAs under the $C E A A$ would have legitimized the Ontario Ministry of Culture's request in this situation. As a consequence, however, it would ultimately download federal responsibility onto already stressed and underfunded provincial systems. The CEAA is built on the premise that responsibility for the environment transcends jurisdiction and should be shared by all levels of government. Public policy concerning cultural heritage is rooted in the mid- $20^{\text {th }}$ century framework that tethered cultural heritage to concepts of property and this 'real property' view has indelibly marked all cultural heritage as real property. This real property-bias consistently reinforces the view that cultural heritage must be the

\footnotetext{
${ }^{187}$ Michael-Allen Marion, "City still seeking answers on provincial letter," Brantford Expositor, March, 2010, accessed October, 2011 at http://www.brantfordexpositor.ca/ArticleDisplay.aspx?e=2477814\&archive=true.
} 
jurisdiction of only one level of government, whereas, the responsibility for cultural heritage as a component of the environment and a product of our shared experience should, just as the environment does, transcend jurisdiction.

Regardless of the lack of formal roles and responsibilities for federal and provincial authorities, there are clearly a number of options available for consultation when undertaking an EA. Notwithstanding the availability of possible authorities on the matter, there remains a lack of triggers to consult a cultural heritage authority when undertaking an EA under the CEAA. This lack of triggers is the result of the legislation governing cultural heritage in Canada. Despite Canada's international obligations as a signatory state to the World Heritage Convention, it remains the only G-8 nation without laws to protect the heritage buildings, sites and engineering works owned by the federal government. ${ }^{188}$ Federal legislation concerning cultural heritage does exist, including:

- Parks Canada Agency Act

- Canada National Parks Act

- Department of Canadian Heritage Act

- Heritage Railway Stations Protection Act

- Historic Sites and Monuments Act

- Heritage Lighthouse Protection Act

- Department of Transport Act (under which historic canals are provided protection)

In addition to legislation, policies such as the Treasury Board Policy on Management of Real Property (which resulted in the FHBRO) exist to guide planning decisions. Unlike legislation protecting natural heritage, such as the Species at Risk Act, none of the aforementioned normative instruments provide legal protection or outline a permitting

\footnotetext{
${ }^{188}$ Christopher Wiebe, Historic Places Act: Canada Needs A Binding Law! (Ottawa: Heritage Canada Foundation, 2006): 2, accessed January, 2012.

http://www.heritagecanada.org/sites/heritagecanada.org/files/magazines/2006/summer/Summer2006_Bindi ngLaw.pdf
} 
process for cultural heritage, with the exception of the narrowly scoped Heritage Railway Stations Protection Act. Even the designation of a federal heritage building as 'Recognised' or 'Classified' does not guarantee conservation. The Historic Sites and Monuments Act, which has existed since 1953, provides no legal protection for National Historic Sites. It only allows for the commemoration of a site, person or event. Unless a National Historic Site is located in a province or territory which provides protection for National Historic Sites under their legislation and the site is not owned by the federal government, it has no legal protection.

As noted in the discussion of the Brantford demolition in Chapter 1, this lack of legal protection has direct implications in the EA process. There is a persistent and widespread belief that all valuable cultural heritage resources, like Species at Risk, have been identified and protected through legal designation. Although this attitude does not take into account the fluid nature of heritage values or the lack of funding and institutional capabilities required to undertake a wide-scale inventory and designation program, it nonetheless persists. The current federal approach to assessing impacts relies on the presupposition that all significant heritage resources and landscapes have previously been identified and that the values of those resources are carefully outlined in a Commemorative Integrity Statement (CIS) or Statement of Significance (SOS). Although local and provincial inventories and the Canadian Heritage Register exist to help screen for cultural heritage resources during the cultural heritage aspect of EAs, the majority of these resources are out of date and inconsistent. By perpetuating these registers and inventories without a clear strategy for their use and the capacity to maintain them, there remains the danger that any resource or landscape not included on that list 
will automatically be considered of little to no value and will not be captured in the planning process.

In 2002, a discussion paper was circulated from the Department of Canadian Heritage. Towards a New Act, Protecting Canada's Historic Places proposed a new and broad-based strategy, the Historic Places Initiative (HPI). Once applied, it was suggested that the HPI would:

- build a culture of heritage conservation;

- provide a framework wherein governments could work together to achieve common cultural heritage related goals;

- develop and share basic tools to conservation historic places; and

- establish the Government of Canada as a "model custodian of historic places." "189

The HPI was to be rolled out in three phases over the course of several years. The first phase, and arguably the most important given the pervasive conflict and confusion surrounding the jurisdiction of cultural heritage, was the federal-provincial-municipal consultation that had taken place in the three years leading up to the publication of Towards a New Act. The three years of consultation had also included an Aboriginal Advisory Committee, elected officials, private cultural heritage experts and volunteers. ${ }^{190}$ One of the most prolific tools established out of the HPI was the Canadian Register of Historic Places. The Register, although inconsistent as the result of varying levels of workload and organizational capacity across the provinces and territories, is a dynamic inventory of designated and non-designated places.

In addition to the HPI's intended role as a catalyst for developing relationships and sharing tools between governments in Canada, it also proposed to address legislative

${ }^{189}$ Canadian Heritage, Towards a New Act, Protecting Canada's Historic Places, (Ottawa: Public Works and Government Services Canada, 2002): 2.

${ }^{190}$ Ibid., 2. 
gaps which to date leave most historic places in Canada with no legal protection or permitting requirements. This Canadian Historic Places Act would provide for the protection of "all historic places on federal lands and protection for archaeological resources on or under federal lands or waters." 191 In addition, the act would formally recognize the Canadian Register and commit the federal government to adhere to HPI standards and guidelines for conservation. The act would further require that non-federal historic places included on the Canadian Register be taken into account in project planning. ${ }^{192}$ Despite positive - albeit geographically inconsistent - results, the Canadian Historic Places Act did not officially pass the discussion paper phase and the HPI was cancelled at the end of 2009 .

The HPI and Canadian Historic Places Act are not novel approaches to public policy. The National Historic Preservation Act $(N H P A)$ provides a tested example of federal legislation concerning cultural heritage. The NHPA was passed in the United States in 1966, representing the first modern legislation concerning cultural heritage not predicated on designation as the sole form of protection. The $N H P A$ was the result of pro-demolition public planning policy in the $1950 \mathrm{~s} .{ }^{193}$ The devastating loss of countless historic sites and places in the post-Second World War era prompted the preparation of With Heritage So Rich, a report demanding federal leadership in the form of an inventory of historic properties, a mechanism for protection of those properties, a program of

\footnotetext{
${ }^{191}$ Ibid., 5.

192 lbid., 5.

${ }^{193}$ Advisory Council on Historic Preservation, Preserving America's Heritage, (Washington: Advisory Council on Historic Preservation, 2010):1.
} 
financial incentives, and an independent federal preservation body. ${ }^{194}$ It was on this report that the NHPA was founded.

Section 106 of the NHPA requires the assessment of potential project impacts on any property or site "that is included in or eligible for inclusion in the National Register."195 Any cultural heritage resource meeting the criteria must be included in the assessment of project impacts, without ultimately requiring legal designation. The $N H P A$ compliments the 1969 National Environmental Protection Act, filling a gap that has been left by Canada's own $C E A A$ with respect to cultural heritage. Furthermore, the $N H P A$ has led to an effective national preservation structure in the United States. The Advisory Council on Historic Preservation informs the National Parks Service and vice versa.

Perhaps the most crucial cultural heritage issue in Canada that was addressed by the HPI was the level of cooperation and knowledge-sharing between federal, provincial and municipal governments as well as Aboriginal groups. While the NHPA does not necessarily provide the most appropriate model to address the Canadian issues of constitution jurisdiction, delegated authority and land-claims, it does provide for intergovernmental consultation. Section 101 of the NHPA outlines responsibilities of the State Historic Preservation Officer, among which is the responsibility to administer the State Historic Preservation Program. Section 101 continues by describing the cooperation by Federal and State agencies, as well as local governments, with respect to undertaking surveys and maintaining state inventories that in turn might feed into the

\footnotetext{
194 John M. Fowler, “The Federal Preservation Program," in A Richer Heritage (Chapel Hill: The University of North Carolina Press, 2003): 35.

195 National Historic Preservation Act, 1966, Section 106.
} 
National Register ${ }^{196}$. The $N H P A$ also outlines a requirement for Federal-State consultation regarding "Federal undertakings that may affect historic properties"197.

In the Canadian context, the provincial role remains unclear and inconsistent within the $C E A A$ framework. In the Brantford case, provincial involvement under the Ontario Heritage Act was not triggered by planning process, whereas the Ardenville Wind Farm triggered involvement of Alberta Culture and Community Spirit under the Historical Resources Act. These two cases illustrate vastly different treatments of cultural heritage resources as a result. ${ }^{198}$ While cultural heritage remains constitutionally a matter of provincial or territorial concern, it should be the responsibility of the federal government to provide guidance for the protection of heritage resources and cultural landscapes as part of Canada's obligations under the World Heritage Convention. The HPI and proposed Canadian Historic Places, which were terminated before they could fully develop, were a step in the right direction.

In addition to legislative considerations specific to cultural heritage, there are also concerns regarding the status of cultural heritage within the $C E A A$ itself. As discussed in Chapter 2, the $C E A A$ definitions are ambiguous with respect to cultural heritage. The original parliamentary report on the $C E A A$ notes the purposeful adoption of a narrow definition for the environment which excludes cultural heritage, ${ }^{199}$ while the definition of environmental effect is explicit in outlining socio-economic and cultural heritage aspects

\footnotetext{
${ }^{196}$ National Historic Preservation Act, Section 101, 3.

197 Ibid., Section 101, 3 (I)(i)

${ }^{198}$ In the case of renewable energy projects in Ontario, participation of the MTCS is now triggered by the Renewable Energy Approvals Under Part V.O.I of the Environmental Protection Act, Ontario Regulation 359/09, Sections 22 and 23, 2009. Other triggers, even under the Ontario Environmental Assessment Act R.S.O., 1990, are less consistent.

${ }^{199}$ Douglas, Bill C-13, 3.
} 
to be included. ${ }^{200}$ The exclusion of cultural heritage from the definition of environment under the $C E A A$ limits the federal government's approach to sustainable development and reinforces the systemic preference of natural environmental components over cultural or social components. This narrow definition is counter to the Supreme Court ruling in Friends of the Oldman River Society v. Canada which spurred the development of the $C E A A$. In addition to finding that responsibility for the environment transcends jurisdiction, the court also found that the environment should not be narrowly defined and, in order to best uphold the principles of sustainable development, should take into account natural, social and cultural factors ${ }^{201}$. Despite commitments to sustainable development made by the Canadian Government, natural and cultural aspects of the environment remain separated through policy and organizational framework.

International examples promote the interconnectedness of culture and nature. The World Heritage List is meant to include the very best examples of the shared heritage of humankind. Although the criteria consider a series of values that may be weighed more or less in the favour of a cultural versus a natural site (or vice versa), there is only one list. Further to the simultaneity of culture and nature in this context, it is becoming more and more common for nominated sites to be evaluated as mixed sites and landscapes. The distinction between nature, culture, and the societies that interact with these sites and landscapes is becoming less and less apparent internationally while persisting in the Canadian context. Dalibard (1991 and 1992) argues that 'heritage' and 'environment' are much more all-encompassing terms than is reflected in their use within the context of conservation, planning and policy. He suggests that we consider "...heritage as a system

\footnotetext{
${ }^{200}$ Canadian Environmental Assessment Act 1992, c.37, Section 2(1).

${ }^{201}$ Friends of Oldman River Society v. Canada, p. 9-10.
} 
of values that addresses equally the concerns raised by the ecological, economic, cultural, and social elements of our habitat." ${ }^{202}$ By this way of thinking, environment can be used as a term to describe everything around us (e.g., vegetation, air, water, land, buildings) while heritage is more related to the values placed on those elements of the environment that give us a sense of place. ${ }^{203}$

The separation of natural and cultural environment is particularly alarming at the federal level in Canada given that Parks Canada has, for its entire history, protected and managed both diverse aspects of the environment. Although outside its mandate, the lack of Parks Canada participation in the cultural heritage aspect of EAs under the CEAA has become more of a concern since the organizational restructuring which placed the agency under Environment Canada, a federal department profoundly involved in the EA process. Environment Canada's mandate does not include any consideration for cultural heritage. Its mandate is to:

- preserve and enhance the quality of the natural environment, including water, air, soil, flora and fauna;

- conserve Canada's renewable resources;

- conserve and protect Canada's water resources;

- forecast daily weather conditions and warnings, and provide detailed meteorological information to all of Canada;

- enforce rules relating to boundary waters; and

- coordinate environmental policies and programs for the federal government. ${ }^{204}$

Bumbaru (1991) proffers a number of root causes for this disconnect or friction between natural and cultural conservationists. He states that it may simply be that, in a country such as Canada, there is such a vast amount of nature relative to a short recorded

\footnotetext{
202 Jacques Dalibard, "Our Environment is our Heritage," ICOMOS Canada Momentum 1991, p.6.

203 Jacques Dalibard, “Towards a New Partnership," ICOMOS Canada Bulletin, Vol. 1, No. 1, 1992, p. 6.

${ }^{204}$ Environment Canada, About Environment Canada, (Ottawa: Environment Canada, 2010), accessed January, 2012 at http://www.ec.gc.ca/default.asp?lang=En\&n=BD3CE17D-1.
} 
and material history. The friction may also be related to the traditional resistance of the heritage conservation movement to accept change whereas sustainable development aims to manage change. ${ }^{205}$ Probably the most compelling suggestion for the inherent friction between natural and cultural conservation, however, is the contradictory mandates of the two callings. One aims to undo the ill-effects of human interventions on nature and return the landscape to a pristine state, while the other celebrates the achievements of humankind, in some cases the triumph of man over nature. ${ }^{206}$ It is not, therefore, surprising that nature and culture often conflict as interests within the planning process. Nor is it unusual that two sets of experts have developed with highly divergent approaches, tools and goals with respect to EA. This was certainly true in both the Ardenville and Brantford cases. The problem, in the context of EA, is not the skillsets of the technical experts feeding the process or the concerns of the general public. The problem is that experts in the process, with very few exceptions, are trained and educated almost exclusively in natural conservation and are given very little training and few tools to understand cultural heritage conservation. Equally specialized experts are found on the cultural heritage side of the debate which leads to narrowly scoped HIAs, misconceptions about planning and development processes and a lack of tools and techniques to undertake or participate in the review of the cultural heritage aspect of EAs. The process management issues explored in this chapter highlighted a number of concerns regarding the lack of legislative status experienced by cultural heritage in Canada. The legislative and bureaucratic frameworks which have developed to protect

\footnotetext{
${ }^{205}$ Dinu Bumbaru, "Patrimoine et environnement: conflit entre nature et culture? Pessimisme et optimism," ICOMOS Canada Momentum, 1991, p. 5.

${ }^{206}$ Bumbaru, 1991, p.5.
} 
and manage the environment fail to take advantage of the inherent synergies between natural and cultural heritage conservation in order to fully address concepts of sustainable development at a federal level. In order to resolve the dissonance between heritage conservation theory and best practices and the current EA framework, roles and responsibilities of cultural heritage authorities at various levels of government must be addressed and formalized, a pan-Canadian approach to legislation must be considered either by encouraging consistency across the provinces and territories or by engaging in federal legislation, and the separation of nature and culture must be addressed in training, education, organizational frameworks and in the very definition of environment under the CEAA.

Although several federal bodies are concerned with cultural heritage (specifically built heritage, cultural landscapes and archaeology) none of these federal entities is mandated such that they should act as a Federal Authority on EAs under the CEAA. It is also possible that the responsibility to act as an authority on these matters should be downloaded to the provinces and territories, but that role would need to be formalized as evidenced by the unwillingness for the City of Brantford to cooperate with provincial authorities in the case study presented in Chapter 1. Despite the availability of cultural heritage authorities at various levels of government, a trigger to consult is still required in the form of legislation or permitting that is not bound to the existing system of legal designation of properties. By perpetuating registers and inventories without a clear strategy for their use and the capacity to maintain them, there is a danger that the cultural heritage aspect of EAs will be limited to desktop surveys which conclude that no 
properties in the register is equivalent to no cultural heritage value in or around the project area.

The Canadian Historic Places Act based on the United States' National Historic Preservation Act, proposed for discussion in 2002 to compliment the now-defunct Historic Places Initiative, had provisions for many of the process management problems persisting today, including:

- the development of roles and responsibilities between various levels of government;

- the early assessment of projects for impacts on cultural heritage and requirement for certification or permitting for such projects; and

- the establishment of legally binding pan-Canadian standards for the protection of cultural heritage.

The tension and confusion arising from the constitutional jurisdiction of cultural heritage, in particular, must be reconciled in order for cultural heritage to be managed at a federal level and consistently across all provinces and territories.

Finally, this chapter highlighted the systemic separation of nature and culture in the federal government as well as the very definition of environment under the CEAA. This separation of culture and nature within the organizational framework is pervasive and must be must be resolved through the provision of well-developed training and education on cultural heritage for students, practitioners and reviews of EA and the improvement of HIA and EA practice and theory among heritage conservation experts. 


\section{Conclusion}

The aim of this paper was to determine if the objectives of heritage conservation are being met within the context of the CEAA. The short answer is 'no'. Two overarching problems were identified with the cultural heritage aspect of EA under the $C E A A$ which revealed systemic deficiencies and inconsistencies with the treatment of cultural heritage in the Canadian system more generally. The problems of evaluative asymmetry and lack of legislative status are not confined to the $C E A A$ and have been established through the development of three major processes: 1) the advancement of EA as a formal and authoritative planning process; 2 ) the evolution of heritage conservation theory and practice; and 3) the creation of the bureaucratic policies and procedures that govern both EA and heritage conservation.

This paper concludes that the goals of heritage conservation are not served by the $C E A A$ for three primary reasons:

1. Heritage Impact Assessment (HIA) remains a novel and underdeveloped practice which lacks, a) the tools and techniques required to formalize the process and develop an authoritative professional designation for experts undertaking HIAs, and b) an accepted pan-Canadian process for undertaking HIAs that can be easily interpreted by decision makers.

2. The separation of heritage conservation from natural environmental sciences has resulted in a federal system in which heritage conservation professionals are unfamiliar with the EA process and EA practitioners are unfamiliar with heritage conservation theory and practice.

3. The lack of federal legislation or permitting with regard to cultural heritage, particularly the exclusion of cultural heritage from the definition of environment under the $C E A A$, prevents Canada from effectively meeting its international obligations with respect to cultural heritage and sustainable development. 
The problems faced by cultural heritage can be grouped into two categories; technical issues, related to evaluative asymmetry and process management issues, related to the lack of legislative status experienced by cultural heritage in the Canadian federal system. Evaluative asymmetry is predicated on the inequality caused by the relative perceived importance of natural features as compared to cultural features in the EA process. The ultimate goal is for policy makers in the federal government concerned with sustainable development strategies and technical experts preparing and reviewing EAs to accept cultural heritage as a component of the environment and to understand how it can be better integrated into the planning process. There are two possible approaches to better integrate cultural heritage into the EA process. The first requires massive changes to the paradigm governing the overall planning process to create a more participative, community-centric EA process, or something similar. The second avenue for improvement is to work within the existing planning framework and promote consistent, well-developed and formalized techniques for the assessment of cultural heritage. In order to be incorporated into the EA framework there is a need to develop HIA techniques, tools and methods and to share them with a wider audience through training and education. As the practice of HIA and methods for its undertaking develop, difficulties associated with: 1) communicating cultural heritage values; and 2) measuring and expressing project impacts on those values, persist and must be addressed.

What the Ardenville and Brantford cases illustrate are not only inconsistencies related to triggers for formal HIA, but also the vast differences in terms of their scope, techniques and methods. This relates both to high-level HIAs or desktop studies undertaken for screenings as well as more extensive HIAs undertaken for development 
projects that are very likely to have a direct impact on cultural heritage resources or landscapes.

The timing of the cultural heritage aspect of the EA for each project was considerably different with considerably different results. In the case of Ardenville, the need for an HIA was triggered by provincial legislation early in the process which allowed for the identification of several archaeological sites which were then accounted for and avoided in the final project design. In contrast, the EA for Brantford was completed after the project planning and decision-making process was completed. The result was that the cultural heritage aspect of the EA did not adequately address the value of the buildings to be demolished or the magnitude of the project impact on those resources. Furthermore, the timing of the EA did not allow for alternatives to be considered.

There is a lack of reliable and comprehensive Canadian baseline data to understand how the cultural heritage aspect of EAs and more extensive HIAs are prepared. Questions that should be asked of a wider data set than was possible for the current paper include:

- How often does a review of cultural heritage aspects of a project appear in EA reports?

- Who is preparing the cultural heritage portion of an EA?

- Is the review of cultural heritage aspects limited to a narrow scope (e.g., only built heritage, only archaeological resources, or only socioeconomic concerns related to First Nations consultation)?

- How often are HIAs undertaken to support an EA? and

- Who is preparing the HIA?

With this data it would be possible to develop a pan-Canadian approach to HIA and to the legislation and policy that triggers HIA at various levels of government in Canada, 
similar to the HPI approach to the Standards and Guidelines for the Conservation of Historic Places in Canada.

The problem of legislative status is rooted in two systemic deficiencies. First, the separation of the natural and cultural environment through policies, training and organizational structure has resulted in a system in which the two fields are relatively unaware of the principles and practices governing one another. Second, the lack of federal legislation or permitting with respect to cultural heritage has led to conflict and confusion over the roles and responsibilities of various federal bodies and different levels of government in Canada. Both case studies illustrated this separation of nature and culture in the preparation and review of the cultural heritage aspects of the EAs and the EAs more generally. In the case of Brantford, PWGSC experts in EA were unfamiliar with theories and practice related to cultural heritage as well as the local and provincial policies and legislation governing their identification and protection. It also identified the lack of familiarity of cultural heritage experts in the federal and provincial governments with the EA process. In the absence of education and training for those in the EA field in the principles of heritage conservation, it is imperative that up-to-date and adequate guidance material exist to help in the preparation and review of the cultural heritage aspects of EAs. The current reference guide, produced by the Canadian Environmental Assessment Agency, does not satisfactorily address the concerns of cultural heritage nor does it reflect the development of tools and techniques for the preparation of HIAs. This separation of nature and culture is to the detriment of Canadian sustainable development practice and must be resolved in favour of a more multidisciplinary approach in the education and training of future EA practitioners and planners. 
Despite federal legislation and policies regarding cultural heritage, there remains a lack of protection and permitting triggers to require the involvement of cultural heritage authorities, federal or provincial, in the federal project planning process. Furthermore, there are no frameworks in place that identify who should participate as a cultural heritage authority. Although there are a number of federal agencies and departments with an interest, none of these federal entities is mandated such that they should act as a Federal Authority on EAs under the CEAA. It is also possible that the responsibility to act as a Federal Authority on these matters should be downloaded to the provinces and territories, but that role would need to be formalized.

The definition of environment under the $C E A A$ is perhaps the most troubling concern with regard to legislative status. Although cultural heritage is included in the definition of environmental effect, it is excluded from that of environment. The Supreme Court ruling in Friends of the Oldman River Society v. Canada which found that responsibility for the environment transcends jurisdiction also found that the definition of environment should better reflect the principles of sustainable development by taking into account natural, social and cultural factors. ${ }^{207} \mathrm{~A}$ more inclusive definition of environment would not necessarily impinge on the constitutional jurisdiction of the provinces and territories; rather it would better reflect the principles of sustainable development and the evolution of heritage conservation theory and practice, which are no longer rooted in matters of property rights. Abandoning our outdated notion of cultural heritage as a matter of real property allows cultural heritage to fit within a broader definition of environment. It follows, then, that the responsibility for cultural heritage as

\footnotetext{
${ }^{207}$ Friends of Oldman River Society v. Canada, p. 9-10.
} 
a component of the environment and a product of our collective experience, surely transcends jurisdiction and should be shared by all levels of government.

The Historic Places Initiative (HPI) in the early 2000s and the proposed Canadian Historic Places Act provided, if only briefly, a starting point for the development of panCanadian tools and legislation for the protection of cultural resources and landscapes, based loosely on the 1966 National Historic Preservation Act in the United States. More importantly, the HPI sought to develop inter-governmental relationships and share tools and techniques aimed at developing a pan-Canadian approach to heritage conservation. The Canadian Register created by the HPI remains as a dynamic resource that can be used for high-level HIAs and desktop surveys of cultural heritage resources. Unfortunately, the Register represents inconsistent and, in some cases, incomplete data and may prove more harm than good in the long run. Perpetuating registers and inventories without a strategy for this type of use and the capacity to maintain them creates a danger that any resource or landscape not included on that list will be considered of little to no value and will consequently not be captured in the planning process.

In their 1996 review of the federal EA process, written on the heels of the Rafferty-Alameda and Oldman River cases, Sadar and Stolte stated that, "It is always difficult, if not impossible, to justify what some perceive to be a loss or erosion of community identity or property, and damage to spiritual, cultural, and heritage sites."208 Although much headway has been made since, this attitude is still prevalent among decision-makers, EA practitioners and many heritage conservation experts. The

\footnotetext{
${ }^{208}$ Sadar and Stolte, An Overview of the Canadian Experience, 222.
} 
continued segregation of those concerned with the natural environment from those concerned with the cultural environment reinforces the idea that the scientific and nonscientific communities act as two very separate cultures, as discussed by C.P. Snow in his 1934 publication The Search. The cultural divide between the natural sciences and heritage conservation is marked by differences in intellectual approach, climate of thought and moral attitudes. ${ }^{209}$ As a result of this cultural divide, natural environment experts seem unclear about how to include cultural heritage elements into their definition of the environment and cultural environment experts have yet to fully develop arguments and techniques that will allow them to make their case within the existing EA framework.

${ }^{209}$ Charles Percy Snow, “Two Cultures," Science, New Series, vol. 133, no. 3373, 1959, p. 419. 


\section{Appendices}

\section{Appendix A Criteria for the assessment of outstanding universal value (as per the}

\section{Operational Guidelines for the Implementation of the World Heritage Convention)}

The Committee considers a property as having outstanding universal value if the property meets one or more of the following criteria. Nominated properties shall therefore:

(i) represent a masterpiece of human creative genius;

(ii) exhibit an important interchange of human values, over a span of time or within a cultural area of the world, on developments in architecture or technology, monumental arts, town-planning or landscape design;

(iii) bear a unique or at least exceptional testimony to a cultural tradition or to a civilization which is living or which has disappeared;

(iv) be an outstanding example of a type of building, architectural or technological ensemble or landscape which illustrates (a) significant stage(s) in human history;

(v) be an outstanding example of a traditional human settlement, land-use, or sea-use which is representative of a culture (or cultures), or human interaction with the environment especially when it has become vulnerable under the impact of irreversible change;

(vi) be directly or tangibly associated with events or living traditions, with ideas, or with beliefs, with artistic and literary works of outstanding universal significance. (The Committee considers that the criterion should preferably be used in conjunction with other criteria);

(vii) contain superlative natural phenomena or areas of exceptional natural beauty and aesthetic importance;

(viii) be outstanding examples representing major stages of earth's history, including the record of life, significant on-going geological processes in the development of landforms, or significant geomorphic or physiographic features;

(ix) be outstanding examples representing significant on-going ecological and biological processes in the evolution and development of terrestrial, fresh water, coastal and marine ecosystems and communities of plants and animals;

(x) contain the most important and significant natural habitats for in-situ conservation of biological diversity, including those containing threatened species of outstanding universal value from the point of view of science or conservation. 


\section{Bibliography}

Advisory Council of Historic Preservation. Preserving America's Heritage. Washington : Advisory Council of Historic Preservation, 2010.

Advisory Council on Historic Preservation. "Protecting Historic Properties: A Citizen's Guide to Section 106 Review." ACHP Publications. 2010. http://www.achp.gov/docs/CitizenGuide.pdf (accessed April 2011).

Alberta Electric System Operator. "AESO Needs Identification Document - TransAlta Ardenville Wind Power Facility." March 2010. http://www.aeso.ca/downloads/854_TransAlta_Ardenville_Wind_Power_Facility _NID_25MAR10.pdf (accessed December 2011).

Alberta Sustainable Resource Development. "Alberta Sustainable Resource Development." About Us. 2012. http://www.srd.alberta.ca/AboutSRD/AlbertaSustainableResourceDevelopment/D efault.aspx (accessed January 2012).

Alberta Utilities Commission. TransAlta Wind Ardenville Wind Plant and Substation. Decision Report, Calgary: Alberta Utilities Commission, 2009.

Araoz, Gustavo. "Preserving heritage places under a new paradigm." Journal of Cultural Heritage Management and Sustainable Development 1, no. 1 (2011): 55-60.

Archaeological Services Inc. "Stage 1 Archaeological Assessment, Redevelopment of the South side of Colborne Street, City of Brantford, Ontario." Toronto, 2010. Australia ICOMOS. "The Burra Charter, the Australia ICOMOS Charter for Places of Cultural Significance (1999 version)." Burra, 1981. 
Barramax Policy Consulting. The Federal Coordination Regulation, A Reference Guide for the Canadian Environmental Assessment Act. Ottawa: Canadian Environmental Assessment Agency, 1997.

Bond, Alan, Lesley Langstaff, Ross Baxter, Hans-Georg Wallentinus Josefin Kofoed, Katri Litsitzin, and Stina Lundström. "Dealing with the cultural heritage aspect of environmental impact assessment in Europe." Impact Assessment and Project Appraisal 22, no. 1 (2004): 37-45.

Brantford Heritage Committee. "Brantford Heritage Committee Report, South Side of Colborne Street." Brantford, March 8, 2010.

Bumbaru, Dinu. "Patrimoine et environnement: conflit entre nature et culture? Pessimisme et optimisme." ICOMOS Canada Momentum, 1991: 5.

Caldwell, Lynton Keith. The National Environmental Policy Act. Bloomington: Indiana University Press, 1998.

Cameron, Christina. "The Spirit of Place: The physical memory of Canada." Journal of Canadian Studies/revues d'etudes canadiannes 35, no. 1 (2000): 77-94.

"Canada National Parks Act, S.C., 2000, c.32." 2000.

"Canadian Environmental Assessment Act, S.C. 2002, c. 37." n.d.

Canadian Environmental Assessment Agency. A Reference Guide for the Canadian Environmental Assessment Act: Assessing Environmental Effects on Physical and Cultural Heritage. Ottawa: Canadian Environmental Assessment Agency, 1996.

-. Canadian Environmental Assessment Agency. 2011. http://www.ceaa.gc.ca/default.asp?lang=En\&n=C10DF5DB$1 \&$ offset $=14$ \& toc $=$ show. . 
Canadian Environmental Assessment Agency. The Canadian Environmental Assessment Act: An Overview. Ottawa: Canadian Environmental Assessment Agency, 2011. Canadian Interviews. "Leo Groarke, Downtown Education." Canadian Interviews. 2010. http://www.canadianinterviews.com/interviews/index.php?ID=318 (accessed January 2012).

Clarke, Simon. "Balancing Environmental and Cultural Impact against the Strategic Need for Wind Power." International Journal of Heritage Studies 15 (2009): 175-191.

Dalibard, Jacques. "Our Environment is our Heritage." ICOMOS Canada Momentum, 1991: 6-7.

Dalibard, Jacques. "Towards a New Partnership." ICOMOS Canada Bulletin 1, no. 1 (1992).

Daschuk, James, and Gregory P. Marchildon. "Historical Chronology of the Oldman River Dam Conflict." unpublished paper, n.d.

Dawson, Bruce. "“Why are you protecting this crap?": Perceptions of Value for an Invented heritage—a Saskatchewan Perspective." Value Based Decision Making for Conservation, Canadian Studies Heritage Conservation Programme Symposium, Carleton University. Ottawa: Carleton University, 2005.

de Loe, Rob. "Return of the Feds, Part II: The Oldman River Dam." Canadian Eater Resources Journal 22, no. 1 (1997): 35-44.

Deacon, Harriet. "Cultural Heritage Impact Assessment in Africa, A Review." n.d. http://www.heritageinafrica.org/news/119.html (accessed September 2011). Denhez, Marc. Heritage Fights Back. Ottawa: Heritage Canada, 1978. 
Denhez, Marc. "The Luftwaffe and Other Development Services, 1939-1946." In The Canadian Home, by Marc Denhez, 79-92. Toronto: Dundurn Press, 1994. Denhez, March. The Heritage Strategy Planning Handbook. Toronto: Dundurn Press, 1997.

"Department of Canadian Heritage Act, S.C., 1995, c.11." 1995.

Department of Canadian Heritage. Towards a New Act: Protecting Canada's Historic

Places. Ottawa: Public Works and Government Services Canada, 2002.

"Department of Environment Act, R.S.C., 1985, c.E-10." 1985.

"Department of Transport Act, R.S., 1985, c.T-18." 1985.

Doelle, Meinhard. "Case Comment: The Implications of the SCC Red Chris Decision for EA in Canada." Journal of Environmental Law and Practice 20, no. 2 (2010): 161-173.

Donnelly, Annie, Barry Dalal-Clayton, and Ross Hughes. A Directory of Impact Assessment Guidelines. second edition. Nottingham: Russell Press, 1998.

Douglas, Kristen. Bill C-13: Canadian Environmental Assessment Act. Legislative Summary, Ottawa: Library of Parliament, 1992.

Droste, Bernd von. "Investing in the future of Planet Earth." ICOMOS Canada Momentum, 1991: 2-4.

Elliot, Nancy. "The Evolution of World Heritage in Canada." In Changing Parks: The History, Future and Cultural Context of Parks and Heritage Landscapes, edited by John S. Marsh and Bruce W. Hodgins, 177-188. Toronto: Natural Heritage/Natural History Inc., 1998. 
Environment Canada. "About Environment Canada." Environment Canada. June 2011. http://www.ec.gc.ca/default.asp?lang=En\&n=BD3CE17D-1 (accessed January 2012).

—. "Environmental Assessment." Environment Canada. July 2010. http://www.ec.gc.ca/ee-ea/Default.asp?lang=En\&n=CBB499FD-1 (accessed January 2012).

_. "Sustainable Development." Sustainable Development. October 2011. http://www.ec.gc.ca/dd-sd/default.asp?lang=En\&n=C2844D2D-1 (accessed January 2012).

Environmental Advisory Committee. Oldman River Dam Environmental Advisory Committee, Final Recommendations. Oldman River Dam Environmental Advisory Committee, 2001.

Erikstad, Lars, et al. "Environmental value assessment in multidisciplinary EIA setting." Environmental Impact Assessment Review 28 (2008): 131-143.

External Committee on Cities and Communities. From Restless Communities to Resilient Places: Building a Stronger Future for All Canadians. Ottawa: Infrastructure Canada, 2006.

Federal Heritage Buildings Review Office. A Guide to Working with the Federal Heritage Buildings Review Office. Ottawa: Parks Canada, 2009.

Fowler, John M. "The Federal Preservation Program." In A Richer Heritage: Historic Preservation in the Twenty-First Century, edited by Robert E. Stipe, 35-79. Chapel Hill: The University of North Carolina Press, 2003. 
Fowler, Peter. "World Heritage Cultural Landscapes, 1992-2002: a Review and

Prospect." In Cultural Landscapes: the Challenges of Conservation, 16-32. UNESCO, 2002.

Frey, Patrice. "Making the Case: Historic Preservation as Sustainable Development, Discussion Draft." Draft White Paper presented in advance of the Sustainable Preservation Research Retreat, 2007.

Frey, Patrice. "Preservation as a Driver of General Economic Growth." In Making the Case: Historic Preservation as Sustainable Development, Draft White Paper. 2007.

Friends of the Oldman River Society v. Canada (Minister of Transport). Supreme Court Ruling (January 23, 1992), 1992.

Fulton, Gordon. "Policy Issues and Their Impact on Practice: Heritage Conservation in Canada." APT Beulletin, 1998: 13-16.

Gelfand, Julie. "Built Heritage Conservation and Wildlife: a Meeting of the Minds?" ICOMOS Canada Momentum, 1991: 8.

Gilpin, Alan. Environmental Impact Assessment: Cutting Edge for the Twenty-First Century. New York: Cambridge University Press, 1995.

Glen, Jack. Once Upon an Oldman: Special Interest Politics and the Oldman River Dam. Vancouver: UBC Press, 1999.

Gorgolewski, Mark. "Session 1: Ecological Building." Heritage and Sustainability: Canadian Communities and Kyoto, Heritage Canada Foundation Annual Conference Proceedings. Ottawa: Heritage Canada Foundation, 2005. 
Government of Alberta. Wildlife Guidelines for Alberta Wind Energy Projects.

Edmonton: Fish and Wildlife Division, Sustainable Resource Development, 2011. Gray, Murray. Geodiversity: valuing and conserving abiotic nature. Mississauga: John Wiley and Sons, 2004.

Groarke, Leo. Reinventing Brantford: A University Comes Downtown. Toronto: Natural Heritage Books, 2009.

Hanebury, Judith. "The Supreme Court Decision in Oldman River Dam: More Pieces in The Puzzle of Jurisdiction over the Environment." Resources: The Newsletter of the Canadian Institute of Resource Law, Winter 1992: 1-6.

Harcourt, Mike. "From Restless Communities to Resilient Places: The Role of the National Government and the Importance of Integrated Community Sustainability Plans." Horizons 10, no. 4 (March 2010): 50-53.

Harrop, D. Owen, and J. Ashley Nixon. Environment Assessment in Practice. New York: Routledge, 1998.

Hébert, Monique. The Oldman River Decision of the Supreme Court of Canada. Background Paper BP-287E, Ottawa: Library of Parliament, Research Branch, 1992.

Heritage Canada Foundation. Exploring The Connection Between Built and Natural Heritage. Ottawa: Heritage Canada Foundation, 2001.

"Heritage Lighthouse Protection Act, S.C. 2008, c.16." 2008.

"Heritage Railway Stations Protection Act, S.C., 1985, c.52(4th Supp.)." 1985.

"Historic Sites and Monuments Act, R.S., 1985, c.H-4." 1985.

"Historical Resources Act, R.S.A. 2000, Chapter H-9, Section 1(e)." 2000. 
ICOMOS. "Charter on the Preservation of Historic Gardens (Florence Charter)." 1982. http://www.international.icomos.org/charters/gardens_e.pdf (accessed September 2011).

—. "Nara Document on Authenticity." 1994. http://whc.unesco.org/uploads/events/documents/event-443-1.pdf (accessed October 2011).

-. "Venice Charter: International Charter for the Conservation and Restoration of Monuments and Sites." ICOMOS, 1964.

International Congress of Architects and Technicians of Historic Monuments. "The Athens Charter for the Restoration of Historic Monuments." Athens, 1931. Jerpasen, Gro B., and Kari C. Larsen. "Visual impact of wind farms on cultural heritage: A Norwegian case study." Environmental Impact Assessment Review 31 (2011): 206-215.

Jokilehto, Jukka. A History of Architectural Conservation. London: ButterworthHeinemen, 1999.

Kalman, Harold. The Evaluation of Historic Buildings. Ottawa: Parks Canada, 1979.

Kennedy, Tom. "\$1.38M from feds for south side demolition." Brant News, January 21, 2010.

Keune, Russell V. "Historic Preservation in a Global Context: An International Perspective." In A Richer Heritage: Historic Preservation in the Twenty-First Century, edited by Robert E. Stipe , 353-382. Chapel Hill: The University of North Carolina Press, 2003. 
Larder, Douglas A. "Notice of Application." November 2009.

http://www.auc.ab.ca/applications/notices/Notices/2009/1604970.pdf (accessed December 2011).

LeBlanc, Francois. "Field Trip Report, Carleton University, Ottawa, Values-Based Decision-Making for Conservation November 18-19, 2005." Getty Conservation Institute. 2005. http://www.icomos.org/ fleblanc/projects/20012007_GCl/field_trip_reports/2005-11-canada-ottawa-carleton.pdf (accessed October 2011).

Lifeways of Canada. "Historical Resources Impact Assessment: Ardenville Wind Farm Project Final Report." Calgary, 2009.

Lisitzin, Katri, and Herb Stovel. "Training Challenges in the Management of Heritage Territories and Landscapes." In Cultural Landscapes: the Challenges of Conservation. World Heritage Papers 7. UNESCO, 2002.

Mackay, A.F. "Evaluative Asymmetry." American Philosophical Quarterly 11 (1975): $37-46$.

Marion, Michael-Allan. "City getting ready to demolish." Brantford Expositor, February $12,2010 a$.

—. "City still seeking answers on provincial letter." Brantford Expositor, March 5, $2010 b$.

Marion, Michael-Allen. "Council OKs purchase of Colborne properties." Brantford Expositor, August 5, 2009: A2. 
Mason, Randall. "Assessing Values in Conservation Planning: Methodological Issues and Choices." In Assessing the Values of Cultural Heritage, edited by Marta de la Torre, 5-30. Los Angeles: The Getty Conservation Institute, 2002.

Mayes, Thompson. "Preservation Law and Public Policy: Balancing Priorities and Building an Ethic." In A Richer Heritage: Historic Preservation in the TwentyFirst Century, edited by Robert E. Stipe, 157-184. Chapel Hill: The University of North Carolina Press, 2003.

Morrison, Helen. Bill C-13: Canadian Environmental Assessment Act. Legislative Summary, Ottawa: Library of Parliament, 1991.

Murtagh, William J. Keeping Time: The History and Theory of Preservation in America. 3rd ed. Edited by William J. Murtagh. Hoboken: John Wiley \& Sons Inc., 2006. "National Historic Preservation Act of 1966, As amended through 2006." 2006.

Natural Resources Canada. Environmental Impact Statement Guidelines for Screenings of Inland Wind Farms Under the Canadian Environmental Assessment Act. Ottawa: Wind Power Production Incentive, Natural Resources Canada, 2003.

Natural Resources Canada. Environmental Screening Report, Ardenville Wind Farm, Municipal District of Willow Creek. Ottawa: Natural Resources Canada, 2009. Ontario Ministry of Culture. Heritage Impact Assessments and Conservation Plans. Sheet No. 5, Information Sheet Series from Heritage Resources in the Land Use Planning Process: Cultural Heritage and Archaeology Policies of the Ontario Provincial Statement, 2005. Toronto: Queen's Printer, 2006.

"Ontario Regulation 359/09 Renewable Energy Approvals Under Part V.0.1 of the Environmental Protection Act." 2009. 
"Ontario Regulation 9/06 Criteria for Determining Cultural Heritage Value or Interest under the Ontario Heritage Act." 2006.

Paci, Chris, Ann Tobin, and Peter Robb. "Reconsidering the Canadian Environmental Impact Assessment Act: A place for traditional environmental knowledge." Environmental Impact Assessment Review 22 (2002): 111-127.

"Parks Canada Agency Act, 1998, c.31." 1998.

Parks Canada. Standards and Guidelines for the Conservation of Historic Places. Ottawa: Parks Canada, 2011.

—. "The Parks Canada Charter." Ottawa: Parks Canada, 2002.

Pendlebury, John. Conservation in the Age of Consensus. New York: Routledge, 2009. Pereira Roders, Ana, and Ron van Oers. "Editorial: bridging cultural heritage and sustainable development." Journal of Heritage Management and Sustainable Development 1, no. 1 (2011): 5-14.

PRA Inc. Formative Evaluation of the Historic Places Initiative. Ottawa: Parks Canada Agency, 2005.

Public Works and Government Services Canada. "Heritage Conservation." Public Works and Government Services Canada, Technical Guides. 2011. http://www.tpsgcpwgsc.gc.ca/biens-property/sngp-npms/bi-rp/tech/patrimoine-heritage-eng.html (accessed January 2012).

Rennick \& Associates. Effectiveness of the Federal Coordination Regulations, Review of the Canadian Environmental Assessment Act. Background Study, Ottawa: Canadian Environmental Assessment Agency, 1999. 
Rössler, Mechtild. "Linking Nature and Culture: World Heritage Cultural Landscapes." In Cultural Landscapes: the Challenge of Conservation, World Heritage Papers 7, 10-15. Paris: UNESCO, 2002.

Sadar, M. Husain, and William J. Stolte. "An Overview of the Canadian Experience in Environmental Impact Assessment (EIA)." Impact Assessment 14, no. 2 (1996): 215-228.

Sadler, Barry. Environmental Assessment in a Changing World: Evaluating Practice to Improve Performance. Ottawa: The Canadian Environmental Assessment Agency and the International Association for Impact Assessment, 1996.

Scotrenewables (Wind Power) Limited. "Merranblo Wind Cluster, Environmental Statement." 2005.

Snow, Charles Percy. "Two Cultures." Science, New Series 133, no. 3373 (1959): 419. "Species at Risk Act, S.C. 2002, c.29." n.d.

Stolte, W. J., and M. H. Sadar. "The Rafferty-Alameda Project and its Environmental Review: Structures, Objectives and History." Canadian Water Resources Journal 19, no. 1 (1993): 1-13.

Taylor Hazell Architects Ltd. "Review of Cultural Heritage Implications, Environmental Assessment Screening for the Demolition and Slop Stabilization of South Side of Colbourne Street (35-151), City of Brantford, Ontario." Toronto, 2010.

TransAlta. Ardenville Wind Facility. March 2011. http://www.transalta.com/facilities/facilities-development/ardenville (accessed December 2011). 
_. "Community Update." TransAlta - Ardenville Wind Farm. April 2010.

http://www.transalta.com/sites/default/files/documents/Ardenville-NewsletterApril-2010.pdf (accessed Deember 2011).

—. "Community Update." TransAlta - Ardenville Wind Farm. June 2010.

http://www.transalta.com/sites/default/files/documents/Ardenville-

Newsletter_Edition-Two.pdf (accessed December 2011).

TransAlta Corporation. "Environmental Assessment Report for a Screening under the Canadian Environmental Assessment Act, Ardenville Wind Farm." Report prepared for Natural Resources Canada, 2009.

TransAlta Wind. "Public Open House Posters." TransAlta - Ardenville Wind Farm. 2008. http://www.transalta.com/sites/default/files/documents/Ardenville\%20Open\%20H ouse\%20Posters.pdf (accessed December 2011).

UEM Consulting Project Team. "Issues and Implications of FedDev Review." Brantford, June 2, 2010.

UNESCO. "Convention on the Protection and Promotion of the Diversity of Cultural Expressions." UNESCO, 2005.

UNESCO. Glossary of Environmental Education Terms. Hungary: National Centre for Educational Technoloty, 1983.

-. "Recommendations Concerning the Protection, at a National Level, of the Cultural and Natural Heritage." 1972. http://www.icomos.org/unesco/national72.html (accessed October 2011).

UNESCO World Heritage Centre. Operational Guidelines for the Implementation of the World Heritage Convention. WHC.08/01, Paris: UNESCO, 2008. 
United Nations. "Report on the United Nations Conference on Environment and Development, Annex 1: Rio Declaration on Environment and Development, A/CONF.151/26 (Vol.1)." 1992.

Urban and Environmental Management Inc. "Environmental Assessment Screening, Demolition and Slope Stabilization of the South Side of Colborne Street (35-151), Brantford, Ontario - Draft for PWGSC Review." Toronto, 2010.

Wiebe, Christopher. "Historic Places Act: Canada Needs a Binding Law!" 2006. http://www.heritagecanada.org/sites/heritagecanada.org/files/magazines/2006/su mmer/Summer2006_BindingLaw.pdf.

World Commission on Environment and Development. The Report of the Commission on Environment and Development: Our Common Future. New York: United Nations, 1987.

Zerner, Henri. "Alois Reigl: Art, Value, and Historicism." Daedalus 105, no. 1 (1976): 177-188. 